\title{
Strategy, Progress, and Challenges of Drug Repurposing for Efficient Antiviral Discovery
}

\author{
Xinlei $\mathrm{Li}^{+}$and Tao Peng* \\ State Key Laboratory of Respiratory Disease, Sino-French Hoffmann Institute, College of Basic Medicine, Guangzhou Medical \\ University, Guangzhou, China
}

\section{OPEN ACCESS}

Edited by:

Sugunadevi Sakkiah,

National Center for Toxicological

Research (FDA), United States

Reviewed by:

Hasan Ejaz,

Al Jouf University, Saudi Arabia Nasser Hadal Alotaibi,

Al Jouf University, Saudi Arabia

${ }^{*}$ Correspondence:

Tao Peng

peng_tao@gibh.ac.cn

${ }^{\dagger}$ Present address:

Xinlei Li,

The Abigail Wexner Research Institute at Nationwide Children's Hospital,

Columbus, $\mathrm{OH}$, United States

Specialty section:

This article was submitted to

Experimental Pharmacology and Drug

Discovery,

a section of the journal

Frontiers in Pharmacology

Received: 29 January 2021 Accepted: 16 April 2021

Published: 04 May 2021

Citation:

Li $X$ and Peng T (2021) Strategy,

Progress, and Challenges of Drug

Repurposing for Efficient

Antiviral Discovery.

Front. Pharmacol. 12:660710.

doi: 10.3389/fphar.2021.660710
Emerging or re-emerging viruses are still major threats to public health. Prophylactic vaccines represent the most effective way to prevent virus infection; however, antivirals are more promising for those viruses against which vaccines are not effective enough or contemporarily unavailable. Because of the slow pace of novel antiviral discovery, the high disuse rates, and the substantial cost, repurposing of the well-characterized therapeutics, either approved or under investigation, is becoming an attractive strategy to identify the new directions to treat virus infections. In this review, we described recent progress in identifying broad-spectrum antivirals through drug repurposing. We defined the two major categories of the repurposed antivirals, direct-acting repurposed antivirals (DARA) and host-targeting repurposed antivirals (HTRA). Under each category, we summarized repurposed antivirals with potential broad-spectrum activity against a variety of viruses and discussed the possible mechanisms of action. Finally, we proposed the potential investigative directions of drug repurposing.

Keywords: drug repurposing, emerging virus, antivirals, broad spectrum, COVID-19

\section{INTRODUCTION}

Since December 2019, a novel coronavirus disease 2019 (COVID-19) has rapidly spread all over the globe to cause a pandemic ( $\mathrm{Li}$ et al., 2020b; Zhu et al., 2020). The pneumonia causative agent was identified to be a new coronavirus, severe acute respiratory syndrome coronavirus 2 (SARS-CoV-2). As of April 6, 2021, more than 130 million cases have been confirmed globally, including approximately 2.85 million deaths. The still ongoing pandemic represents the most recent example of how emerging or re-emerging human or zoonotic viruses pose a threat to public health. These viruses include but not limited to Ebola virus (EBOV), Zika virus (ZIKV), West Nile virus (WNV), yellow fever virus (YFV), dengue virus (DENV), henipaviruses (Nipah, Hendra), SARS-CoV, Middle East respiratory syndrome (MERS-CoV), Lassa virus (LASV), Crimean-Congo hemorrhagic fever virus (CCHFV), Rift Valley fever virus (RVFV), chikungunya virus (CHIKV), human immunodeficiency virus (HIV) and influenza A virus (IAV). We listed six viral families in which a number of viruses have merged or remerged in recent years to have caused or potentially cause an epidemic or pandemic, including Coronaviridae, Filoviridae, Flaviviridae, Arenaviridae, Nairoviridae, and Orthomyxoviridae. The genome structure, important viruses, and key features regarding virus-host interactions are summarized in Table 1.

The emerging or remerging virus outbreak has emphasized the urgent need for preventative or treatment regimens. Vaccines are recognized as a preferred promising line of defense. However, vaccine development is a complex process and multiple challenges are involved in light of the fact 


\begin{tabular}{|c|c|c|c|c|}
\hline Virus family & Genome & Important viruses & Key features/Virus-host interactions & Ref \\
\hline Coronaviridae & $\begin{array}{l}\text { ss (+) RNA; } \\
26-32 \mathrm{~kb}\end{array}$ & $\begin{array}{l}\text { SARS-CoV, SARS-CoV-2, MERS-CoV, } \\
\text { HCoV-229 E, HCoV-OC43, HCoV-NL63, } \\
\text { HCoV-HKU1 }\end{array}$ & $\begin{array}{l}\text { Enveloped viruses; case fatality rate: 30\% (MERS-CoV), } \\
10 \% \text { (SARS-CoV), 3\% (SARS-CoV-2); receptor: ACE2 } \\
\text { (SARS-CoV, SARS-CoV-2); DPP4 (MERS-CoV); S } \\
\text { protein proteolytic cleavage by cathepsins or TMPRSS2 } \\
\text { is necessary for infection; RNA proofreading is viable } \\
\text { due to the exoribonuclease activity }\end{array}$ & $\begin{array}{l}\text { de Wit et al. (2016); Chen } \\
\text { (2020) }\end{array}$ \\
\hline Flaviviridae & $\begin{array}{l}\text { ss (+) RNA; } \\
9.6-12.3 \mathrm{~kb}\end{array}$ & DENV, ZIKV, YFV, WNV & $\begin{array}{l}\text { Enveloped viruses; cause hemorrhagic fever, liver } \\
\text { damage, congenital malformations (microcephaly); } \\
\text { transmission by vectors like mosquitos or ticks }\end{array}$ & $\begin{array}{l}\text { Mukhopadhyay et al. (2005); } \\
\text { Barrows et al. (2018) }\end{array}$ \\
\hline Filoviridae & $\begin{array}{l}\text { ss (-) RNA; } \\
19 \mathrm{~kb}\end{array}$ & EBOV, MARV & $\begin{array}{l}\text { Enveloped filamentous virions can exceed to } \\
14,000 \mathrm{~nm} \text { in length; cause fatal viral hemorrhagic } \\
\text { fevers; case fatality rate: from } 25 \text { to } 90 \% \text {; DC-SIGN, or } \\
\text { integrins as attachment factor; receptor: NPC1 } \\
\text { (EBOV) }\end{array}$ & - \\
\hline Arenaviridae & $\begin{array}{l}\text { ss (-) RNA; } \\
\text { segmented }\end{array}$ & LASV, JUNV & $\begin{array}{l}\text { Enveloped viruses; case fatality rate: } 20-30 \% \text { (JUNV), } \\
1 \% \text { (LASV); entry factors: Alpha-dystroglycan, LAMP1 } \\
\text { (LASV); cause hemorrhagic fever; virus spreads } \\
\text { through rodents }\end{array}$ & $\begin{array}{l}\text { Jae et al. (2014); Pontremoli } \\
\text { et al. (2019) }\end{array}$ \\
\hline Nairoviridae & $\begin{array}{l}\text { ss }(-) \text { RNA; } \\
\text { segmented }\end{array}$ & CCHFV & $\begin{array}{l}\text { Enveloped viruses with circular genome; case fatality } \\
\text { rate: } 10-40 \% \text { (CCHFV); virus entry is clathrin-, } \mathrm{pH}- \\
\text { and cholesterol dependent; cause hemorrhagic fever; } \\
\text { transmission by vectors like ticks }\end{array}$ & $\begin{array}{l}\text { Simon et al. (2009); Zivcec } \\
\text { et al. (2016) }\end{array}$ \\
\hline Orthomyxoviridae & $\begin{array}{l}\text { ss (-) RNA; } \\
\text { segmented }\end{array}$ & $\begin{array}{l}\text { IAV (H1N1, H2N2, H5N1, H3N2, H7N9, } \\
\ldots)\end{array}$ & $\begin{array}{l}\text { Enveloped viruses; genome reassortment is common; } \\
\text { case fatality rate varies, } 2-3 \%(1918 \mathrm{H} 1 \mathrm{~N} 1)\end{array}$ & $\begin{array}{l}\text { Ramos and Fernandez-Sesma } \\
\text { (2012) }\end{array}$ \\
\hline
\end{tabular}

TABLE 2 | Compound library for drug repurposing.

\begin{tabular}{|c|c|c|c|}
\hline Library & $\begin{array}{l}\text { Library } \\
\text { scale }\end{array}$ & Introduction & Refs \\
\hline Prestwick chemical library & 1,520 & 99\% approved drugs (FDA, EMA and other agencies) & Ulferts et al. (2016) \\
\hline $\begin{array}{l}\text { NCATS pharmaceutical collection (or NCGC } \\
\text { pharmaceutical Collection) }\end{array}$ & $\sim 3,500$ & 2,500 approved molecules, plus about 1,000 investigational compounds & Huang et al. (2011) \\
\hline ReFRAME compound library & $\sim 12,000$ & $\begin{array}{l}\text { Containing nearly all small molecules that have reached clinical development } \\
\text { or undergone significant preclinical profiling, } 38 \% \text { of which are approved } \\
\text { drugs }\end{array}$ & $\begin{array}{l}\text { Janes et al. (2018); Riva } \\
\text { et al. (2020) }\end{array}$ \\
\hline $\begin{array}{l}\text { Library of pharmacologically active compounds } \\
\text { (LOPAC), sigma }\end{array}$ & 1,280 & $\begin{array}{l}\text { Biologically annotated collection of inhibitors, receptor ligands, pharma- } \\
\text { developed tools, and approved drugs }\end{array}$ & Hu et al. (2014) \\
\hline $\mathrm{NIH}$ clinical collection & 727 & All have a history of use in human clinical trials and known safety profiles & van Cleef et al. (2013) \\
\hline
\end{tabular}

that the pathogens that need to be confronted may display high genetic variability (e.g., HIV) or an identity hardly predicted in advance (e.g., SARS-CoV-2 or ZIKV). Thus, unprecedented demands have emerged on antivirals that can be rapidly available in clinical practices. In the absence of a vaccine available to use, hepatitis $\mathrm{C}$ virus (HCV) is supposed to be eliminated in the use of the direct-acting antivirals, which probably represents the first virus to be cured by antivirals. That strengthens the promising potential of antivirals in terms of virus treatment.

Drug repurposing (also called drug repositioning) is a strategy for identifying new uses for approved or investigational drugs that beyond the original indicative scope to facilitate antiviral development. Typically, antiviral discovery development is time and resource-consuming, which involves three major stages including drug discovery (3-6 years), preclinical studies in experimental animal models (about 3 years), clinical trials in humans from phase I to III (about 5 years). Finally, if a therapeutic succeeds to pass all the processes, it needs to get approved by the appropriate agency. It is estimated that only 5\% of the candidate molecules are finally approved and up to 3 billion dollars are consumed. Given that the repurposed drugs have been proven to be safe in humans, drug repurposing likely can skip phase I and probably the phase II clinical trials. Thus, the attrition rate to be a novel antiviral is reduced, although the phase III trial is still needed. Remdesivir, an adenosine analog to inhibit EBOV RNA-dependent RNA polymerase (RdRp) (Tchesnokov et al., 2019), is the latest example. Although remdesvir did not show therapeutic activity against EBOV infection in a real-world phase III clinical trial (Nakkazi, 2018), remdesivir shows potent antiviral activity against SARS-CoV-2, SARS-CoV, and MERS$\mathrm{CoV}$ in vitro or in vivo in preclinical animal models (de Wit et al., 


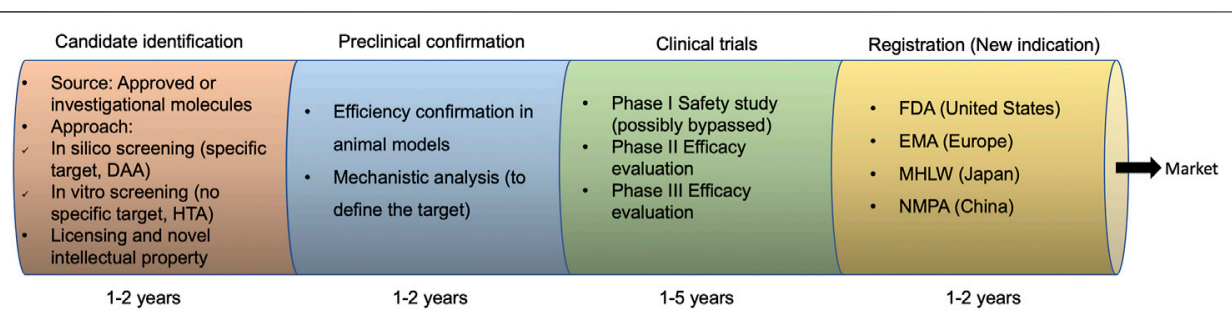

FIGURE 1 | Drug repurposing development process. DAA, direct-acting antivirals; HTA, host-targeting antivirals; FDA, Food and Drug Administration; EMA, the European Medicines Agency; MHLW, Ministry of Health, Labor, and Welfare; NMPA, National Medical Products Administration.

2020; Wang et al., 2020a). Two randomized phase III clinical trials indicate that patients who received remdesivir had a shorter time to recover (Spinner et al., 2020; Wang et al., 2020c), based upon which the U.S. Food and Drug Administration (FDA) has approved remdesivir for use in COVID-19 patients, less than 1 year after the outbreak of the pandemic. From the above example, drug repurposing could significantly facilitate antiviral development for emergency use. Given the urgent need for therapeutics for emerging or re-emerging viruses and a great number of approved or developmental therapeutics, drug repurposing represents a better way for antiviral discovery. In this review, we discussed the strategies of drug repurposing for antiviral development, summarized the promising drug candidates that have the antiviral potency with broadspectrum activity, and analyzed the possible caveats of this strategy of drug discovery.

\section{STRATEGIES TO DEVELOP REPURPOSED ANTIVIRALS}

A typical drug repurposing strategy comprises four steps (Figure 1), including the identification of a candidate therapeutic for the new indication as an antiviral; antiviral efficiency confirmation and/or mechanistic analysis in preclinical animal models; antiviral efficacy evaluation in clinical trials (phase I may be not prerequisite if sufficient safety data has already been obtained as parts of the original indication); and approval of the novel indication by government agencies such as the FDA, the European Medicines Agency (EMA), Ministry of Health, Labor and Welfare (MHLW) of Japan, and National Medical Products Administration (NMPA) of China.

\section{APPROACHES FOR ANTIVIRAL REPURPOSING}

The identification of the right drug for the new indication is crucial. The major approaches involve high throughput in silico or in vitro screening. The in silico screening is commonly used for the identification of a compound that binds to the given target, commonly a virally encoded protein, such as RNA-dependent RNA polymerase (Patel and Kukol, 2017). The in vitro screening involves the high throughput antiviral screening, leading to the subsequent validation for the most potent candidates. These candidates can target host proteins or viral proteins (Kouznetsova et al., 2014; Chopra et al., 2016; Xu et al., 2016; Li et al., 2017c). For either approach, compound libraries, in particular those with approved molecules, are needed (Table 2). These include the Drugbank library, NIH Clinical Compound (NCC) Collection (van Cleef et al., 2013), the Prestwick Chemical Library (Ulferts et al., 2016), the Library of Pharmacologically Active Compounds (LOPAC) (Hu et al., 2014), a library of approved drugs that were assembled by the NIH Chemical Genomics Centre (NCGC) called the NCGC Pharmaceutical Collection (NPC) (Huang et al., 2011), and the ReFRAME (Repurposing, Focused Rescue, and Accelerated Medchem) Library (Janes et al., 2018). Recently, the LOPAC and ReFRAME drug libraries were successfully used for the discovery of the SARS-CoV-2 antiviral candidates (Riva et al., 2020).

\section{CATEGORIES OF REPURPOSED ANTIVIRALS}

Based on the origin and feature of the repurposed antiviral targets, two major categories are divided: direct-acting repurposed antiviral (DARA) and host-targeting repurposed antiviral (HTRA) repurposing. The representative antivirals with repurposed potentials are summarized in Figure 2.

\section{Direct-Acting Repurposed Antiviral (DARA)}

A large majority of antivirals approved by the FDA are directacting antivirals (DAA) other than host-targeting agents (HTA) (Chaudhuri et al., 2018). DARAs contain antiviral activity relying on structural similarity or identical enzymatic activity of virally encoded targets, particularly viral polymerase, protease, reverse transcriptase, or viral proteins with ion channel activity. Below we reported the advances in repurposed antivirals targeting the two important viral enzymes, RdRp and protease.

\section{RdRp Inhibitors \\ Remdesivir (GS-5734)}

Remdesivir was an investigational compound in the class of nucleotide analogs, which was originally developed to treat Filoviridae members EBOV or Marburg infection and rapidly pushed through clinical trials due to the EBOV epidemic in West Africa from 2013 through 2016. However, in August 2019, 


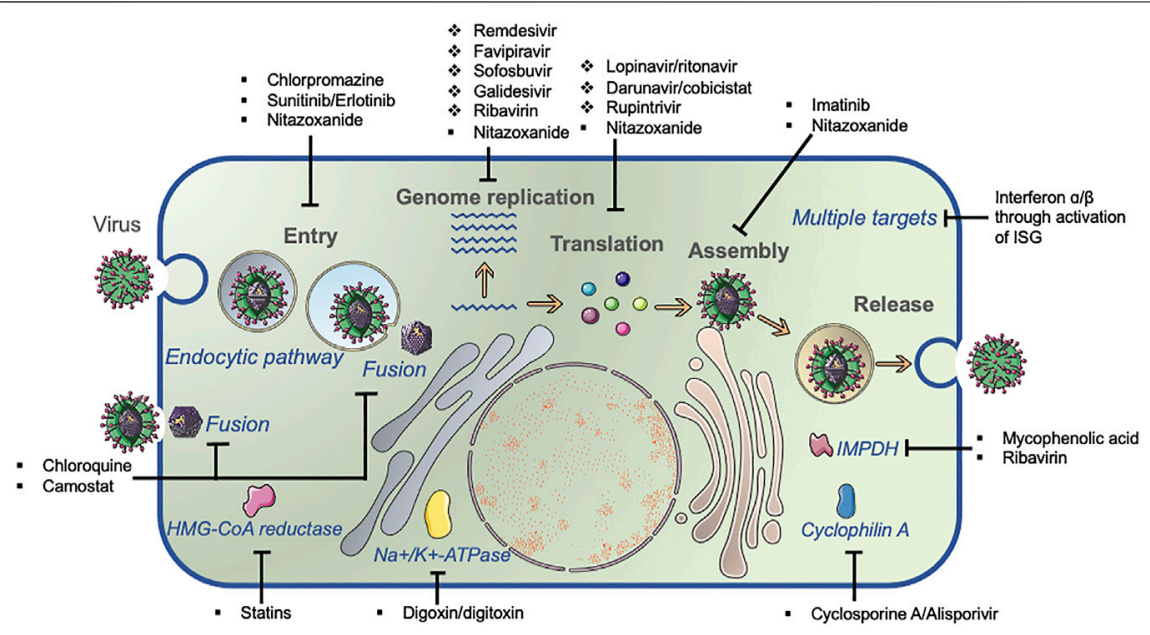

FIGURE 2 | Common viral lifecycle and broad-spectrum antiviral identification. The common viral lifecycle comprises three steps: viral entry, genome replication, and virus assembly/release. Direct-acting antivirals (DAA, $*$ ) and host-targeting antivirals (HTA, - ) inhibit virus replication by targeting viral protein and host molecules that are required for virus replication, respectively.

remdesivir was announced to be less effective than the other two monoclonal antibody regimens (Mulangu et al., 2019). It has also been found to show antiviral activity against other RNA viruses such as Pneumoviridae member RSV $(\mathrm{EC50}=0.019 \mu \mathrm{M})$; Paramyxoviridae Nipah virus $(\mathrm{EC} 50=0.029 \mu \mathrm{M})$, Hendra virus $(\mathrm{EC} 50=0.055 \mu \mathrm{M})$, parainfluenza type three virus (EC50 $=0.018 \mu \mathrm{M}), \mathrm{MV}(\mathrm{EC} 50=0.037 \mu \mathrm{M})$ and $\mathrm{MuV}$ viruses $(\mathrm{EC} 50=$ $0.79 \mu \mathrm{M})$; Arenaviridae JUNV $($ EC50 $=0.47 \mu \mathrm{M})$, LASV $($ EC50 = $1.48 \mu \mathrm{M}$ ); some Flaviviridae viruses like Kyasanur Forest disease virus $(\mathrm{KFDV})(\mathrm{EC} 50=1.8 \mu \mathrm{M})$, Omsk Hemorrhagic Fever virus $(\mathrm{OHFV})(\mathrm{EC} 50=1.2 \mu \mathrm{M})$, Tick-borne encephalitis (TBEV) $(\mathrm{EC50}=2.1 \mu \mathrm{M})$, and Coronaviridae including MERS-CoV $(\mathrm{EC50}=0.074 \mu \mathrm{M})$, SARS-CoV $(\mathrm{EC50}=0.069 \mu \mathrm{M})$, and SARS-CoV-2 (EC50 = $0.77 \mu \mathrm{M})$ (Warren et al., 2016; Lo et al., 2017; Sheahan et al., 2017a; Choy et al., 2020) (Table 3). The parent nucleoside of remdesivir, GS-441524 (1'-cyano substituted adenine nucleoside analog or Nuc) also shows a broad-spectrum but less effective antiviral activity against infections of coronaviruses like MERS-CoV and feline coronavirus (Warren et al., 2016; Pedersen et al., 2019).

Remdesivir shows prophylactic or therapeutic potency when administrated in SARS-CoV-infected mice, in which reduced viral load in lung and improved clinical symptoms and respiratory function was observed (Sheahan et al., 2017a). A similar prophylactic or therapeutic potency of remdesivir against MERS-CoV was seen in macaques or mouse models (de Wit et al., 2020; Sheahan et al., 2020). Remdesivir efficiently inhibits SARS$\mathrm{CoV}-2$ replication in vitro (Wang et al., 2020b), and was used as a compassionate use in the first COVID-19 case in the United States (Holshue et al., 2020) before large-scale clinical studies (NCT04280705; NCT04292899; NCT04292730; NCT04257656) were launched. One large-scale study in which hospitalized COVID-19 patients were given remdesivir for 10 days showed significantly shortened time to recovery (Beigel et al., 2020). Another study indicated that remdesivir treatment in moderate COVID-19 patients for 5 days led to symptom improvement significantly higher than the standard care group (Spinner et al., 2020). Contrarily, a smaller scale study only found remdesivir resulted in a marginally but numerically faster time to clinical improvement (Wang et al., 2020c). Based upon these clinical studies, the full and conditional use of remdesivir in hospitalized COVID-19 patients was approved by FDA in October 2020. Although World Health Organization (WHO) recommends against it, based on the interim result of the WHO Solidarity Trial.

Mechanistically, remdesivir exerts the antiviral activity through competing with ATP that is supposed to incorporate into viral RdRp for RNA replication. It results in delayed EBOV and MERS-CoV RNA chain termination at the fifth and third position, respectively after the initiation site (Warren et al., 2016; Tchesnokov et al., 2019; Gordon et al., 2020).

\section{Ribavirin (RBV)}

$\mathrm{RBV}$ is on the WHO's list of essential medicines, it is licensed to treat RSV infection (Committee on Infectious Diseases, 1993), or $\mathrm{HCV}$ infection in combination with interferon (IFN)- $\alpha$ or directacting antivirals (AASLD-IDSA HCV Guidance Panel, 2018). $\mathrm{RBV}$ is also effective against other hepatotropic viruses including HBV(Galban-Garcia et al., 2000) and HEV (Kamar et al., 2014; Kamar et al., 2019) in clinical studies, although no convincing activity against $\mathrm{HBV}$ was obtained in cell culture systems (Isorce et al., 2016). Ribavirin was clinically used to treat a variety of viral hemorrhagic fevers, including Lassa fever (McCormick et al., 1986), Crimean-Congo hemorrhagic fever (Fisher-Hoch et al., 1995), and Hantavirus infection (Ogg et al., 2013) alone or in combination with favipiravir, even though RBV might be effective only at early stages (Johnson et al., 2018; Eberhardt et al., 2019).

The clinical use of RBV as a supplement to other agents like corticosteroid for SARS-CoV treatment was documented in China and Canada (Peiris et al., 2003), while RBV had an 
TABLE 3 | Approved or investigational direct-acting antivirals with repurposed potential against other virus infections.

\begin{tabular}{|c|c|c|c|c|c|c|c|c|}
\hline \multirow[t]{2}{*}{ Category } & \multirow[t]{2}{*}{ Agent name } & \multirow[t]{2}{*}{ Primary indication } & \multicolumn{4}{|c|}{ Broad antiviral activity } & \multirow[t]{2}{*}{ Clinical trials } & \multirow[t]{2}{*}{ Ref } \\
\hline & & & Virus name & $\begin{array}{c}\mathrm{EC} 50 / \\
\mathrm{EC} 90(\mu \mathrm{M})\end{array}$ & $\begin{array}{l}\text { CC50 } \\
(\mu \mathrm{M})\end{array}$ & SI & & \\
\hline \multirow[t]{52}{*}{$\begin{array}{l}\text { Viral RdRp } \\
\text { inhibitor }\end{array}$} & Remdesivir & $\begin{array}{l}\text { Antiviral (EBOV, no } \\
\text { approval) }\end{array}$ & EBOV & $\begin{array}{l}0.07 / 0.22 \text { (Huh7 } \\
\text { cells) }\end{array}$ & 3.7 & 52.86 & Phase III failed & Warren et al. (2016) \\
\hline & & & JUNV & $0.47 / 2.8$ & N.D. & N.D. & & Warren et al. (2016) \\
\hline & & & MERS-CoV & 0.074/N.D. & $>10$ & $>135$ & & $\begin{array}{l}\text { Sheahan et al. } \\
(2017 b)\end{array}$ \\
\hline & & & SARS-CoV & 0.069/N.D. & $>10$ & $>144$ & & $\begin{array}{l}\text { Sheahan et al. } \\
\text { (2017b) }\end{array}$ \\
\hline & & & SARS-CoV-2 & $0.77 / 1.76$ & $>100$ & $>129.87$ & Approved for hospitalized COVID-19 patients & Wang et al. (2020b) \\
\hline & & & RSV & $0.021 / 0.059$ & 6.195 & 395 & & Lo et al. (2017) \\
\hline & & & $\mathrm{NiV}$ & $0.029 / 0.053$ & 8.294 & 286 & & Lo et al. (2017) \\
\hline & Ribavirin & Antiviral (HCV, RSV) & $\mathrm{HCV}$ & $8.4 / \mathrm{N} . \mathrm{D}$. & 108 & 12.86 & Approved & $\begin{array}{l}\text { Ortega-Prieto et al. } \\
\text { (2013) }\end{array}$ \\
\hline & & & RSV & 69.5/N.D. & N.D. & N.D. & Approved & Kim et al. (2017) \\
\hline & & & HBV & N.D./N.D. & N.D. & N.D. & Phase I NCT04356677; phase II NCT04276688; & Isorce et al. (2016) \\
\hline & & & HEV & $6.9 / 50.38$ & N.D. & N.D. & phase III NCT04392427 & Todt et al. (2018) \\
\hline & & & ZIKA & $23 / 281$ & N.D. & N.D. & & $\begin{array}{l}\text { Kamiyama et al. } \\
(2017)\end{array}$ \\
\hline & & & LASV & 2.47/N.D. & $>50$ & $>20$ & & Welch et al. (2016) \\
\hline & & & EBOV & 5.34/N.D. & $>50$ & $>9$ & & Welch et al. (2016) \\
\hline & & & SARS-CoV & 81.9/N.D. & $>819$ & $>10$ & & Saijo et al. (2005) \\
\hline & & & MERS-CoV & $66.9 / 86.6$ & N.D. & N.D. & & $\begin{array}{l}\text { Falzarano et al. } \\
\text { (2013a) }\end{array}$ \\
\hline & & & SARS-CoV-2 & 109.5/N.D. & $>400$ & 3.65 & $\begin{array}{l}\text { Phase II/III NCT04460443, NCT04497649; phase } \\
\text { III NCT04392427, ... }\end{array}$ & Wang et al. (2020b) \\
\hline & Favipiravir & Antiviral (IAV) & $\mathrm{IAV}(\mathrm{H} 1 \mathrm{~N} 1)$ & $1.97 / 3.75$ & $>128$ & $>64$ & Approved & $\begin{array}{l}\text { Sleeman et al. } \\
(2010)\end{array}$ \\
\hline & & & LASV & 29.3/43.2 & $>1000$ & $>34$ & & $\begin{array}{l}\text { Oestereich et al. } \\
(2016)\end{array}$ \\
\hline & & & JUNV & $0.79 / 5.0$ & 188 & 239 & & Furuta et al. (2013) \\
\hline & & & CCHFV & $6.37 / 10.18$ & $>100$ & $>15.7$ & & $\begin{array}{l}\text { Oestereich et al. } \\
\text { (2014b) }\end{array}$ \\
\hline & & & RVFV & $5.0 / 32$ & $>980$ & $>196$ & & Furuta et al. (2013) \\
\hline & & & Rabies & 32.4/N.D. & N.D. & N.D. & & Yamada et al. (2016) \\
\hline & & & RSV & N.D./36 & $>1600$ & N.D. & & $\begin{array}{l}\text { Jochmans et al. } \\
(2016)\end{array}$ \\
\hline & & & EBOV & $67 / 110$ & $>1000$ & $>14.9$ & & $\begin{array}{l}\text { Oestereich et al. } \\
\text { (2014a) }\end{array}$ \\
\hline & & & SARS-CoV-2 & 61.88/N.D. & $>400$ & $>6.46$ & Phase III: NCT04425460, NCT04373733; phase & Wang et al. (2020b) \\
\hline & & & WNV & 53/N.D. & N.D. & N.D. & IV NCT04359615. & Morrey et al. (2008) \\
\hline & & & YFV & $180 / 330$ & $>6370$ & $>19$ & & Julander et al. (2009) \\
\hline & & & ZIKA & 22/N.D. & $>637$ & $>26$ & & Zmurko et al. (2016) \\
\hline & & & EV-71 & 68.74/N.D. & $>1000$ & $>14.55$ & & Wang et al. (2016b) \\
\hline & Sofosbuvir & Antiviral (HCV) & $\mathrm{HCV}$ & 0.032-0.13/N.D. & N.D. & N.D. & Approved & Han et al. (2019) \\
\hline & & & YFV & 4.2/N.D. & 381 & 90 & & $\begin{array}{l}\text { de Freitas et al. } \\
\text { (2019) }\end{array}$ \\
\hline & & & DENV & $1.4 / 6.4$ & $>100$ & $>71$ & & Xu et al. (2017) \\
\hline & & & $\mathrm{CHIKV}$ & 1/N.D. & 402 & 402 & & Ferreira et al. (2019) \\
\hline & & & ZIKA & $1.37 / 12.3$ & $>200$ & $>145$ & & $\begin{array}{l}\text { Bullard-Feibelman et } \\
\text { al. (2017) }\end{array}$ \\
\hline & & & HEV & 1.97/N.D. & $>100$ & $>51$ & & Netzler et al. (2019) \\
\hline & & & HBV & - & - & - & Phase II NCT03312023 & - \\
\hline & & & SARS-CoV-2 & - & - & - & $\begin{array}{l}\text { Phase II/III: NCT04460443, NCT04443725; } \\
\text { phase IV NCT04498936; ... }\end{array}$ & - \\
\hline & Galidesivir & Antiviral (EBOV, & EBOV & $11.8 / 25.4$ & $>11,800$ & $>100$ & Preclinical & Warren et al. (2014) \\
\hline & & investigational) & MARV & $4.4 / 10.5$ & 1065 & 242 & Phase I NCT03800173 & Warren et al. (2014) \\
\hline & & & SUDV & $3.4 / 10.3$ & $>3400$ & $>100$ & & Warren et al. (2014) \\
\hline & & & TBEV & 0.95/N.D. & N.D. & N.D. & & Eyer et al. (2019) \\
\hline & & & YFV & $14.1 / 46.8$ & $>14,100$ & $>100$ & Phase I NCT03891420 & Warren et al. (2014) \\
\hline & & & WNV & 2.33/N.D. & $>100$ & $>42$ & & Eyer et al. (2017) \\
\hline & & & DENV & $32.8 / 89.3$ & $>9710$ & $>296$ & & Warren et al. (2014) \\
\hline & & & ZIKA & $3.8 / 18.2$ & N.D. & N.D. & & Julander et al. (2017) \\
\hline & & & RVFV & $41.6 / 98.0$ & $>41,600$ & $>100$ & & Warren et al. (2014) \\
\hline & & & LASV & $43.0 />100$ & $>4300$ & $>100$ & & Warren et al. (2014) \\
\hline & & & RSV & $11.0 / 25.7$ & $>980$ & $>89$ & & Warren et al. (2014) \\
\hline & & & $\mathrm{IAV}(\mathrm{H} 1 \mathrm{~N} 1)$ & $10.7 / 17$ & $>3167$ & $>296$ & & Warren et al. (2014) \\
\hline & & & SARS-CoV & $57.7 />95$ & $>17,080$ & $>296$ & & Warren et al. (2014) \\
\hline & & & SARS-CoV-2 & - & - & - & Phase I NCT03891420 & - \\
\hline
\end{tabular}


TABLE 3 | (Continued) Approved or investigational direct-acting antivirals with repurposed potential against other virus infections.

\begin{tabular}{|c|c|c|c|c|c|c|c|c|}
\hline \multirow[t]{2}{*}{ Category } & \multirow[t]{2}{*}{ Agent name } & \multirow[t]{2}{*}{ Primary indication } & \multicolumn{4}{|c|}{ Broad antiviral activity } & \multirow[t]{2}{*}{ Clinical trials } & \multirow[t]{2}{*}{ Ref } \\
\hline & & & Virus name & $\begin{array}{c}\text { EC50/ } \\
\text { EC90 }(\mu \mathrm{M})\end{array}$ & $\begin{array}{c}\text { Cc50 } \\
(\mu \mathrm{M})\end{array}$ & SI & & \\
\hline \multirow{15}{*}{$\begin{array}{l}\text { Viral protease } \\
\text { inhibitor }\end{array}$} & \multirow{5}{*}{$\begin{array}{l}\text { Lopinavir/ } \\
\text { ritonavir }\end{array}$} & \multirow[t]{5}{*}{ Antiviral (HIV) } & HIV (lopinavir) & 0.018/N.D. & N.D. & N.D. & \multirow[t]{4}{*}{ Approved } & Masse et al. (2007) \\
\hline & & & HIV (ritonavir) & 0.046/N.D. & N.D. & N.D & & Masse et al. (2007) \\
\hline & & & $\begin{array}{l}\text { SARS-CoV } \\
\text { (lopinavir) }\end{array}$ & 17.1/N.D. & $>32$ & $>2$ & & de Wilde et al. (2014) \\
\hline & & & $\begin{array}{l}\text { MERS-CoV } \\
\text { (lopinavir) }\end{array}$ & 8.0/N.D. & 24.4 & 3.1 & & de Wilde et al. (2014) \\
\hline & & & $\begin{array}{l}\text { SARS-CoV-2 } \\
\text { (lopinavir) }\end{array}$ & 26.63/N.D. & 49.75 & 1.87 & $\begin{array}{l}\text { Phase III: NCT04372628, NCT04321174; phase } \\
\text { IV: NCT04350684, NCT0435067; . . }\end{array}$ & Choy et al. (2020) \\
\hline & \multirow[t]{10}{*}{ Rupintrivir } & \multirow{10}{*}{$\begin{array}{l}\text { Antiviral (HRV, } \\
\text { investigational) }\end{array}$} & HRV-100 & $0.022 / 0.032$ & N.D. & N.D. & \multirow[t]{10}{*}{ Phase II completed } & Binford et al. (2005) \\
\hline & & & Echovirus-6 & $0.051 / 0.094$ & N.D. & N.D. & & Binford et al. (2005) \\
\hline & & & CVB2 & 0.022/0.088 & N.D. & N.D. & & Binford et al. (2005) \\
\hline & & & CVA16/860 F & 0.015/N.D. & $>50$ & $>3500$ & & Zhang et al. (2013) \\
\hline & & & EV71/695 F & 0.014/N.D. & $>50$ & $>3500$ & & Zhang et al. (2013) \\
\hline & & & $\mathrm{HCoV}-229 \mathrm{e}$ & 0.3/N.D. & $>500$ & $>1500$ & & Kim et al. (2012) \\
\hline & & & TGEV & 2.5/N.D. & $>500$ & $>200$ & & Kim et al. (2012) \\
\hline & & & $\mathrm{BOC}$ & 15.3/N.D. & $>500$ & $>32$ & & Kim et al. (2012) \\
\hline & & & Norovirus/ & $0.32 / 1.5$ & $>50$ & $>150$ & & Rocha-Pereira et al. \\
\hline & & & Norwalk & & & & & (2014) \\
\hline
\end{tabular}

EC50 of $81.9 \mu \mathrm{M}$ in vitro (Saijo et al., 2005). RBV is also effective to inhibit MERS-CoV with an EC50 ranging from $66.9 \mu \mathrm{M}(16.33 \mu \mathrm{g} / \mathrm{ml})$ to $169.7 \mu \mathrm{M}(41.45 \mu \mathrm{g} / \mathrm{ml})$ in vitro (Falzarano et al., 2013a). RBV alongside IFN- $\alpha$ was reported to reduce the hospital mortality rate from 70 to $29 \%$ in hospitalized MERS patients at 14 days after admission (Omrani et al., 2014). RBV also shows antiviral activity against SARS-CoV-2 in vitro with an EC50 of $109.5 \mu \mathrm{M}$ (Wang et al., 2020b), while another report did not find the favorable effect of RBV (Choy et al., 2020). The higher EC50 of RBV against either MERS-CoV or SARS-CoV-2 may be due to the reduced RBV uptake (Ibarra and Pfeiffer, 2009) or inabilities to accumulate sufficient amounts of phosphorylated RBV metabolites required for the effective RBV antiviral actions (Shah et al., 2010). As of early January 2021, at least seven clinical trials (phase I NCT04335123; phase II NCT04494399; phase II NCT04563208; phase II NCT04605588; NCT04664010; phase II NCT04276688; phase II/III NCT04402203) have been launched to investigate the efficacy of RBV alone or in combination with other agents for COVID-19 treatment.

Mechanistically, at least two types of antiviral machinery may be involved. Upon the uptake into cells, RBV is metabolized to form a purine RNA nucleotide-like form, which interferes with viral RNA polymerases, leading to hypermutation of RNA that reduces the viability and is lethal to RNA viruses. RBV is also an inhibitor of inosine- $5^{\prime}$-monophosphate dehydrogenase (IMPDH), which is essential for the de novo synthesis of guanosine- $5^{\prime}$-monophosphate (GMP). RBV structure may interfere with the RNA capping process that relies on natural guanosine to prevent RNA degradation. Upon the inhibition of IMPDH, RBV can lower the intracellular pool of GTP, and DNA virus replication is then inhibited. Alternatively, RBV has the potential to reduce cell death, affect type 1 cytokine production or inflammatory response, which may help combat HBV, HCV, or LASV infection (Tam et al., 1999; Oestereich et al., 2016).

\section{Favipiravir}

Favipiravir (6-fluoro-3-hydroxy-2-pyrazinecarboxamide) was firstly designed to inhibit influenza RdRp, despite of different serotypes and strains of influenza A, B, or C (Furuta et al., 2013). Favipiravir has been approved since 2014 in Japan for emergent use to treat influenza. In addition, favipiravir has shown a broad antiviral activity against other negative sense RNA viruses such as RSV (Pneumoviridae, EC90 $=36 \mu \mathrm{M}$ ), CCHFV (Nairoviridae, EC50 $=6.37 \mu \mathrm{M})$, LSAV $($ Arenaviridae, EC50 $=29.3 \mu \mathrm{M})$, JUNV (Arenaviridae, EC50 $=0.79 \mu \mathrm{M})$, Rabies virus (Rhabdoviridae, EC50 $=32.4 \mu \mathrm{M}$ ), EBOV (Filoviridae, EC50 $=67 \mu \mathrm{M}$ ), or positive sense RNA viruses like SARS-CoV-2 (Coronaviridae, EC50 = $61.88 \mu \mathrm{M})$, Flaviviridae ZIKA $(\mathrm{EC} 50=22 \mu \mathrm{M}), \mathrm{WNV}(\mathrm{EC} 50=$ $53 \mu \mathrm{M})$, YFV $(\mathrm{EC} 50=180 \mu \mathrm{M})$, and enterovirus EV71 (Picornaviridae, EC50 = 68.74 $\mu \mathrm{M}$ ) (Morrey et al., 2008; Oestereich et al., 2014a; Oestereich et al., 2014b; Jochmans et al., 2016; Oestereich et al., 2016; Yamada et al., 2016; Zmurko et al., 2016; Furuta et al., 2017; Wang et al., 2020b) (Table 3).

A preclinical study in EBOV-infected macaques shows a higher plasma favipiravir concentrations greater than $70-80 \mu \mathrm{g} / \mathrm{ml}$ or $446-509 \mu \mathrm{M}$ were associated with reduced viral loads and extended survival rate (Guedj et al., 2018). A similar study in IFNAR-/- mice also shows a high dose [300 mg/ $(\mathrm{kg} / \mathrm{d})]$ of favipiravir enhances EBOV clearance and prevents a lethal outcome (Oestereich et al., 2014a). Clinically, favipiravir showed good tolerance in EBOV patients but no strong antiviral efficacy (Sissoko et al., 2016), possibly due to the low median trough drug concentrations $(46 \mu \mathrm{g} / \mathrm{ml}$ or $293 \mu \mathrm{M}$ at day 2 posttreatment) (Nguyen et al., 2017). Thus, the optimal dosage and potency of favipiravir merit further investigation.

Favipiravir exhibited antiviral activity against SARS-CoV2 in vitro (Wang et al., 2020b) and showed a significantly shorter viral clearance time than the control group (4 vs. 11 days) and a higher improvement in chest imaging in a non-randomized clinical study (Cai et al., 2020). Another 
small-sized open-label phase II/III clinical trial (NCT04434248) also found that favipiravir enabled SARS-CoV-2 viral clearance in $62.5 \%$ of patients within 4 days, as compared to $30 \%$ of patients on a standard of care; however, the viral clearance rate by day 10 after favipiravir administration was only marginally improved (Ivashchenko et al., 2020). Although favipiravir has been approved in some countries, large-scale, placebo-controlled, double-blinded clinical trials may be still needed to further evaluate the efficacy and safety of favipiravir.

The mechanism of action of inhibiting influenza RdRp by favipiravir involves the conversion to the metabolite favipiravir ribofuranosyl- $5^{\prime}$-triphosphate (favipiravir-RTP), which further incorporates into influenza $\mathrm{RdRp}$ to inhibit the polymerase activity at nanomolar to micromolar concentrations (Furuta et al., 2013). The inhibition of other viral RdRp by favipiravir may involve a similar mechanism.

\section{Sofosbuvir}

Sofosbuvir that targets HCV RdRp NS5B from 15 subtypes in six genotypes with an EC50 ranging from 0.032 to $0.13 \mu \mathrm{M}$ is an approved oral direct-actin antiviral to treat chronic hepatitis $\mathrm{C}$ (Han et al., 2019). A cocktail treatment regimen containing sofosbuvir and HCV protease NS3/4A inhibitors has already been approved for pan-genotypic HCV infection. Sofosbuvir shows antiviral effects against other virus members in Flaviviridae family, such as ZIKA (EC50 = 4.25 $\mu \mathrm{M})$ (BullardFeibelman et al., 2017; Mumtaz et al., 2017; Sacramento et al., 2017), DENV(Sacramento et al., 2017), CHIKV (EC50 = $1 \mu \mathrm{M})$ (Ferreira et al., 2019), and YFV $(\mathrm{EC50}=4.2 \mu \mathrm{M})$ (de Freitas et al., 2019). Strikingly, HEV, another hepatotropic virus but evolutionally distant from $\mathrm{HCV}$, was reported to be susceptible to sofosbuvir $(\mathrm{EC} 50=1.97 \mu \mathrm{M})$ (Todt et al., 2018; Netzler et al., 2019) (Table 3). A phase II clinical trial of sofosbuvir for HBV treatment (phase II NCT03312023) is also under investigation. Besides, the binding residue of sofosbuvir on coronavirus RdRp is conserved among SARS-CoV, SARS-CoV-2, and MERS-CoV(Jacome et al., 2020), although sofosbuvir did not exhibit the inhibitory effect against MERS-CoV RdRp in a cellbased reporter assay (Min et al., 2020). Sofosbuvir binds to SARSCoV-2 RdRp and inhibits virus infection in lung and brain cells (Elfiky, 2020a), and clinical trials have initiated in multiple countries (phase II NCT04561063, phase II NCT04532931, phase II/III NCT04460443; phase II/III NCT04497649; phase III NCT04530422, phase III NCT04535869, phase IV NCT04498936).

\section{Galidesivir (BCX4430, Immucillin-A)}

Galidesivir, an imino-C-nucleoside analog, was originally developed to combat EBOV infection (Warren et al., 2014). Galidesivir strongly inhibits EBOV RdRp activity in vitro and post-exposure intramuscular administration of galidesivir protects mice or macaques against Ebola virus or Marburg disease (Warren et al., 2014). Currently, a phase I clinical trial (NCT03800173) for Marburg disease is being performed.

Galidesivir was subsequently identified to exhibit broadspectrum antiviral effectiveness against other RNA virus families like Flaviviridae members TBEV $($ EC50 $=0.95 \mu \mathrm{M})$,
YFV $($ EC50 $=14.1 \mu \mathrm{M})$, WNV $($ EC50 $=2.33 \mu \mathrm{M})$, DENV $(\mathrm{EC} 50=32.8 \mu \mathrm{M})$, and ZIKA $(\mathrm{EC50}=3.8 \mu \mathrm{M})$, Arenaviridae (LASV, EC50 = $43.0 \mu \mathrm{M})$, Phleboviridae (RVFV, EC50 = $41.6 \mu \mathrm{M}), \quad$ Pneumoviridae (RSV, EC50 = $11.0 \mu \mathrm{M})$, Orthomyxoviridae (IAV H1N1, EC50 = $10.7 \mu \mathrm{M}$ ), and Coronaviridae MERS-CoV $(\mathrm{EC} 50=68.4 \mu \mathrm{M})$ and SARS-CoV $(\mathrm{EC} 50=57.7 \mu \mathrm{M})$ (Warren et al., 2014; Eyer et al., 2017; Julander et al., 2017; Westover et al., 2018; Eyer et al., 2019). Preclinical studies showed intramuscular or intraperitoneal administration of galidesivir in Syrian golden hamsters effectively limited systemic RVFV infection and improved survival outcomes (Westover et al., 2018). Galidesivir also showed anti-ZIKA activity in a lethal mouse model even when the treatment was initiated during the peak of viremia (Julander et al., 2017). Despite the anti-coronavirus activity in vitro, and the predicted strong binding of galidesivir with SARSCoV-2 RdRp (Elfiky, 2020b), an early stage clinical showed that treatment with galidesivir offered COVID-19 patients no benefit compared to a placebo.

\section{Viral Protease Inhibitor}

\section{Lopinavir/ritonavir (LPV/r)}

$\mathrm{LPV} / \mathrm{r}$ is a fixed-dose combination for HIV prevention and treatment. It combines LPV with a low dose of ritonavir (RTV), both of which are HIV protease inhibitors. In HIV1 NL4-3 infection system in vitro, LPV and RTV have an EC50 of 0.018 and $0.046 \mu \mathrm{M}$, respectively, against HIV-1, but LPV has a much higher potency than RTV does $($ EC50 = $0.015 \mu \mathrm{M}$ for LPV vs. $0.349 \mu \mathrm{M}$ for RTV) for HIV-2 (Masse et al., 2007). RTV is also a very potent inhibitor of intestinal and hepatic cytochrome P450 3A4 (Eagling et al., 1997), which is involved in LPV catabolism. As with $\mathrm{LPV} / \mathrm{r}$, darunavir/cobicistat $(\mathrm{DRV} / \mathrm{c})$ is also a dose-fixed combination containing HIV protease inhibitor DRV and CYP3A enzymatic antagonist cobicistat (Masse et al., 2007). Low doses of RTV or cobicistat could slow down the breakdown of HIV protease inhibitors, thereby greatly increases its blood concentration.

Some viruses, like SARS-CoV, MERS-CoV, and SARS-CoV2 , encode proteases, which are structurally and functionally similar to HIV protease. LPV shows an EC50 of 17.1, 8.0, and $26.63 \mu \mathrm{M}$, respectively against the three coronaviruses (de Wilde et al., 2014; Choy et al., 2020) (Table 3). LPV/r combination shows greater anti-MERS-CoV activity than LPV does (EC50 of 8.5 vs. $11.6 \mu \mathrm{M}$ ) in vitro (Sheahan et al., 2020). LPV/ $\mathrm{r}$ alongside IFN- $\beta$ shows improved clinical and pathological features in a nonhuman primate MERS model (Chan et al., 2015), while prophylactic or therapeutic LPV/ $r$-IFN- $\beta$ treatment only slightly improves the disease outcomes in patients (Sheahan et al., 2020). Similarly, SARS patients receiving $\mathrm{LPV} / \mathrm{r}$ were found to have an improvement in respiratory syndrome (Chu et al., 2004). However, the potency of $\mathrm{LPV} / \mathrm{r}$ for SARS-CoV is only effective if administrated early but not as rescue or salvage therapy (Chan et al., 2003). Despite of its potential for COVID-19 treatment, a randomized trial showed the hospitalized COVID-19 patients did not benefit from LPV/r therapy (Cao et al., 2020). 


\section{Rupintrivir (AG-7088)}

Rupintrivir is a peptidomimetic compound inhibiting viral protease activity, it is designed to combat human rhinovirus (HRV, belonging to family Piconaviridae) infection. Rupintrivir shows potent in vitro activity against all 48 HRV serotypes tested, with a range of EC50s of 0.007 to $0.104 \mu \mathrm{M}$ (Binford et al., 2005). A phase II placebocontrolled randomized, double-blind trial experimentally shows the biosafety and potential efficacy in volunteers (Hayden et al., 2003). Because of a lack of efficacy in natural HRV infection in a subsequent clinical trial, further development of rupintrivir was suspended.

Rupintrivir has shown antiviral activity against a spectrum of viruses that encodes 3C or 3C-like protease, for instance, rupintrivir exhibits antiviral activities against multiple enteroviruses, including EV71 (strain 695F, EC50 $=0.014 \mu \mathrm{M}$ ), coxsackievirus B2 (CVB2, EC50 $=0.022 \mu \mathrm{M})$, CVA16 (strain $860 \mathrm{~F}, \mathrm{EC} 50=0.015 \mu \mathrm{M})$ (Hung et al., 2011). Two studies show rupintrivir exhibits cross-genotypic inhibitory activity against either human or mouse norovirus, a member in the family Caliciviridae, with the EC50 of 0.32 and $13 \mu \mathrm{M}$, respectively (Kim et al., 2012; Rocha-Pereira et al., 2014). A molecular modeling study shows rupintrivir is capable to bind with SARS-CoV main proteinase 3CL pro (Anand et al., 2003); however, rupintrivir fails to show good activity at even $100 \mu \mathrm{M}$, although some rupintrivir derivatives show better potency $(\mathrm{IC50}=11-39 \mu \mathrm{M}$ ) (Shie et al., 2005). Rupintrivir exerts an antiviral effect on coronaviruses including CoV-229E $(\mathrm{EC} 50=0.3 \mu \mathrm{M})$, transmissible gastroenteritis virus (TGEV, $\mathrm{EC} 50=2.5 \mu \mathrm{M})$, bovine coronavirus $(\mathrm{BCV}, \mathrm{EC} 50=15.3 \mu \mathrm{M})$ (Table 3). Rrupintrivir also showed inhibition for SARS-CoV-2 main protease with a $50 \%$ inhibitory concentration of $68 \pm 7 \mu \mathrm{M}$ (Vatansever et al., 2021).

Rupintrivir has poor aqueous solubility and low oral bioavailability in animals, the hydrolyzed metabolites are reportedly 400-fold less active than rupintrivir but predominates the biotransformation pathway. The above features may limit its potential clinical application.

\section{Host-Targeting Antiviral (HTA) Repurposing}

HTA repurposing identifies antivirals targeting to host proteins, functions, or pathways, which are required for virus life cycle including viral entry, genome replication, protein translation, and virus assembly and release. As the entire viral life cycle cannot be completed without cells, HTA may exhibit broad antiviral activity against different viruses. Based on the essential steps of a viral life cycle, four major categories of host-targeting repurposed antivirals (HTRA) are classified as below.

\section{HTRA Aiming Virus Entry Step}

The first step of the viral life cycle is to enter permissive cells. Some enveloped viruses like HIV, and Nipah virus enter cells via direct membrane fusion with the plasma membrane, resulting in the release of nucleocapsid directly to the cytosol (Bossart et al., 2002; Wilen et al., 2012). Bacteriophages can inject their genomes alone into bacterial cells. Except for the aforementioned two mechanisms, most viruses depend on an endocytic pathway to be internalized into cells. The involved pathways include clathrinmediated endocytosis, caveolar/lipid raft-mediated endocytosis, or micropinocytosis, through which viruses are internalized into the early endosome, intermediate endosome, and then late endosome or lysosome in a stepwise manner. Finally, the exposure of virions either naked or enveloped to low $\mathrm{pH}$ and proteolytic enzymes will trigger changes in the naked virions, or membrane fusion between the organelle and enveloped viruses, to help deliver the viral genome or the intact nucleocapsid into cytosol. Aftermath, most RNA viruses replicate in different locations within the cytosol, whereas DNA viruses continue the journey to the nucleus.

\section{Chlorpromazine (CPZ) and Other Dopamine Antagonists}

$\mathrm{CPZ}$ is a phenothiazine used to treat psychotic disorders including schizophrenia or manic-depression in adults. CPZ can treat in children severe behavioral problems like attention deficit hyperactivity disorder. CPZ is also indicated to treat anxiety before surgery, nausea and vomiting, and chronic hiccups that do not improve following other treatments (Lopez-Munoz et al., 2005). CPZ is on the list of WHO's essential medicines, among the most effective and safest medicines. CPZ antagonizes dopamine receptors, which are divided into two classes based on which G-protein they are coupled: the D1-like class (including D1 and D5) and the D2like class, which comprises D2, D3, and D4 receptors. CPZ can bind to and block two types of dopamine receptors, in particular D2 dopamine receptors, exerting antipsychotic activity.

$\mathrm{CPZ}$ has proved to inhibit clathrin-mediate endocytosis by preventing the assembly of the clathrin-coated pit on the cell surface (Wang et al., 1993). Thus, CPZ and other dopamine receptor antagonists show antiviral activity against a broad spectrum of viruses that use clathrin-mediated endocytosis to enter cells. These viruses include HIV(Bosch et al., 2008), rubella virus (Kee et al., 2004), human adenovirus (HAdV) (Diaconu et al., 2010), EV71 (Hussain et al., 2011), HAV (Rivera-Serrano et al., 2019), HEV (Yin et al., 2016a), HCV (Blanchard et al., 2006), DENV (Carro et al., 2018), ZIKA (Persaud et al., 2018; Li et al., 2020a), CSFV (Shi et al., 2016), CCHFV (Simon et al., 2009; Ferraris et al., 2015b), SFV (Pohjala et al., 2011), EBOV (Bhattacharyya et al., 2010), MERS-CoV (de Wilde et al., 2014), and SARS-CoV (Inoue et al., 2007).

HIV can either enter cells through direct viral membrane fusion with the plasma membrane, or cell-to-cell transmission and viral synapses between $T$ cells. The latter type of HIV entry is sensitive to $\mathrm{CPZ}$ treatment, suggesting the involvement of clathrin-mediated endocytosis (Bosch et al., 2008). Viruses within Flaviviridae family, such as HCV, DENV, ZIKA, and CSFV also enter cells dependent on clathrin-mediated endocytosis and are susceptible to $\mathrm{CPZ}$ treatment (Zhu et al., 2012; Shi et al., 2016). Cell surface $\mathrm{Fc} \gamma \mathrm{R}$ was reported to be required for antibody-dependent enhancement of DENV or ZIKV infection (Khandia et al., 2018). Interestingly, the viral entry mediated by Fc $\gamma$ RII needs the formation of clathrin-coated vesicles whilst $\mathrm{F} c \gamma \mathrm{RI}$-dependent viral entry is independent of clathrin (Carro et al., 2018). On the contrary, naked and enveloped viruses may comparably be sensitive to CPZ. HAV 
and HEV had been recognized as naked viruses until recently the membrane-trapped viral particles were identified (Feng et al., 2013; Yin et al., 2016a). The naked and enveloped HAV or HEV are both sensitive to CPZ treatment (Yin et al., 2016a; RiveraSerrano et al., 2019), suggesting the clathrin-mediated endocytosis is equally needed. Coronaviruses such as MERS$\mathrm{CoV}$ and SARS-CoV share the same clathrin-mediated endocytosis for virus entry. In light of this, clinical studies have initiated (phase II/III NCT04354805; phase III NCT04366739) to evaluate the safety and effectiveness of CPZ for COVID-19 treatment, although observative clinical studies have suggested that $\mathrm{CPZ}$ at the prescribed dose may not be clinically effective for COVID-19 (Hoertel et al., 2021).

\section{Sunitinib, Erlotinib (Receptor Tyrosine Kinase Inhibitors)}

Sunitinib and erlotinib are inhibitors to receptor tyrosine kinases (RTK) that play important roles in both tumor angiogenesis and tumor cell proliferation. Sunitinib has been approved for the treatment of cancers, such as gastrointestinal stromal cell tumor, renal cell carcinoma, and imatinib-resistant gastrointestinal stromal tumor; while erlotinib is licensed to treat non-small cell lung cancer, and pancreatic cancer (Hartmann and Kanz, 2008; Neveu et al., 2015). Erlotinib is on the list of WHO's essential medicines.

The major antiviral mechanism of sunitinib involves the inhibition of adaptor protein 2 (AP2)-associated protein kinase 1 (AAK1), which phosphorylates membrane trafficking adaptor proteins AP-1 and AP-2 to enhance the binding with clathrinassociated cargos for bidirectional transport and endocytosis from the plasma membrane, respectively (Ricotta et al., 2002). The inhibition of AAK1 thereby inhibits virus entry, or assembly and release. For instance, sunitinib reportedly inhibits DENV entry and infectious virus release but not RNA replication (Bekerman et al., 2017). In a multiple cycle infection system, the EC50 against DENV1 is $0.6 \mu \mathrm{M}$, similar EC50s $(0.3-1.2 \mu \mathrm{M})$ of sunitinib against other members in the family Flaviviridae (HCV, ZIKV, other DENV serotypes) were reported (Bekerman et al., 2017) (Table 4). Sunitinib is also effective against infections of other viruses including EBOV $(\mathrm{EC} 50=0.47 \mu \mathrm{M})$, CHIKV $(\mathrm{EC50}=4.67 \mu \mathrm{M})$, JUNV $(\mathrm{EC50}=4.8 \mu \mathrm{M})$, HIV $(\mathrm{EC} 50=$ $0.8 \mu \mathrm{M})$, and RSV (EC50 $<0.12 \mu \mathrm{M})$ (Bekerman et al., 2017). Albeit sunitinib and erlotinib combinations showed no efficacy in murine models of DENV and EBOV infection (Bekerman et al., 2017).

EGFR is involved in multiple virus entry processes such as DNA viruses HBV, HPV, and RNA viruses HCV, RSV, and porcine reproductive and respiratory syndrome virus in cell cultures (Lupberger et al., 2011; Wang et al., 2016a; Iwamoto et al., 2019; Lingemann et al., 2019; Mikuličić et al., 2019). Specifically, EGFR mediates HCV entry by regulating CD81-claudin-1 associations and viral glycoprotein-dependent membrane fusion (Lupberger et al., 2011). EGFR reportedly associates with sodium taurocholate cotransporting polypeptide (NTCP), the HBV receptor on the hepatocyte cell surface, and inhibition of EGFR dramatically impairs HBV virion internalization (Iwamoto et al., 2019; Gan et al., 2020). However, a recent clinical study suggests that $\mathrm{HBV}$ reactivation may occur in lung cancer patients receiving erlotinib treatment (Yao et al., 2019). Therefore, the safety and efficacy of sunitinib/erlotinib need to be cautiously investigated.

\section{Chloroquine (CQ) (Lysosomotropic Agents)}

$\mathrm{CQ}$ is a medication primarily used to treat or prevent a nonresistant malaria infection, it is also occasionally used for amebiasis treatment. Additionally, CQ has shown antiinflammatory properties for the clinical management of some autoimmune diseases such as rheumatoid arthritis and lupus erythematosus (Rainsford et al., 2015). CQ is on the list of WHO's essential medicines. The anti-malarial mechanism of action involves the lysosomotropic feature, which allows CQ to accumulate in an acidic digestive vacuole inside red blood cells, where CQ binds to hemes to form a toxic product resulting in cell lysis and ultimately parasite cell autodigestion. Also, because of the involvement of lysosomes in the autophagy process, the inhibition by CQ of lysosomal enzymes leads to the accumulation of the autophagy cargos that are supposed to break down in lysosomes, leading to the impairment of autophagy machinery.

Due to the lysosomotropic feature, CQ or other agents like hydroxychloroquine (HCQ) and Bafilomycin A, accumulate in lysosomes, acidic endosomes, or trans-Golgi network vesicles to elevate the $\mathrm{pH}$ and subsequently inhibit the residential hydrolase activity (Thome et al., 2013). Such an inhibition in lysosomal function leads to the uptake impairment of a panel of viruses. These include HCV (Ashfaq et al., 2011), DENV (Farias et al., 2014; Farias et al., 2015), ZIKA (Li et al., 2017b; Shiryaev et al., 2017), CCHFV (Ferraris et al., 2015a), CHIKV (Khan et al., 2010), MERS-CoV (Dyall et al., 2014), SARS-CoV (Keyaerts et al., 2004; Vincent et al., 2005), and SARS-CoV-2 (Wang et al., 2020b).

CQ exerts antiviral activity against DENV infection either in vitro (Farias et al., 2014) and in vivo in an infected monkey model (Farias et al., 2015). However, a double-blind and placebocontrolled trial in 307 dengue patients found that CQ does not reduce the duration of viremia and the viral NS1 antigenemia (Tricou et al., 2010). Although CQ shows antiviral activity against $\mathrm{EBOV}$ in vitro; however, CQ fails to protect against EBOV infection and disease pathogenesis in the in vivo guinea pig model (Dowall et al., 2015). CQ shows antiviral activity against some strains of HIV in vitro (Tsai et al., 1990) with an EC50 of $0.4-0.9 \mu \mathrm{M}$ when treated in combination with hydroxyurea plus didanosine in a lymphocytic cell line (Boelaert et al., 1999). And HCQ exhibits anti-HIV activity in vivo (Sperber et al., 1995). The mechanism may involve the inhibition of cell-to-cell transmission of HIV, which requires clathrin-mediated endocytosis (Bosch et al., 2008), or the inhibition of p120 production at a post-transcriptional level, possibly by impairing hydrolases or other enzymes in acidic vesicles (Savarino et al., 2001).

CQ shows broad and good antiviral activity against coronavirus infection in vitro. However, no efficacy is observed to reduce SARS-CoV virus titers in a nonlethal mouse model (Barnard et al., 2006a). Although CQ and HCQ had drawn a lot of attention for the treatment of COVID-19, the safety or severe side effects of CQ or HCQ at a high dose is 


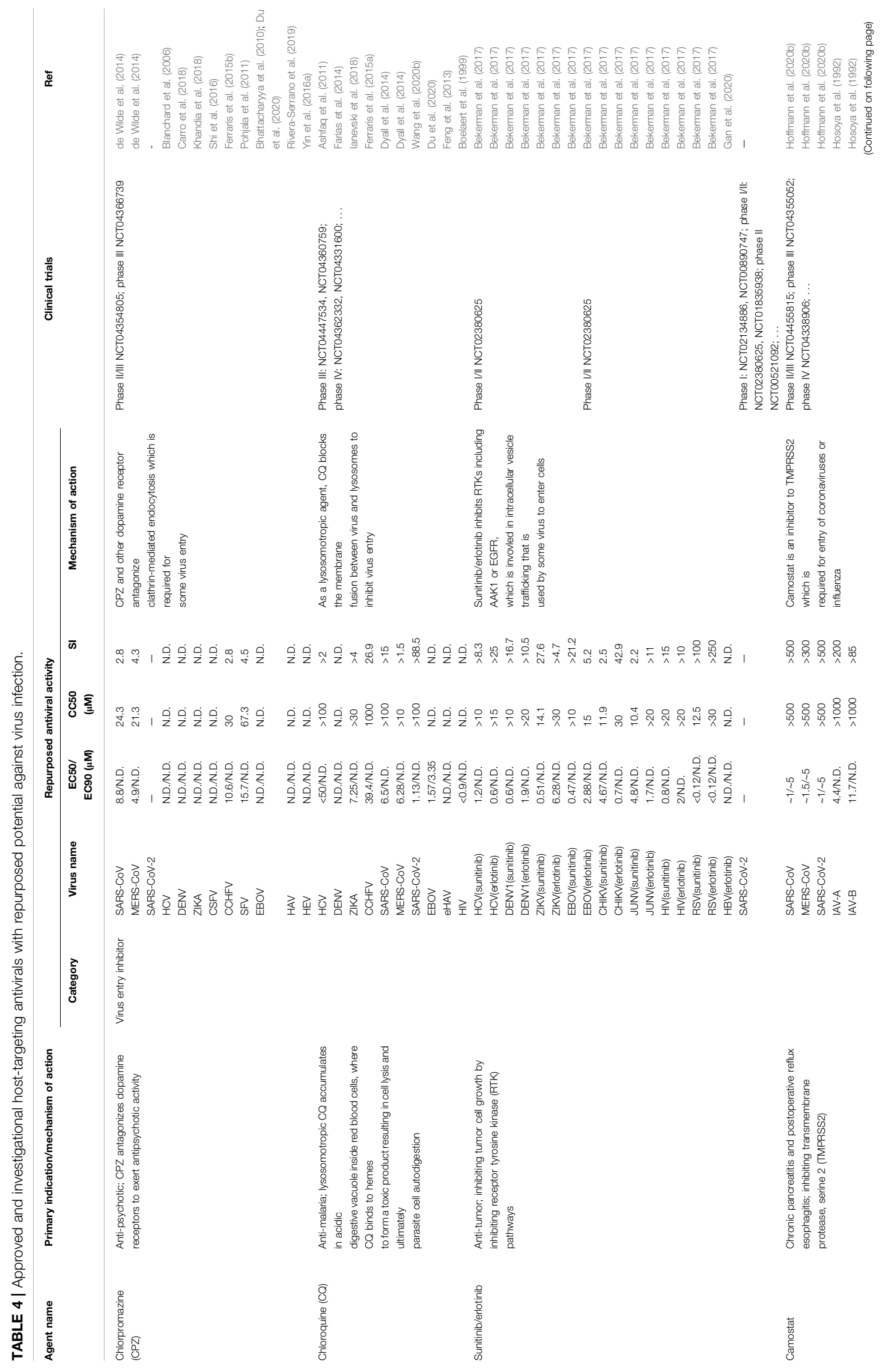




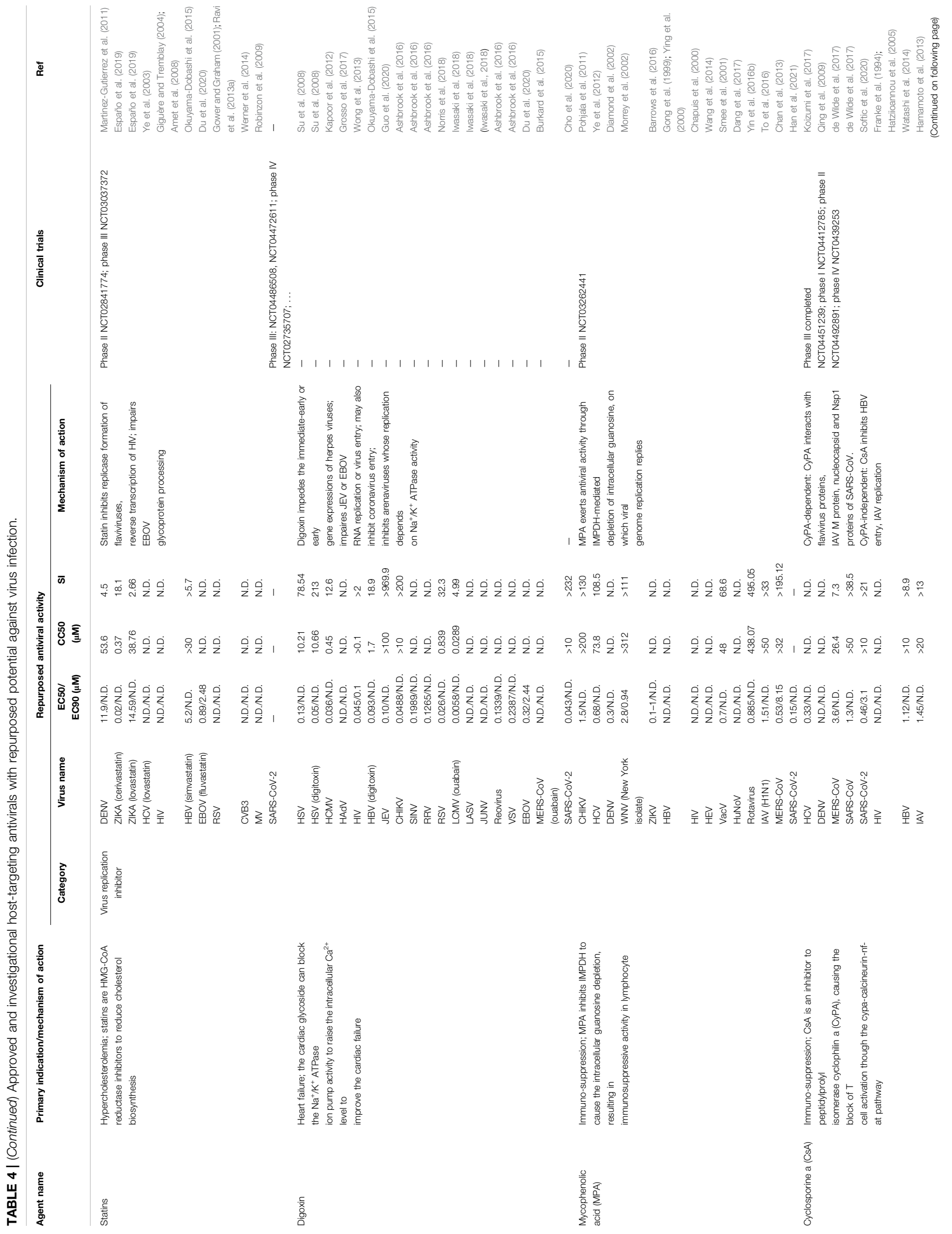


TABLE 4 | (Continued) Approved and investigational host-targeting antivirals with repurposed potential against virus infection.

\begin{tabular}{|c|c|c|c|c|c|c|c|c|c|}
\hline \multirow[t]{2}{*}{ Agent name } & \multirow[t]{2}{*}{ Primary indication/mechanism of action } & \multicolumn{6}{|c|}{ Repurposed antiviral activity } & \multirow[t]{2}{*}{ Clinical trials } & \multirow[t]{2}{*}{ Ref } \\
\hline & & Category & Virus name & $\begin{array}{c}\text { EC50/ } \\
\text { EC90 ( } \mu \mathrm{M})\end{array}$ & $\begin{array}{l}\mathrm{Cc} 50 \\
(\mu \mathrm{M})\end{array}$ & sı & Mechanism of action & & \\
\hline \multirow[t]{6}{*}{ Imatinib } & Antit-tumor; imatinib inhibits tyrosine kinase & Virus assembly/ & EBOV & N.D./N.D. & N.D. & N.D. & Imatinib decreases the budding or & Phase II: NCT04357613, NCT04346147; phase III: & Garcia et al. (2012) \\
\hline & c-Abl to block tumor cell proliferation & release inhibitor & DENV & N.D./N.D. & N.D. & N.D. & release & NCT04394416, NCT04422678; ... & Clark et al. (2016) \\
\hline & & & MERS-COV & 17.7/N.D. & $>50$ & $>2.8$ & of EBOV, VacV, and DENV; imatinib also & & Dyall et al. (2014) \\
\hline & & & SARS-COV & 9.82/N.D. & $>50$ & $>5$ & inhibits CVB entry & & Dyall et al. (2014) \\
\hline & & & SARS-CoV-2 & 4.86/N.D. & 37.3 & 7.7 & & & Han et al. (2021) \\
\hline & & & VacV & N.D./N.D. & N.D. & N.D. & & & Reeves et al. (2011) \\
\hline \multirow[t]{11}{*}{ Interferon $\alpha / \beta$} & Approved for antiviral (HCV, HBV) and multiple & Inhibition of multiple & $\mathrm{HCV}(\mathbb{I F N}-\mathrm{a})$ & ${ }^{*} .5 / 10$ & $>10,000$ & $>4000$ & IFN exerts the broad-specrum antiviral & & Okuse et al. (2005) \\
\hline & $\begin{array}{l}\text { sclerosis treatment; IFN induces the } \\
\text { production of }\end{array}$ & targets & $\mathrm{HBV}(\mathrm{FN}-\mathrm{a} 2)$ & $" 7754$ N.D. & N.D. & N.D. & $\begin{array}{l}\text { activity by } \\
\text { inducing ISG production, which may }\end{array}$ & $\begin{array}{l}\text { Phase I NCT03294798; phase II NCT03575208; phase } \\
\text { IV NCTO3357822, NCT04035837; ... }\end{array}$ & Chen et al. (2020) \\
\hline & inteferon-stimulated genes through JAK-STAT & & HIV & N.D./N.D. & N.D. & N.D. & inhibit each & Phase $1 / 2$ NCT0247143 & lyer et al. (2017) \\
\hline & pathway & & EBOV (IFN- $\beta)$ & ${ }^{*} 74 / N . D$ & N.D. & N.D. & step of the viral life cycle & & McCarthy et al. (2016) \\
\hline & & & EBOV $(\mathbb{F N}-a)$ & ${ }^{*} 748 / \mathbb{D} . \mathrm{D}$ & N.D. & N.D. & & & McCarthy et al. (2016) \\
\hline & & & DENV & ${ }^{*} 182.1 /$ N.D. & N.D. & N.D. & & & Pires de Mello et al. (2018a) \\
\hline & & & $\mathrm{ZIKV}$ & *407.8/N.D. & N.D. & N.D. & & & Pires de Mello et al. (2018b) \\
\hline & & & SARS-CoV(IFN- $a)$ & ${ }^{*} 4950 / N . D$. & $>10,000$ & $>2$ & & & Cinatl et al. (2003) \\
\hline & & & SARS-COV(IFN- $\beta$ ) & 95/N.D. & $>10,000$ & $>105$ & & & Cinatt et al. (2003) \\
\hline & & & $\begin{array}{l}\text { MERS- } \\
\text { CoV(IFN- }-2-2 b)\end{array}$ & $\begin{array}{l}{ }^{5} 58.08 / \\
320.11\end{array}$ & N.D. & N.D. & & & Falzarano et al. (2013a) \\
\hline & & & $\begin{array}{l}\text { SARS-CoV-2 (IFN- } \alpha \\
\text { or } \beta)\end{array}$ & $\begin{array}{l}\star 1.35 \text { or } \\
0.76 / N . D .\end{array}$ & N.D. & N.D. & & $\begin{array}{l}\text { Phase III: NCT04492475, NCT04320238; phase IV: } \\
\text { NCT04350671, NCT04254874; ... }\end{array}$ & Mantlo et al. (2020) \\
\hline \multirow[t]{12}{*}{ Nitazoxanide } & Anti-parasite; nitazoxanide interferences with & & IAV (H1N1/PR8) & 3.25/N.D. & $>163$ & $>50$ & Nitazoxanide inhibits morphogenesis of & Phase II NCT03905655 & Rossignol et al. (2009) \\
\hline & & & $\mathrm{seV}$ & 1.63/N.D. & $>163$ & $>100$ & IAV and & & Rossignol (2014) \\
\hline & pyrruvate:ferredoxin oxidoreductase (PFOR) & & RSV & 0.98/N.D. & $>163$ & $>166$ & rotavirus; post-entry steps of $\mathrm{SeV}$ and & & Rossignol (2014) \\
\hline & enzyme-dependent electron transfer reaction & & HCV & $0.68 / 3.03$ & 123.7 & 181 & RSV; HBV & & Korba et al. (2008) \\
\hline & to disrupt parasite enegery metabolism & & JEV & $0.39 /$ N.D. & 60 & 154 & DNA replication; viral protease activity of & & Shi et al. (2014) \\
\hline & & & $\mathrm{ZIKV}$ & $1.48 / 4.0$ & 77 & 52 & $\mathrm{ZIKV}$ & & Li et al. (2017c) \\
\hline & & & HIV & 1.63/N.D. & $>100$ & $>50$ & or coronavirus; induce innate immune & & Tan et al. (2012) \\
\hline & & & HBV & $0.39 / 2.7$ & $>325$ & $>833$ & genes & & Korba et al. (2008) \\
\hline & & & Rotavirus & 6.5/N.D. & $>163$ & $>25$ & & & La Frazia et al. (2013) \\
\hline & & & CHIKV & 2.96/N.D. & 25 & 8.45 & & & Wang et al. (2016c) \\
\hline & & & MHV & 1/N.D. & $>10$ & $>10$ & & & Cao et al. (2015) \\
\hline & & & SARS-COV-2 & 2.12N.D. & 35.53 & 16.76 & & $\begin{array}{l}\text { Phase III: NCT04382846, NCTO4392427; phase IV: } \\
\text { NCT04498936, NCT04406246; ... }\end{array}$ & Wang et al. (2020b) \\
\hline
\end{tabular}

Note: N.D. not determined. \# $\mathrm{pg} / \mathrm{ml} ;{ }^{*} \mathrm{IU} / \mathrm{ml}$ for IFN unit. 
concerned (Borba et al., 2020; Cortegiani et al., 2020), and recent clinical studies (including WHO Solidarity trial) indicate that CQ or HCQ has little efficacy for COVID-19 (Boulware et al., 2020).

\section{Camostat or Nafamostat Mesylate (TMPRSS2 Inhibitor)}

Camostat and nafamostat are serine protease inhibitors that inhibit the transmembrane protease, serine 2 (TMPRSS2). Camostat is approved in Japan for the treatment of postoperative reflux esophagitis and chronic pancreatitis, while nafamostat is approved for pancreatitis, an anticoagulant in patients with disseminative blood vessel coagulation, hemorrhagic lesions, and hemorrhagic tendencies (Jia et al., 2005; Maruyama et al., 2011).

Camostat and nafamostat exhibit effectiveness against a broad spectrum of viruses from different families including IAV (Hosoya et al., 1992; Hosoya et al., 1993; Lee et al., 1996), myxoviruses (Hosoya et al., 1992), DENV (Rathore et al., 2019), MERS-CoV (Shirato et al., 2013), SARS-CoV (Kawase et al., 2012), and SARS-CoV-2 (Hoffmann et al., 2020b) (Table 4). Particularly, camostat and nafamostat are effective to inhibit type A or B IAV replication in vitro at a micromolar level, while showing no efficacy against other respiratory viruses tested including RSV and parainfluenza virus (Hosoya et al., 1992). Additionally, camostat mesylate at an ED50 (the survival rate of influenza virus-infected chick embryos by $50 \%$ ) of $0.8 \mu \mathrm{g} / \mathrm{g}$ can increase the survival rate of influenza virus-infected chick embryos (Lee et al., 1996). The mechanism of camostat antiviral activity involves the inhibition of hemagglutinin (HA) cleavage, which is essential for the process of IAV infection and is achieved intracellularly or extracellularly by host proteases like TMPRSS2 (Yamaya et al., 2015).

SARS-CoV and SARS-CoV-2 both use angiotensin-converting enzyme 2 (ACE2) as a receptor, whereas MERS-CoV utilizes DDP4 as the receptor for entry (Li et al., 2003; Raj et al., 2013; Lan et al., 2020). These three coronaviruses all use two mechanisms to enter cells. One involves the direct membrane fusion at the cell surface after the virions binding to receptors, the membrane fusion is triggered by TMPRSS2 serine protease to generate a cleaved form of spike (S) protein for fusion step (Kawase et al., 2012; Shirato et al., 2013; Yamamoto et al., 2016; Hoffmann et al., 2020a). Alternatively, these viruses enter cells through the endocytic pathway in the absence of TMPRSS2, involving the cleavage and priming of $S$ protein by cysteine protease cathepsin $\mathrm{B} / \mathrm{L}$ in acidic endosomes (Simmons et al., 2005; Qian et al., 2013; Hoffmann et al., 2020a). Inhibition of both TMPRSS2 serine protease and cathepsin $\mathrm{B} / \mathrm{L}$ cysteine protease activities are required for full blockade of the above coronavirus infection (Kawase et al., 2012; Hoffmann et al., 2020a), while TMPRSS2 inhibition by camostat or nafamostat only results in partial impairment in virus entry (Kawase et al., 2012; Shirato et al., 2013). Strikingly, camostat at a dose of $30 \mathrm{mg} / \mathrm{g}$ shows antiviral efficacy by improving the survival rate in a lethal SARS-CoVinfected mouse model; however, a cysteine protease inhibitor SMDC256160 at a higher dose of $50 \mathrm{mg} / \mathrm{g}$ is no effective (Zhou et al., 2015). The result suggests that TMPRSS2 rather than cathepsin $\mathrm{B} / \mathrm{L}$ facilitates the spread of SARS-CoV in the infected mice. It would be of interest to evaluate the treatment efficacy of camostat or nafamostat for SARS-CoV-2 infection, and multiple clinical studies have been available for camostat (phase I/II NCT04321096; phase I/II NCT04435015; phase II NCT04353284; phase II NCT04374019; phase II NCT04470544; phase II/III NCT04455815; phase III NCT04355052; phase IV NCT04338906) and nafamostat (phase II/III NCT04352400; phase II/III NCT04418128; phase II/III NCT04473053).

\section{HTRA Targeting Virus Replication Step}

After the viral genome is uncoated from nucleocapsid, viral genome replication and protein translation occur. Positivesense RNA viruses, for instance, coronaviruses and flaviviruses, directly use the viral genome as a template for viral protein translation using host machinery. Negative-sense RNA viruses like filoviruses and myxoviruses, need to generate positive-sense RNA by the virally encoded polymerase, and then protein translation is initiated. Retrovirus and HBV replication involve one additional step, copying RNA to DNA by using virally encoded reverse transcriptase. DNA viruses need to use a host RNA polymerase to generate RNA from the viral DNA genome for protein translation. A number of viruses replicate in specific compartments, so-called replication organelles, in the cytoplasm, involving the aberrant lipid-rich membrane rearrangement (de Wilde et al., 2018). Specifically, some flaviviruses or alphaviruses replicate on an architecture composed of single-membrane spherules (den Boon and Ahlquist, 2010); while coronaviruses or picornaviruses form double-membrane vesicles as replicase sites (de Wilde et al., 2013; van der Schaar et al., 2016). To facilitate viral genome amplification, a variety of host proteins or related pathways are required to generate a favorable environment for virus production. These host proteins or pathways that interact with viral proteins are ideal host-targeting antivirals with a potential comprehensive antiviral efficacy.

\section{Statins (HMG-CoA Reductase Inhibitors)}

Statins are reversible inhibitors of 3-hydroxy-3-methylglutarylCoA (HMG-CoA) reductase, a rate-limiting enzyme involved in cholesterol biosynthesis. The statins are clinically approved to reduce cholesterol levels to prevent primary and secondary cardiovascular diseases. There are various forms of statins, which include lovastatin, atorvastatin, fluvastatin, pitavastatin, pravastatin, rosuvastatin, and simvastatin. Simvastatin is on the list of the WHO's essential medicines. Statins have been reported to inhibit a panel of disparate viruses including the viruses within the family Flaviviridae (HCV, DENV, and ZIKV) (Ye et al., 2003; Soto-Acosta et al., 2017; Españo et al., 2019), HIV (Amet et al., 2008), HBV (Okuyama-Dobashi et al., 2015), MV (Robinzon et al., 2009), EBOV (Shrivastava-Ranjan et al., 2018), RSV (Gower and Graham, 2001), EBV (Katano et al., 2004; Cohen, 2005), PRV (Desplanques et al., 2010), SFTSV (Urata et al., 2018), and parainfluenza (Bajimaya et al., 2017), because cholesterol biosynthesis is required for the replication of these viruses.

Statins efficiently inhibit flaviviral replication either in cell cultures or in animal models. Lovastatin impairs HCV RNA replication by blocking geranylgeranylation of a host protein required for $\mathrm{HCV}$ replication. Statins inhibit infectious ZIKV 
production as well as virus spread, possibly through the inhibition at either the early stage and the post-entry steps (Españo et al., 2019). Lovastatin impairs DENV replicase complex formation or virus assembly (Martinez-Gutierrez et al., 2011; Soto-Acosta et al., 2017). In addition, lovastatin, either prophylactically or even $48 \mathrm{hr}$ post-infection significantly prolongs the survival rate of DENV-infected mice (Martinez-Gutierrez et al., 2014). Lovastatin is able to inhibit HIV reverse transcriptase activity (Mazière et al., 1994), HIV attachment (Giguère and Tremblay, 2004), or HIV virion release (Amet et al., 2008). However, drugdrug interactions are reported to exist for statins and viral protease inhibitors like $\mathrm{HCV}$ NS3/4A antagonists or HIV protease inhibitors (Busti et al., 2004; Chauvin et al., 2013). Thus, the efficacy of statins against Flavivirus or HIV infection in the real world needs to be further assessed.

Negative strand RNA viruses are susceptible to statins. Lovastatin shows antiviral potency in RSV-infected mice prophylactically and prevents the illness-associated weight loss (Gower and Graham, 2001), which is consistent with the observation that RSV induces HMG-CoA reductase activity and lovastatin is able to inhibit RSV replication in vitro (Ravi et al., 2013b). Lovastatin impairs coxackie virus B3 infection through downregulating coxsackie and adenovirus receptor expression (Werner et al., 2014). Lovastatin inhibits hPIV assembly and release but no other steps (Bajimaya et al., 2017). Statins are capable of impairing EBOV glycoprotein processing and infectious EBOV production and the glycoprotein-induced attachment (Hacke et al., 2015; Shrivastava-Ranjan et al., 2018). Retrospective clinical studies found that statins may help improve the outcome in hospitalized flu patients (Rothberg et al., 2012), although no effect was observed in IAV-infected rodent models (Kumaki et al., 2012; Belser et al., 2013; Glück et al., 2013).

Statins may benefit COVID-19 patients according to a retrospective study in 13,981 COVID-19 patients (Zhang et al., 2020). Currently, at least eight clinical trials are being on the way to continue the investigation into the efficacy of statins for COVID-19 (NCT04333407; phase II NCT04348695; phase II NCT04380402; phase II/III NCT04466241; phase III NCT04486508; phase III NCT04472611; phase III NCT04343001; phase IV NCT02735707).

\section{Digoxin (Ion Pump Modulator)}

Digoxin is a cardiac glycoside or cardiotonic steroid, on the WHO's list of essential medicines. Digoxin has been used to treat certain heart dysfunctions including atrial fibrillation, and other heart failures (Gheorghiade et al., 2006). Digoxin has been shown to block the $\mathrm{Na}^{+} / \mathrm{K}^{+}$-ATPase with an inhibitory potency around 100-200 nM (Noel et al., 2018), resulting in elevated intracellular $\mathrm{Na}^{+}$level, and subsequent $\mathrm{Ca}^{2+}$ level via the sodiumcalcium exchanger. Digoxin and its analogs are reported to inhibit a global type of viruses, including dsDNA virus adenovirus (Grosso et al., 2017) and HSV (Dodson et al., 2007), retrovirus HIV (Wong et al., 2018), HBV (Okuyama-Dobashi et al., 2015), positive-sense alphavirus CHIKV, SINV, and RRV (Ashbrook et al., 2016), negative-sense enveloped RNA virus VSV, dsRNA naked virus reovirus (Ashbrook et al., 2016), RSV (Norris et al.,
2018), arenaviruses including LCMV, LASV, and JUNV (Iwasaki et al., 2018), filovirus EBOV (Du et al., 2020), and coronaviruses (Burkard et al., 2015) (Table 4).

Cardiac glycoside efficiently inhibits DNA virus replication. Digoxin or ouabain exhibits herpes virus, such as HSV and HCMV, at the immediate-early or early gene expression stage, the antiviral activity replies on the inhibition in $\mathrm{Na}^{+} / \mathrm{K}^{+}$-ATPase activity (Dodson et al., 2007; Su et al., 2008; Kapoor et al., 2012), Besides, digoxin also reportedly inhibits HSV release step ( $\mathrm{Su}$ et al., 2008). Digoxin also inhibits HAdV DNA synthesis (Grosso et al., 2017).

Other cardiac glycosides but not digoxin are able to inhibit $\mathrm{HBV}$ infection in vitro, possibly through blocking HBV preS1 protein binding to its receptor NTCP (Okuyama-Dobashi et al., 2015). Digoxin inhibits HIV protein expression in peripheral blood mononuclear cells, by a mechanism involving the impaired activity of the CLK family of SR protein kinases (Wong et al., 2013), or the modulation of MEK1/2-ERK1/2 signaling (Wong et al., 2018). In addition, digoxin may also negatively affect HIV integration in T cells (Zhyvoloup et al., 2017). As digoxin exhibits anti-HIV activity with an excellent EC50 (1.1-1.3 nM) at which it is far below the concentration in clinical use, cardiac glycosides merit further investigation to validate the efficacy for HIV treatment.

Digoxin and ouabain at nanomolar inhibit JEV infection in multiple cell culture systems, and ouabain protects against the JEV infection-induced lethality in mice (Guo et al., 2020). The inhibitory mechanism of digoxin or ouabain against (+) ssRNA virus infection may involve impaired RNA replication or virus entry (Ashbrook et al., 2016; Guo et al., 2020).

$\mathrm{Na}^{+} / \mathrm{K}^{+}$-ATPase is implicated in the entry process of coronaviruses including MHV and FIPV, cardiac glycosides like ouabain or bufalin inhibit MHV, FIPV, and MERS-CoV infections, by inhibiting virus entry and membrane fusion steps (Burkard et al., 2015). By contrast, cardiac glycosides inhibit SARS-CoV-2 at the post-entry step rather than S proteinmediated virus fusion or syncytia formation (Cho et al., 2020; Musarrat et al., 2020). Despite the excellent antiviral activity of cardiac glycosides against SARS-CoV-2 in vitro, no clinical trials have been initiated. One of the possible concerns is the association between digoxin use and increased all-cause mortality.

\section{Mycophenolic Acid (MPA) (IMPDH Inhibitor)}

MPA, also called mycophenolate, is an immunosuppressant approved to prevent transplant organ rejection and to treat Crohn's disease (van Gelder and Hesselink, 2015). MPA is a reversible, non-competitive inhibitor of IMPDH, which is the rate-limiting enzyme for the de novo synthesis of guanosine nucleotides that are substrates for DNA or RNA synthesis. MPA is more potent to inhibit type II than type I IMPDH enzyme, the former type expresses in activated lymphocytes, while the latter one in other most cells (Allison and Eugui, 2000). DNA or RNA virus replication replies on host guanosine pool, thus, MPA shows a broad spectrum antiviral activity against a variety of viruses, including HIV (Chapuis et al., 2000), HEV (Wang et al., 2014), HBV (Gong et al., 1999), BK 
polyoma virus (Acott et al., 2009), HCV and flaviviruses (DENV, WNV, JEV, and ZIKA) (Diamond et al., 2002; Morrey et al., 2002; Henry et al., 2006; Sebastian et al., 2011; Ye et al., 2012; Barrows et al., 2016; Adcock et al., 2017), orthobunyaviruses (Guama and Tacaiuma viruses) (Livonesi et al., 2007), orthopoxviruses like Vaccinia virus (VacV) and cowpox (Smee et al., 2001), rotavirus (Chan et al., 2013), SINV (Scheidel and Stollar, 1991), IAV (To et al., 2016; Cho et al., 2017; Hui et al., 2018), and MERSCoV(Chan et al., 2013) (Table 4).

MPA displays anti-HIV activity both in vitro and in HIV patients (Margolis et al., 1999; Chapuis et al., 2000), and a phase II clinical study (NCT03262441) is currently under investigation. Additionally, MPA potentiates the antiviral effect of reverse transcriptase inhibitors such as abacavir (Margolis et al., 1999). The antiviral mechanisms involve the depleted guanosine pool, as well as the induction of $\mathrm{T}$ cell apoptosis (Chapuis et al., 2000).

MPA is also effective for $\mathrm{HBV}$, at $31.2 \mu \mathrm{M}(10 \mu \mathrm{g} / \mathrm{ml}$, the therapeutic concentration in serum for immunosuppressive effect) in primary hepatocytes drastically reduces the secretion of HBV DNA and HBsAg, as well as the intracellular cccDNA level (Gong et al., 1999). Moreover, MPA and RBV, another IMPDH inhibitor, enhance the anti-HBV activity of nucleoside analogs including entecavir (Ying et al., 2000; Ying et al., 2007).

Although MPA shows anti-HCV potency in vitro or a mouse model (Henry et al., 2006; Pan et al., 2012; Ye et al., 2012), it fails to show antiviral efficacy in a double-blinded and placebocontrolled clinical study (Firpi et al., 2003). MPA presents anti-JEV activity in vitro with an EC50 of $9.68 \mu \mathrm{M}(3.1 \mu \mathrm{g} / \mathrm{ml})$ and up to $75 \%$ protection against the lethal challenge of JEV in vivo (Sebastian et al., 2011). MPA effectively dampens DENV replication with an EC50 of $0.3 \mu \mathrm{M}$ in vitro (Diamond et al., 2002; Manchala et al., 2019), and similarly inhibits ZIKV with the EC50 between 0.1 and $1 \mu \mathrm{M}$ (Barrows et al., 2016), although high cytotoxicity was also observed (Adcock et al., 2017).

MPA inhibits human and avian-originated IAV in vitro, including IAV-A $(\mathrm{H} 1 \mathrm{~N} 1)\left(\mathrm{pdm} 09 / \mathrm{H} 1 / 415, \mathrm{EC}_{50}=1.51 \mu \mathrm{M}\right), \mathrm{A}$ $(\mathrm{H} 3 \mathrm{~N} 2), \mathrm{A}(\mathrm{H} 5 \mathrm{~N} 1)\left(\right.$ Vietnam/1194/2004, $\left.\mathrm{EC}_{50}=0.94 \mu \mathrm{M}\right), \mathrm{A}$ (H7N9) and IAV-B (To et al., 2016; Cho et al., 2017). MPA also shows efficacy in an H5N1-infected mouse model (Cho et al., 2017).

After a repurposed drug screening, MPA exhibited good antiMERS-CoV activity with an EC50 $(0.53 \mu \mathrm{M})$, EC90 $(8.15 \mu \mathrm{M})$, and high SI value (>195.12) (Chan et al., 2013). MPA in combination with IFN- $\beta$ further lowers the EC50 by $1-3$ times (Chan et al., 2013). Contrarily, IMPDH inhibitors including MPA slightly enhance SARS-CoV replication in the lungs (Barnard et al., 2006b). MPA enables to inhibit SARS-CoV-2 infection in different cell cultures (Kato et al., 2020; Han et al., 2021), however, no clinical evidence is available to show the efficacy of MPA in COVID-19 patients.

\section{Cyclosporine A (CsA) (Cyclophilin Inhibitor)}

CsA is an immunosuppressant firstly isolated from fungus and has been approved to treat and prevent graft-versus-host disease in bone marrow transplantation, to prevent rejection of kidney, heart, and liver, or to treat autoimmune diseases like rheumatoid arthritis and psoriasis transplants (Griffiths and Voorhees, 1990; Faulds et al., 1993). CsA was recently approved as eye drops to treat dry eye disease (Mandal et al., 2019). CsA is on the WHO's list of essential medicines. The immunomodulatory mechanism of CsA involves its binding to peptidylprolyl isomerase cyclophilin A (CyPA). The CsA-CyPA complex is able to inhibit the calcineurin phosphatase activity, the nuclear translocation of the nuclear factor of activated T cells (NF$\mathrm{AT}$ ), eventually block the transcription of cytokines and $\mathrm{T}$ cell activation (Matsuda and Koyasu, 2000). CsA and its analog like alisporivir (ALV) have shown a broad-spectrum antiviral capacity against viruses, including Flaviviridae members HCV and ZIKV (Watashi et al., 2003; Henry et al., 2006; Koizumi et al., 2017; Dong et al., 2019), hepatotropic viruses HBV and HEV (Wang et al., 2014; Watashi et al., 2014), HIV (Keckesova et al., 2006; Saini and Potash, 2006; Nicolás et al., 2017), coronavirus SARS-CoV, SARS-CoV-2, CoV-NL63, and MERS-CoV(de Wilde et al., 2011; Pfefferle et al., 2011; Tanaka et al., 2013; CarbajoLozoya et al., 2014; Guisado-Vasco et al., 2020), rotavirus (Shen et al., 2015; Yin et al., 2016b), norovirus (Dang et al., 2017), DNA virus CMV (Abdullah et al., 2018), and IAV (Hamamoto et al., 2013; Ma et al., 2016).

CsA inhibits HCV RNA replication and the antiviral capacity seems independent of its immunosuppressive effect (Watashi et al., 2003; Henry et al., 2006), as ALV, a nonimmunosuppressive CsA analog, maintains the anti-HCV capacity (Crouchet et al., 2018). ALV in follow-up clinical trials (phase I to III) shows a higher sustained virological response rate than IFN and ribavirin do (Stanciu et al., 2019). However, serious side effects were more frequent in ALV-treated patients, the clinical studies were then halted. CyPA interacts with flavivirus proteins and is required for viral replication (Chatterji et al., 2009; Chatterji et al., 2010), and CsA is capable of inhibiting the infections of DENV, WNV, and YFV(Qing et al., 2009). Interestingly, CsA shows strong adulticidal activity against mosquitos, although no direct anti-ZIKV activity was found in a mosquito cell culture system (Dong et al., 2019).

CsA displays anti-HBV activity in vitro, and the inhibition is independent of CyPA or calcineurin (Watashi et al., 2014; Phillips et al., 2015). The inhibitory mechanism involves the block of the interactions of NTCP, the HBV entry receptor, with HBV large envelope protein (Watashi et al., 2014). CsA derivatives that maintain the anti-HBV activities but lose the impact on NTCP transporter activity have been successfully developed (Shimura et al., 2017). CyPA interacts with IAV matrix (M) protein (Liu et al., 2009), but CsA inhibits IAV or IBV infection at the steps of viral replication, IAV protein translation, or virus assembly/ release, in a CyPA-independent manner (Liu et al., 2012; Hamamoto et al., 2013; Ma et al., 2016). Further preclinical and clinical studies for either virus infection are warranted later.

CyPA specifically binds to the nucleocapsid and Nsp1 proteins of SARS-CoV and is detectable in the SARS-CoV particles (Chen et al., 2005; Pfefferle et al., 2011). CsA inhibits diverse coronaviruses including SARS-CoV, MERS-CoV, HCoV-229E, HCoV-NL63, and MHV (de Wilde et al., 2011; Pfefferle et al., 2011; de Wilde et al., 2013). $16 \mu \mathrm{M}$ CsA drastically inhibits infectious SARS-CoV production by $>3 \log$, although CsA less 
than $4 \mu \mathrm{M}$ seems to have pro-viral activity (de Wilde et al., 2011). CsA inhibits SARS-CoV RNA replication or post-entry steps (Pfefferle et al., 2011; Softic et al., 2020), and the early step is also possibly affected (de Wilde et al., 2011). Despite the encouraging results in cell culture systems, treatment with RBV and ALV does not protect from SARS-CoV infection in a mouse model (de Wilde et al., 2017). $9 \mu \mathrm{M}$ CsA treatment completely blocks the MERS-CoV-induced cytopathology in Vero cells, and CsA in combination with IFN- $\alpha$ display more effective anti-MERS-CoV activity (de Wilde et al., 2013; Li et al., 2018). ALV displays antiviral activity against SARS-CoV-2 with an EC50 of $0.46 \mu \mathrm{M}$ in vitro (Softic et al., 2020), and CsA in a cohort study showed a 4 fold decrease in observed mortality in hospitalized COVID-19 patients (Guisado-Vasco et al., 2020). Currently, at least four clinical trials have been in the process to evaluate the efficacy of CsA or ALV to treat COVID-19 (NCT04451239; phase I NCT04412785; phase II NCT04492891; phase IV NCT04392531). More results will be available soon.

\section{HTRA Targeting Virus Assembly/Release Step}

After a sufficient viral structure protein pool is available, viral assembly, a dynamic process driven by programmed sequential reactions is initiated, which involves interactions between the viral genomes and viral capsid proteins, and virus-host protein associations. The newly assembled nonenveloped virions disrupt the cytoskeleton to facilitate dispersal of viral progenies, whilst enveloped viruses gain their envelope from an intracellular organelle or plasma membrane to exit the cells by a budding or exocytosis process, albeit the dividing line between nonenveloped and enveloped viruses has become blurred given that non-lytic spread mechanisms have been identified for HAV, HEV, and some enteroviruses (Feng et al., 2013; Bird et al., 2014; Chen et al., 2015; Yin et al., 2016a). The host endosomal sorting complexes required for transport (ESCRT) and autophagy machinery have emerged roles to mediate the virus release despite the envelopment.

\section{Imatinib (STI-571) (c-Abl Inhibitors)}

Imatinib is a 2-phenyl amino pyrimidine derivative that functions as a specific inhibitor of many tyrosine kinases, including c-Abl, c-Kit, and platelet-derived growth factor receptor. It replaces ATP in the enzymatically active site, leading to the decreased activity of these tyrosine kinases. Imatinib is a medication used to treat cancer including chronic myelogenous leukemia, acute lymphocytic leukemia, and gastrointestinal stromal tumors. Imatinib is on the list of WHO's essential medicines. c-Abl is also implicated in the lifecycle of different viruses, and imatinib has been reported to inhibit infection of EBOV, DENV, MERS-CoV, SARS-CoV, coxsackievirus, and $\mathrm{VacV}$ (Table 4).

c-Abl1 inhibitor imatinib or nilotinib drastically decreases the budding or release of EBOV, as the inhibition of phosphorylation of the viral matrix protein VP40 (Garcia et al., 2012). Similarly, imatinib significantly dampens the extracellular enveloped $\mathrm{VacV}$ virion release without affecting cell-associated enveloped virions, and imatinib shows prophylactical or therapeutic antiviral effect in $\mathrm{VacV}$-infected mice (Reeves et al., 2011). In addition, imatinib significantly inhibits DENV replication at the post-entry steps, reducing the production of infectious DENV (Clark et al., 2016).

Interestingly, imatinib appears to inhibit the entry step of group B coxsackieviruses (CVBs), blocking the aggregation of virions to the tight junction, where the virions subsequently initiate the internalization step to finally surmount the epithelial barrier (Coyne and Bergelson, 2006).

Imatinib or other $\mathrm{c}-\mathrm{Abl}$ inhibitors nilotinib and dasatinib are able to inhibit MERS-CoV or SARS-CoV infection (Dyall et al., 2014). Specifically, imatinib and dasatinib show effectiveness against both viruses, while nilotinib is only effective for SARS$\mathrm{CoV}$ (Dyall et al., 2014). Recently, imatinib was reported to inhibit SARS-CoV-2 in stem cell-differentiated lung organoids $(\mathrm{EC} 50=4.86 \mu \mathrm{M})$ (Han et al., 2021). The detailed mechanism for this inhibition warrants further investigation. Currently, at least five clinical trials including three phase III studies (NCT04394416; NCT04422678; NCT04356495) have been carried out to investigate the treatment efficacy of imatinib for COVID-19.

\section{Other Agents}

Other agents that are also capable of inhibiting virus assembly/ release include statins, which, as mentioned previously, inhibits virion assembly of DENV or parainfluenza, and impairs infectious HIV or EBOV release (Amet et al., 2008; MartinezGutierrez et al., 2011; Bajimaya et al., 2017; Shrivastava-Ranjan et al., 2018). Another example is nitazoxanide, exhibiting multiple targeting features, can inhibit assembly/release of IAV, rotavirus, and possibly paramyxoviruses (Rossignol et al., 2009; La Frazia et al., 2013; Piacentini et al., 2018).

\section{Repurposed Agents With Multiple Targets}

Some repurposed agents have more than three potential targets, either viral or host proteins. The most documented example is IFN- $\alpha / \beta$, which is a crucial member of innate immunity, the first line to defend pathogens including viruses. Another instance is nitazoxanide, which has shown a very broad antiviral efficiency, representing divergent antiviral mechanisms for different viruses.

\section{Interferon}

Almost all viruses can induce interferon response that is mediated by different sensors including cGAS for DNA viruses; RIG-I, MDA5 for RNA viruses (Tan et al., 2018). These pattern recognition receptors recognize the invaders containing pathogen-associated molecular patterns to induce IFN, which in turn secretes out of cells and binds to receptors to induce the activation of JAK-STAT pathway. As a result, a broad spectrum of interferon-stimulated genes (ISG) is induced and exert antiviral effects through different mechanisms (Liu et al., 2013; Bailey et al., 2014; Li et al., 2017a). Clearly, the ISG network is diverse and complicated, each ISG functions in concert with others, in a combinatorial or even redundant way to combat virus infection. There are three classes of IFNs, type I, type II, and type III, distinguished by their different receptors. The type I IFNs include IFN- $\alpha$, IFN- $\beta$, IFN- $\varepsilon$, IFN- $\kappa$, and IFN- $\omega$; type II IFN comprises IFN- $\gamma$; and type III IFNs refer to IFN- $\lambda 1$ (IL-29), IFN- $\lambda 2$ (IL$28 \mathrm{~A})$, IFN- $\lambda 3$ (IL-28B), and IFN- $\lambda 4$ (Stanifer et al., 2019). IFN- $\alpha$ 
has been used for clinical purposes against HCV and HBV for a long time, and IFN- $\beta$ is approved to treat multiple sclerosis (Rice et al., 2001; Heim, 2013; Ezzikouri et al., 2020).

IFNs have been explored clinically to treat different virus infections including EBOV (Rhein et al., 2015; Konde et al., 2017; Fanunza et al., 2018; Lee et al., 2019), DENV (Pires de Mello et al., 2018a), ZIKA (Ngono and Shresta, 2018; Caine et al., 2019), MERS-CoV, SARS-CoV, and SARS-CoV-2 (Cinatl et al., 2003; Tan et al., 2004; Kindler et al., 2016; Haji Abdolvahab et al., 2021). A clinical study suggests that IFN- $\beta$-1a facilitates EBOV viral clearance and enhances survival rate (Konde et al., 2017), consistent with cell culture data that EBOV is sensitive to IFN- $\alpha$ or $\beta$ (McCarthy et al., 2016). AG129 mice that are deficient in interferon $a / \beta / \gamma$ signaling are more susceptible to all four serotypes of DENV (Sarathy et al., 2015; Milligan et al., 2017), suggesting the importance of IFN for DENV control. Similarly, IFN- $\alpha / \beta$ receptor (IFNAR)-deficient mice are highly susceptible to ZIKV infection (Lazear et al., 2016), and IFN- $\alpha$ considerately inhibits ZIKV infection in vitro alone or in combination with favipiravir (Pires de Mello et al., 2018b). Moreover, IFN- $\lambda$ protects the female reproductive tract against ZIKV infection in mice (Caine et al., 2019).

IFNs enable to inhibit SARS-CoV or MERS-CoV in cell cultures (Cinatl et al., 2003; Falzarano et al., 2013a), and show potency in macaques infected with SARS-CoV or MERS-CoV (Haagmans et al., 2004; Falzarano et al., 2013b). A retrospective cohort study in MERS-CoV patients shows that IFN- $a-2 a$ plus RBV results in a significant survival rate at 14 days than control supportive care (Omrani et al., 2014). However, the same treatment regimen did not benefit MERS patients in another clinical study (Al-Tawfiq et al., 2014). A preliminary, uncontrolled study shows that IFN plus corticosteroids are associated with better disease outcomes in SARS patients compared to corticosteroid treatment alone (Loutfy et al., 2003). Interestingly, a dual role of IFN for SARS pathology in mice was recently reported, while delayed IFN response correlates with severe lung immunopathology and reduced survival rate, early IFN administration ameliorates immunopathology (Channappanavar et al., 2016). IFN- $\alpha$ or IFN- $\beta$ efficiently inhibits SARS-CoV-2 infection in vitro (EC50 1.35 and $0.76 \mathrm{IU} / \mathrm{ml}$, respectively) (Mantlo et al., 2020). However, the Solidarity clinical trials launched by WHO concluded that IFN does not affect overall mortality in hospitalized COVID-19 patients. In spite of that, multiple clinical studies are still in progress to evaluate the efficacy of IFNA for COVID-19 including four phase III (NCT04492475; NCT04320238; NCT04324463; NCT04315948) and five phase IV (NCT04350671; NCT04254874; NCT04350684; NCT04291729; NCT02735707) trials.

\section{Nitazoxanide}

Nitazoxanide is licensed in the United States to treat parasite infection-induced diarrhea (Ortiz et al., 2001) due to the interference with the pyruvate: ferredoxin oxidoreductase (PFOR) enzyme-dependent electron transfer reaction which is essential to anaerobic energy metabolism. Nitazoxanide reduces IAV-induced duration of clinical symptoms and viral shedding in a double-blind, randomized, and placebo-controlled phase IIb/III clinical trial (Haffizulla et al., 2014). A phase III clinical trial (NCT01610245) is then initiated. The mechanism of action of nitazoxanide against IAV infection involves the inhibition in the maturation of viral hemagglutinin (HA) at the post-translational stage, thus impairing HA intracellular trafficking and insertion into the host plasma membrane (Rossignol et al., 2009). Besides, nitazoxanide is found to clinically effective to treat infections of adenovirus (Esquer Garrigos et al., 2018), rotavirus (Rossignol and El-Gohary, 2006; Teran et al., 2009), HBV (Rossignol and Keeffe, 2008), and HCV (Rossignol et al., 2008; Elazar et al., 2009; Rossignol et al., 2010). In addition, nitazoxanide enables to inhibition of other viral infections in vitro including HIV (Tan et al., 2012), JEV (Shi et al., 2014), ZIKV (Cao et al., 2017; Li et al., 2017c), feline calicivirus (Fumian et al., 2018), rubella virus (Perelygina et al., 2017), CHIKV(Wang et al., 2016c), paramyxovirus SeV and RSV(Piacentini et al., 2018), coronavirus MHV, MERS-CoV, and SARS-CoV-2 (Cao et al., 2015; Rossignol, 2016; Wang et al., 2020b).

Different antiviral mechanisms are involved for nitazoxanide in the context of different virus infections. Nitazoxanide prohibits SeV or RSV fusion step after entry into cells (Piacentini et al., 2018), HBV DNA replication and viral protein synthesis (Korba et al., 2008), viral RNA replication or protein processing of HCV, ZIKV, or MHV (Rossignol and Keeffe, 2008; Cao et al., 2015; Li et al., 2017c), viral morphogenesis of IAV or rotavirus (Rossignol et al., 2009; La Frazia et al., 2013). Nitazoxanide also triggers innate immune genes, like IRF1, RIG-I, or PKR, to combat norovirus or EBOV replication (Dang et al., 2018; Jasenosky et al., 2019).

$\mathrm{HBV}$ or HCV is susceptible to nitazoxanide treatment. An open-label small-scale clinical trial shows the preliminary efficacy of nitazoxanide in treating chronic hepatitis B (Rossignol and Keeffe, 2008). A further phase II clinical study (NCT03905655) is currently instigated. Clinical trials in hepatitis $\mathrm{C}$ patients show the improved SVR rate when treated alone or in combination with IFN and/or RBV (Rossignol et al., 2008; Elazar et al., 2009; Rossignol et al., 2010).

Nitazoxanide has potent antiviral activity against coronavirus. Nitazoxanide emerges as one of the most potent antivirals against MHV after drug repurposing screening (Cao et al., 2015), similar activity is observed for MERS-CoV (Rossignol, 2016) or SARSCoV-2 (Wang et al., 2020b). A preliminary clinical study suggests the potential efficacy of nitazoxanide for COVID-19 treatment (Rocco et al., 2021). Currently, at least 18 clinical trials have been launched to test the antiviral efficacy in COVID-19 patients including five phase III (NCT04382846; NCT04392427; NCT04343248; NCT04359680; NCT04486313) and three phase IV (NCT04498936; NCT04406246; NCT04341493) clinical studies (Table 4).

\section{CHALLENGES AND PERSPECTIVE}

Currently, most of the approved antivirals are used to treat infections of HIV, HCV, HBV, and IAV, very few novel antivirals for recently emerging viruses including SARS-CoV-2, MERS-CoV, EBOV, ZIKV, and DENV. Drug repurposing has 
played a crucial role in pushing the approved or investigational therapeutics through clinical trials, because of higher success rate, less investment, and faster approval.

Drug repurposing is not risk-free, the success rate is reported around $30 \%$. There are still a lot of hurdles before the repurposed drug is approved. Even though repurposed drugs could be exempted from phase I clinical trial, which mainly focuses on the drug safety evaluation, drug safety still represents one of the biggest concerns for repurposing. For instance, the safety of the drug that has been evaluated in a group of participants for the original indication does not necessarily guarantee safety in another group of people. In this scenario, drug safety may need to re-evaluate. Moreover, the dosing regimen of the repurposed drug validated previously may be different in new indications. A major obstacle to successful repurposing attributes to the higher effective concentrations in the new indication than those in the original indications. It suggests that greater harm and less benefit may be instigated. To overcome the obstacle, cocktailbased combinatorial regimens that contains at least two repurposed drugs targeting different steps of the viral lifecycle would be beneficial. In addition, drug-drug interactions may be another challenge when a repurposed drug has to use in combination with other drugs and no drug-drug interaction data is available. Thus, drug safety issue needs to be carefully appraised and addressed if necessary.

Apart from the safety issue, the intellectual property barrier is another important issue that needs to address. Commonly, drug repurposing focuses on drugs for which the patents on the original indication have been expired. For the off-patent generic drugs, a new method-of-use patent can be obtained for the new indication. However, enforceability or market exclusivity can be a major issue, as other company-manufactured generic drugs may be prescribed as off-label use for the new indication, which would be hardly prohibited. That may reduce the profit and financial incentive for drug repurposing. The off-label use can be limited if a new formulation or dosing regimen is required for the novel indication so that it cannot be easily fulfilled with the

\section{REFERENCES}

Abdullah, A. A., Abdullah, R., Nazariah, A. Z., Balakrishnan, K. N., Firdaus, J. A. F., Jamilu, A. B., et al. (2018). Cyclophilin A as a Target in the Treatment of Cytomegalovirus Infections. Antivir. Chem. Chemother. 26, 2040206618811413. doi:10.1177/2040206618811413

Acott, P., O’Regan, P. A., and Crocker, J. F. (2009). Suppression of Early and Chronic BK Polyoma Virus Replication by Mycophenolic Acid in Vero Cells. Transpl. Int. 22 (2), 225-231. doi:10.1111/j.1432-2277.2008.00766.x

Adcock, R. S., Chu, Y. K., Golden, J. E., and Chung, D. H. (2017). Evaluation of Anti-zika Virus Activities of Broad-Spectrum Antivirals and NIH Clinical Collection Compounds Using a Cell-Based, High-Throughput Screen Assay. Antivir. Res 138, 47-56. doi:10.1016/j.antiviral.2016.11.018

Al-Tawfiq, J. A., Momattin, H., Dib, J., and Memish, Z. A. (2014). Ribavirin and Interferon Therapy in Patients Infected with the Middle East Respiratory Syndrome Coronavirus: an Observational Study. Int. J. Infect. Dis. 20, 42-46. doi:10.1016/j.ijid.2013.12.003

Allison, A. C., and Eugui, E. M. (2000). Mycophenolate Mofetil and its Mechanisms of Action. Immunopharmacology 47 (2-3), 85-118. doi:10.1016/s01623109(00)00188-0 available generic versions of the drug. On the other hand, with the appropriate licensing, repurposing of drugs that are still covered by existing patent property is also achievable, even though many repurposed uses of patent drugs have been reported in the literature, which may limit the ability to gain the new patent protection. The reliable and novel evidence to support the new indication of the repurposed drug is a necessity to obtain the granted patents. Other challenges include self-medication, misuse, drug shortage, and price hike of the drugs with potential repurposed indications (Mallhi et al., 2020a; Mallhi et al., 2020b). The misuse of repurposed drugs would be devastating and should be discouraged particularly during a pandemic. The availability and affordability of these repurposed agents should also be vigilantly monitored.

With more approaches to address the safety, efficacy, and patent issues by deploying recombination therapies and reinforcing collaboration and negotiation, drug repurposing for a novel, efficient, and broad-spectrum antiviral development would strengthen the efforts to combat the emerging and re-emerging viruses.

\section{AUTHOR CONTRIBUTIONS}

XL drafted the manuscript. TP edited and revised the manuscript. All authors reviewed and approved the final version of the manuscript for publication.

\section{ACKNOWLEDGMENTS}

We express our thanks to Mike Bray, the Editor-in-chief of the journal Antiviral Research for his constructive advice to improve the manuscript. We thank support from the 111 Project (\#D18010), Infinitus China, and Guangzhou Institute of Respiratory Health Open Project (Funds provided by China Evergrande Group, Project \#2020GIRHHMS01).

Amet, T., Nonaka, M., Dewan, M. Z., Saitoh, Y., Qi, X., Ichinose, S., et al. (2008). Statin-induced Inhibition of HIV-1 Release from Latently Infected U1 Cells Reveals a Critical Role for Protein Prenylation in HIV-1 Replication. Microbes Infect. 10 (5), 471-480. doi:10.1016/j.micinf.2008. 01.009

Anand, K., Ziebuhr, J., Wadhwani, P., Mesters, J. R., and Hilgenfeld, R. (2003). Coronavirus Main Proteinase (3CLpro) Structure: Basis for Design of Anti-SARS Drugs. Science 300 (5626), 1763-1767. doi:10.1126/science. 1085658

Ashbrook, A. W., Lentscher, A. J., Zamora, P. F., Silva, L. A., May, N. A., Bauer, J. A., et al. (2016). Antagonism of the Sodium-Potassium ATPase Impairs Chikungunya Virus Infection. mBio 7 (3). doi:10.1128/mBio.00693-16

Ashfaq, U. A., Javed, T., Rehman, S., Nawaz, Z., and Riazuddin, S. (2011). Lysosomotropic Agents as HCV Entry Inhibitors. Virol. J. 8, 163. doi:10. $1186 / 1743-422 x-8-163$

Bailey, C. C., Zhong, G., Huang, I. C., and Farzan, M. (2014). IFITM-family Proteins: The Cell's First Line of Antiviral Defense. Annu. Rev. Virol. 1, 261-283. doi:10.1146/annurev-virology-031413-085537

Bajimaya, S., Hayashi, T., Frankl, T., Bryk, P., Ward, B., and Takimoto, T. (2017). Cholesterol Reducing Agents Inhibit Assembly of Type I Parainfluenza Viruses. Virology 501, 127-135. doi:10.1016/j.virol.2016.11.011 
Barnard, D. L., Day, C. W., Bailey, K., Heiner, M., Montgomery, R., Lauridsen, L., et al. (2006b). Enhancement of the Infectivity of SARS-CoV in BALB/c Mice by IMP Dehydrogenase Inhibitors, Including Ribavirin. Antivir. Res. 71 (1), 53-63. doi:10.1016/j.antiviral.2006.03.001

Barnard, D. L., Day, C. W., Bailey, K., Heiner, M., Montgomery, R., Lauridsen, L., et al. (2006a). Evaluation of Immunomodulators, Interferons and Known In Vitro SARS-coV Inhibitors for Inhibition of SARS-coV Replication in BALB/c Mice. Antivir. Chem. Chemother. 17 (5), 275-284. doi:10.1177/ 095632020601700505

Barrows, N. J., Campos, R. K., Liao, K. C., Prasanth, K. R., Soto-Acosta, R., Yeh, S. C., et al. (2018). Biochemistry and Molecular Biology of Flaviviruses. Chem. Rev. 118 (8), 4448-4482. doi:10.1021/acs.chemrev.7b00719

Barrows, N. J., Campos, R. K., Powell, S. T., Prasanth, K. R., Schott-Lerner, G., SotoAcosta, R., et al. (2016). A Screen of FDA-Approved Drugs for Inhibitors of Zika Virus Infection. Cell Host Microbe 20 (2), 259-270. doi:10.1016/j.chom. 2016.07.004

Beigel, J. H., Tomashek, K. M., Dodd, L. E., Mehta, A. K., Zingman, B. S., Kalil, A. C., et al. (2020). Remdesivir for the Treatment of Covid-19-Preliminary Report. N. Engl. J. Med. 383 (19)-18131826. doi:10.1056/NEJMoa2007764

Bekerman, E., Neveu, G., Shulla, A., Brannan, J., Pu, S. Y., Wang, S., et al. (2017). Anticancer Kinase Inhibitors Impair Intracellular Viral Trafficking and Exert Broad-Spectrum Antiviral Effects. J. Clin. Invest. 127 (4), 1338-1352. doi:10. 1172/JCI89857

Belser, J. A., Szretter, K. J., Katz, J. M., and Tumpey, T. M. (2013). Simvastatin and Oseltamivir Combination Therapy Does Not Improve the Effectiveness of Oseltamivir Alone Following Highly Pathogenic Avian H5N1 Influenza Virus Infection in Mice. Virology 439 (1), 42-46. doi:10.1016/j.virol.2013.01.017

Bhattacharyya, S., Warfield, K. L., Ruthel, G., Bavari, S., Aman, M. J., and Hope, T. J. (2010). Ebola Virus Uses Clathrin-Mediated Endocytosis as an Entry Pathway. Virology 401 (1), 18-28. doi:10.1016/j.virol.2010.02.015

Binford, S. L., Maldonado, F., Brothers, M. A., Weady, P. T., Zalman, L. S., Meador, J. W., 3rd, et al. (2005). Conservation of Amino Acids in Human Rhinovirus 3C Protease Correlates with Broad-Spectrum Antiviral Activity of Rupintrivir, a Novel Human Rhinovirus 3C Protease Inhibitor. Antimicrob. Agents Chemother. 49 (2), 619-626. doi:10.1128/AAC.49.2.619-626.2005

Bird, S. W., Maynard, N. D., Covert, M. W., and Kirkegaard, K. (2014). Nonlytic Viral Spread Enhanced by Autophagy Components. Proc. Natl. Acad. Sci. U. S. A. 111 (36), 13081-13086. doi:10.1073/pnas.1401437111

Blanchard, E., Belouzard, S., Goueslain, L., Wakita, T., Dubuisson, J., Wychowski, C., et al. (2006). Hepatitis C Virus Entry Depends on Clathrin-Mediated Endocytosis. J. Virol. 80 (14), 6964-6972. doi:10.1128/JVI.00024-06

Boelaert, J. R., Sperber, K., and Piette, J. (1999). Chloroquine Exerts an Additive In Vitro Anti-HIV Type 1 Effect when Associated with Didanosine and Hydroxyurea. AIDS Res. Hum. Retroviruses 15 (14), 1241-1247. doi:10.1089/ 088922299310133

Borba, M. G. S., Val, F. F. A., Sampaio, V. S., Alexandre, M. A. A., Melo, G. C., Brito, M., et al. (2020). Effect of High vs. Low Doses of Chloroquine Diphosphate as Adjunctive Therapy for Patients Hospitalized with Severe Acute Respiratory Syndrome Coronavirus 2 (SARS-CoV-2) Infection: A Randomized Clinical Trial. JAMA Netw. Open 3 (4), e208857. doi:10.1001/jamanetworkopen.2020. 8857

Bosch, B., Grigorov, B., Senserrich, J., Clotet, B., Darlix, J. L., Muriaux, D., et al. (2008). A Clathrin-dynamin-dependent Endocytic Pathway for the Uptake of HIV-1 by Direct T Cell-T Cell Transmission. Antivir. Res 80 (2), 185-193. doi:10.1016/j.antiviral.2008.06.004

Bossart, K. N., Wang, L. F., Flora, M. N., Chua, K. B., Lam, S. K., Eaton, B. T., et al. (2002). Membrane Fusion Tropism and Heterotypic Functional Activities of the Nipah Virus and Hendra Virus Envelope Glycoproteins. J. Virol. 76 (22), 11186-11198. doi:10.1128/jvi.76.22.11186-11198.2002

Boulware, D. R., Pullen, M. F., Bangdiwala, A. S., Pastick, K. A., Lofgren, S. M., Okafor, E. C., et al. (2020). A Randomized Trial of Hydroxychloroquine as Postexposure Prophylaxis for Covid-19. N. Engl. J. Med. 383 (6), 517-525. doi:10.1056/NEJMoa2016638

Bullard-Feibelman, K. M., Govero, J., Zhu, Z., Salazar, V., Veselinovic, M., Diamond, M. S., et al. (2017). The FDA-Approved Drug Sofosbuvir Inhibits Zika Virus Infection. Antivir. Res 137, 134-140. doi:10.1016/j.antiviral.2016. 11.023
Burkard, C., Verheije, M. H., Haagmans, B. L., van Kuppeveld, F. J., Rottier, P. J., Bosch, B. J., et al. (2015). ATP1A1-mediated Src Signaling Inhibits Coronavirus Entry into Host Cells. J. Virol. 89 (8), 4434-4448. doi:10.1128/JVI.03274-14

Busti, A. J., Hall, R. G., and Margolis, D. M. (2004). Atazanavir for the Treatment of Human Immunodeficiency Virus Infection. Pharmacotherapy 24 (12), 1732-1747. doi:10.1592/phco.24.17.1732.52347

Caine, E. A., Scheaffer, S. M., Arora, N., Zaitsev, K., Artyomov, M. N., Coyne, C. B., et al. (2019). Interferon Lambda Protects the Female Reproductive Tract against Zika Virus Infection. Nat. Commun. 10 (1), 280. doi:10.1038/s41467-01807993-2

Cai, Q., Yang, M., Liu, D., Chen, J., Shu, D., Xia, J., et al. (2020). Experimental Treatment with favipiravir for COVID-19: An Open-Label Control Study. Engineering (Beijing) 6 (10), 1192-1198. doi:10.1016/j.eng.2020.03.007

Cao, B., Wang, Y., Wen, D., Liu, W., Wang, J., Fan, G., et al. (2020). A Trial of Lopinavir-Ritonavir in Adults Hospitalized with Severe Covid-19. N. Engl. J. Med. 382 (19), 1787-1799. doi:10.1056/NEJMoa2001282

Cao, J., Forrest, J. C., and Zhang, X. (2015). A Screen of the NIH Clinical Collection Small Molecule Library Identifies Potential Anti-coronavirus Drugs. Antivir. Res 114, 1-10. doi:10.1016/j.antiviral.2014.11.010

Cao, R. Y., Xu, Y. F., Zhang, T. H., Yang, J. J., Yuan, Y., Hao, P., et al. (2017). Pediatric Drug Nitazoxanide: A Potential Choice for Control of Zika. Open Forum Infect. Dis. 4 (1), ofx009. doi:10.1093/ofid/ofx009

Carbajo-Lozoya, J., Ma-Lauer, Y., Malešević, M., Theuerkorn, M., Kahlert, V., Prell, E., et al. (2014). Human Coronavirus NL63 Replication Is Cyclophilin A-dependent and Inhibited by Non-immunosuppressive Cyclosporine A-Derivatives Including Alisporivir. Virus. Res. 184, 44-53. doi:10.1016/j. virusres.2014.02.010

Carro, A. C., Piccini, L. E., and Damonte, E. B. (2018). Blockade of Dengue Virus Entry into Myeloid Cells by Endocytic Inhibitors in the Presence or Absence of Antibodies. Plos Negl. Trop. Dis. 12 (8), e0006685. doi:10.1371/journal.pntd. 0006685

Chan, J. F., Chan, K. H., Kao, R. Y., To, K. K., Zheng, B. J., Li, C. P., et al. (2013). Broad-spectrum Antivirals for the Emerging Middle East Respiratory Syndrome Coronavirus. J. Infect. 67 (6), 606-616. doi:10.1016/j.jinf.2013.09.029

Chan, J. F., Yao, Y., Yeung, M. L., Deng, W., Bao, L., Jia, L., et al. (2015). Treatment with Lopinavir/Ritonavir or Interferon-Betalb Improves Outcome of MERSCoV Infection in a Nonhuman Primate Model of Common Marmoset. J. Infect. Dis. 212 (12), 1904-1913. doi:10.1093/infdis/jiv392

Chan, K. S., Lai, S. T., Chu, C. M., Tsui, E., Tam, C. Y., Wong, M. M., et al. (2003). Treatment of Severe Acute Respiratory Syndrome with Lopinavir/ritonavir: a Multicentre Retrospective Matched Cohort Study. Hong Kong Med. J. 9 (6), 399-406.

Channappanavar, R., Fehr, A. R., Vijay, R., Mack, M., Zhao, J., Meyerholz, D. K., et al. (2016). Dysregulated Type I Interferon and Inflammatory MonocyteMacrophage Responses Cause Lethal Pneumonia in SARS-CoV-Infected Mice. Cell Host Microbe 19 (2), 181-193. doi:10.1016/j.chom.2016.01.007

Chapuis, A. G., Paolo Rizzardi, G., D’Agostino, C., Attinger, A., Knabenhans, C., Fleury, S., et al. (2000). Effects of Mycophenolic Acid on Human Immunodeficiency Virus Infection In Vitro and In Vivo. Nat. Med. 6 (7), 762-768. doi:10.1038/77489

Chatterji, U., Bobardt, M., Selvarajah, S., Yang, F., Tang, H., Sakamoto, N., et al. (2009). The Isomerase Active Site of Cyclophilin A Is Critical for Hepatitis C Virus Replication. J. Biol. Chem. 284 (25), 16998-17005. doi:10.1074/jbc.M109. 007625

Chatterji, U., Lim, P., Bobardt, M. D., Wieland, S., Cordek, D. G., Vuagniaux, G., et al. (2010). HCV Resistance to Cyclosporin A Does Not Correlate with a Resistance of the NS5A-Cyclophilin A Interaction to Cyclophilin Inhibitors. J. Hepatol. 53 (1), 50-56. doi:10.1016/j.jhep.2010.01.041

Chaudhuri, S., Symons, J. A., and Deval, J. (2018). Innovation and Trends in the Development and Approval of Antiviral Medicines: 1987-2017 and beyond. Antivir. Res. 155, 76-88. doi:10.1016/j.antiviral.2018.05.005

Chauvin, B., Drouot, S., Barrail-Tran, A., and Taburet, A. M. (2013). Drug-drug Interactions between HMG-CoA Reductase Inhibitors (Statins) and Antiviral Protease Inhibitors. Clin. Pharmacokinet. 52 (10), 815-831. doi:10.1007/ s40262-013-0075-4

Chen, J., Li, Y., Lai, F., Wang, Y., Sutter, K., Dittmer, U., et al. (2020). Functional Comparison of IFN-Alpha Subtypes Reveals Potent HBV Suppression by a 
Concerted Action of IFN-Alpha and -gamma Signaling. Hepatology 73 (2), 486-502. doi:10.1002/hep.31282

Chen, J. (2020). Pathogenicity and Transmissibility of 2019-nCoV-A Quick Overview and Comparison with Other Emerging Viruses. Microbes Infect. 22 (2), 69-71. doi:10.1016/j.micinf.2020.01.004

Chen, Y. H., Du, W., Hagemeijer, M. C., Takvorian, P. M., Pau, C., Cali, A., et al. (2015). Phosphatidylserine vesicles enable efficient en bloc transmission of enteroviruses. Cell 160 (4), 619-630. doi:10.1016/j.cell.2015.01.032

Chen, Z., Mi, L., Xu, J., Yu, J., Wang, X., Jiang, J., et al. (2005). Function of HAb18G/CD147 in Invasion of Host Cells by Severe Acute Respiratory Syndrome Coronavirus. J. Infect. Dis. 191 (5), 755-760. doi:10.1086/427811

Cho, J., Lee, Y. J., Kim, J. H., Kim, S. I., Kim, S. S., Choi, B. S., et al. (2020). Antiviral Activity of Digoxin and Ouabain against SARS-CoV-2 Infection and its Implication for COVID-19. Sci. Rep. 10 (1), 16200. doi:10.1038/s41598-02072879-7

Cho, J., Yi, H., Jang, E. Y., Lee, M. S., Lee, J. Y., Kang, C., et al. (2017). Mycophenolic Mofetil, an Alternative Antiviral and Immunomodulator for the Highly Pathogenic Avian Influenza H5N1 Virus Infection. Biochem. Biophys. Res. Commun. 494 (1-2), 298-304. doi:10.1016/j.bbrc.2017.10.037

Chopra, G., Kaushik, S., Elkin, P. L., and Samudrala, R. (2016). Combating Ebola with Repurposed Therapeutics Using the CANDO Platform. Molecules 21 (12), 1537. doi:10.3390/molecules 21121537

Choy, K. T., Yin-Lam Wong, A., Kaewpreedee, P., Sia, S. F., Chen, D., Yan Hui, K. P., et al. (2020). Remdesivir, Lopinavir, Emetine, and Homoharringtonine Inhibit SARS-CoV-2 Replication In Vitro. Antivir. Res 178, 104786. doi:10. 1016/j.antiviral.2020.104786

Chu, C. M., Cheng, V. C., Hung, I. F., Wong, M. M., Chan, K. H., Chan, K. S., et al. (2004). Role of Lopinavir/ritonavir in the Treatment of SARS: Initial Virological and Clinical Findings. Thorax 59 (3), 252-256. doi:10.1136/thorax.2003.012658

Cinatl, J., Morgenstern, B., Bauer, G., Chandra, P., Rabenau, H., and Doerr, H. W. (2003). Treatment of SARS with Human Interferons. Lancet 362 (9380), 293-294. doi:10.1016/s0140-6736(03)13973-6

Clark, M. J., Miduturu, C., Schmidt, A. G., Zhu, X., Pitts, J. D., Wang, J., et al. (2016). GNF-2 Inhibits Dengue Virus by Targeting Abl Kinases and the Viral E Protein. Cell Chem. Biol. 23 (4), 443-452. doi:10.1016/j.chembiol.2016.03.010

Cohen, J. I. (2005). HMG CoA Reductase Inhibitors (Statins) to Treat Epstein-Barr Virus-Driven Lymphoma. Br. J. Cancer 92 (9), 1593-1598. doi:10.1038/sj.bjc. 6602561

Cortegiani, A., Ingoglia, G., Ippolito, M., Giarratano, A., and Einav, S. (2020). A Systematic Review on the Efficacy and Safety of Chloroquine for the Treatment of COVID-19. J. Crit. Care 57, 279-283. doi:10.1016/j.jcrc.2020.03.005

Coyne, C. B., and Bergelson, J. M. (2006). Virus-induced Abl and Fyn Kinase Signals Permit Coxsackievirus Entry through Epithelial Tight Junctions. Cell 124 (1), 119-131. doi:10.1016/j.cell.2005.10.035

Crouchet, E., Wrensch, F., Schuster, C., Zeisel, M. B., and Baumert, T. F. (2018). Host-targeting therapies for hepatitis $\mathrm{C}$ virus infection: current developments and future applications. Therap. Adv. Gastroenterol. 11, 1-15. doi:10.1177/ 1756284818759483

Dang, W., Xu, L., Ma, B., Chen, S., Yin, Y., Chang, K. O., et al. (2018). Nitazoxanide Inhibits Human Norovirus Replication and Synergizes with Ribavirin by Activation of Cellular Antiviral Response. Antimicrob. Agents Chemother. 62 (11), e00707-18. doi:10.1128/aac.00707-18

Dang, W., Yin, Y., Wang, Y., Wang, W., Su, J., Sprengers, D., et al. (2017). Inhibition of Calcineurin or IMP Dehydrogenase Exerts Moderate to Potent Antiviral Activity against Norovirus Replication. Antimicrob. Agents Chemother. 61 (11), e01095-17. doi:10.1128/aac.01095-17

de Freitas, C. S., Higa, L. M., Sacramento, C. Q., Ferreira, A. C., Reis, P. A., Delvecchio, R., et al. (2019). Yellow Fever Virus Is Susceptible to Sofosbuvir Both In Vitro and In Vivo. Plos Negl. Trop. Dis. 13 (1), e0007072. doi:10.1371/ journal.pntd.0007072

de Wilde, A. H., Falzarano, D., Zevenhoven-Dobbe, J. C., Beugeling, C., Fett, C., Martellaro, C., et al. (2017). Alisporivir Inhibits MERS- and SARS-Coronavirus Replication in Cell Culture, but Not SARS-Coronavirus Infection in a Mouse Model. Virus. Res. 228, 7-13. doi:10.1016/j.virusres.2016.11.011

de Wilde, A. H., Jochmans, D., Posthuma, C. C., Zevenhoven-Dobbe, J. C., van Nieuwkoop, S., Bestebroer, T. M., et al. (2014). Screening of an FDA-Approved Compound Library Identifies Four Small-Molecule Inhibitors of Middle East
Respiratory Syndrome Coronavirus Replication in Cell Culture. Antimicrob. Agents Chemother. 58 (8), 4875-4884. doi:10.1128/aac.03011-14

de Wilde, A. H., Raj, V. S., Oudshoorn, D., Bestebroer, T. M., van Nieuwkoop, S., Limpens, R., et al. (2013). MERS-coronavirus Replication Induces Severe In Vitro Cytopathology and Is Strongly Inhibited by Cyclosporin A or Interferona Treatment. J. Gen. Virol. 94 (Pt 8), 1749-1760. doi:10.1099/vir.0.052910-0

de Wilde, A. H., Snijder, E. J., Kikkert, M., and van Hemert, M. J. (2018). Host Factors in Coronavirus Replication. Curr. Top. Microbiol. Immunol. 419, 1-42. doi:10.1007/82_2017_25

de Wilde, A. H., Zevenhoven-Dobbe, J. C., van der Meer, Y., Thiel, V., Narayanan, K., Makino, S., et al. (2011). Cyclosporin A Inhibits the Replication of Diverse Coronaviruses. J. Gen. Virol. 92 (Pt 11), 2542-2548. doi:10.1099/vir.0.034983-0

de Wit, E., Feldmann, F., Cronin, J., Jordan, R., Okumura, A., Thomas, T., et al. (2020). Prophylactic and Therapeutic Remdesivir (GS-5734) Treatment in the Rhesus Macaque Model of MERS-CoV Infection. Proc. Natl. Acad. Sci. U S A. 117 (12), 6771-6776. doi:10.1073/pnas.1922083117

de Wit, E., van Doremalen, N., Falzarano, D., and Munster, V. J. (2016). SARS and MERS: Recent Insights into Emerging Coronaviruses. Nat. Rev. Microbiol. 14 (8), 523-534. doi:10.1038/nrmicro.2016.81

den Boon, J. A., and Ahlquist, P. (2010). Organelle-like Membrane Compartmentalization of Positive-Strand RNA Virus Replication Factories. Annu. Rev. Microbiol. 64, 241-256. doi:10.1146/annurev.micro.112408.134012

Desplanques, A. S., Pontes, M., De Corte, N., Verheyen, N., Nauwynck, H. J., Vercauteren, D., et al. (2010). Cholesterol Depletion Affects Infectivity and Stability of Pseudorabies Virus. Virus. Res. 152 (1-2), 180-183. doi:10.1016/j. virusres.2010.06.008

Diaconu, I., Cerullo, V., Escutenaire, S., Kanerva, A., Bauerschmitz, G. J., Hernandez-Alcoceba, R., et al. (2010). Human Adenovirus Replication in Immunocompetent Syrian Hamsters Can Be Attenuated with Chlorpromazine or Cidofovir. J. Gene Med. 12 (5), 435-445. doi:10.1002/ jgm. 1453

Diamond, M. S., Zachariah, M., and Harris, E. (2002). Mycophenolic Acid Inhibits Dengue Virus Infection by Preventing Replication of Viral RNA. Virology 304 (2), 211-221. doi:10.1006/viro.2002.1685

Committee on Infectious Diseases (1993). American Academy of Pediatrics Committee on Infectious Diseases: Use of Ribavirin in the Treatment of Respiratory Syncytial Virus Infection. Pediatrics 92 (3), 501-504.

Dodson, A. W., Taylor, T. J., Knipe, D. M., and Coen, D. M. (2007). Inhibitors of the Sodium Potassium ATPase that Impair Herpes Simplex Virus Replication Identified via a Chemical Screening Approach. Virology 366 (2), 340-348. doi:10.1016/j.virol.2007.05.001

Dong, S., Kang, S., and Dimopoulos, G. (2019). Identification of Anti-flaviviral Drugs with Mosquitocidal and Anti-zika Virus Activity in Aedes aegypti. Plos Negl. Trop. Dis. 13 (8), e0007681. doi:10.1371/journal.pntd.0007681

Dowall, S. D., Bosworth, A., Watson, R., Bewley, K., Taylor, I., Rayner, E., et al. (2015). Chloroquine Inhibited Ebola Virus Replication In Vitro but Failed to Protect against Infection and Disease in the In Vivo guinea Pig Model. J. Gen. Virol. 96 (12), 3484-3492. doi:10.1099/jgv.0.000309

Du, X., Zuo, X., Meng, F., Wu, F., Zhao, X., Li, C., et al. (2020). Combinatorial Screening of a Panel of FDA-Approved Drugs Identifies Several Candidates with Anti-ebola Activities. Biochem. Biophys. Res. Commun. 522 (4), 862-868. doi:10.1016/j.bbrc.2019.11.065

Dyall, J., Coleman, C. M., Hart, B. J., Venkataraman, T., Holbrook, M. R., Kindrachuk, J., et al. (2014). Repurposing of Clinically Developed Drugs for Treatment of Middle East Respiratory Syndrome Coronavirus Infection. Antimicrob. Agents Chemother. 58 (8), 4885-4893. doi:10.1128/AAC.03036-14

Eagling, V. A., Back, D. J., and Barry, M. G. (1997). Differential Inhibition of Cytochrome P450 Isoforms by the Protease Inhibitors, Ritonavir, Saquinavir and Indinavir. Br. J. Clin. Pharmacol. 44 (2), 190-194. doi:10.1046/j.1365-2125. 1997.00644.x

Eberhardt, K. A., Mischlinger, J., Jordan, S., Groger, M., Gunther, S., and Ramharter, M. (2019). Ribavirin for the Treatment of Lassa Fever: A Systematic Review and Meta-Analysis. Int. J. Infect. Dis. 87, 15-20. doi:10. 1016/j.ijid.2019.07.015

Elazar, M., Liu, M., McKenna, S. A., Liu, P., Gehrig, E. A., Puglisi, J. D., et al. (2009). The Anti-hepatitis C Agent Nitazoxanide Induces Phosphorylation of Eukaryotic Initiation Factor 2alpha via Protein Kinase Activated by Double- 
Stranded RNA Activation. Gastroenterology 137 (5), 1827-1835. doi:10.1053/j. gastro.2009.07.056

Elfiky, A. A. (2020a). Anti-HCV, Nucleotide Inhibitors, Repurposing against COVID-19. Life Sci. 248, 117477. doi:10.1016/j.lfs.2020.117477

Elfiky, A. A. (2020b). Ribavirin, Remdesivir, Sofosbuvir, Galidesivir, and Tenofovir against SARS-CoV-2 RNA Dependent RNA Polymerase (RdRp): A Molecular Docking Study. Life Sci. 253, 117592. doi:10.1016/j.lfs.2020.117592

Españo, E., Nam, J. H., Song, E. J., Song, D., Lee, C. K., and Kim, J. K. (2019). Lipophilic Statins Inhibit Zika Virus Production in Vero Cells. Sci. Rep. 9 (1), 11461. doi:10.1038/s41598-019-47956-1

Esquer Garrigos, Z., Barth, D., Hamdi, A. M., Abu Saleh, O. M., and Sohail, M. R. (2018). Nitazoxanide Is a Therapeutic Option for Adenovirus-Related Enteritis in Immunocompromised Adults. Antimicrob. Agents Chemother. 62 (12), e01937-18. doi:10.1128/aac.01937-18

Eyer, L., Nougairède, A., Uhlíŕová, M., Driouich, J. S., Zouharová, D., Valdés, J. J., et al. (2019). An E460D Substitution in the NS5 Protein of Tick-Borne Encephalitis Virus Confers Resistance to the Inhibitor Galidesivir (BCX4430) and Also Attenuates the Virus for Mice. J. Virol. 93 (16). doi:10. 1128/jvi.00367-19

Eyer, L., Zouharová, D., Širmarová, J., Fojtíková, M., Štefánik, M., Haviernik, J., et al. (2017). Antiviral Activity of the Adenosine Analogue BCX4430 against West Nile Virus and Tick-Borne Flaviviruses. Antivir. Res 142, 63-67. doi:10. 1016/j.antiviral.2017.03.012

Ezzikouri, S., Kayesh, M. E. H., Benjelloun, S., Kohara, M., and Tsukiyama-Kohara, K. (2020). Targeting Host Innate and Adaptive Immunity to Achieve the Functional Cure of Chronic Hepatitis B. Vaccines (Basel) 8 (2). doi:10.3390/ vaccines8020216

Falzarano, D., de Wit, E., Martellaro, C., Callison, J., Munster, V. J., and Feldmann, H. (2013a). Inhibition of Novel Beta Coronavirus Replication by a Combination of Interferon-Alpha2b and Ribavirin. Sci. Rep. 3, 1686. doi:10.1038/srep01686

Falzarano, D., de Wit, E., Rasmussen, A. L., Feldmann, F., Okumura, A., Scott, D. P., et al. (2013b). Treatment with Interferon-Alpha2b and Ribavirin Improves Outcome in MERS-CoV-Infected Rhesus Macaques. Nat. Med. 19 (10), 1313-1317. doi:10.1038/nm.3362

Fanunza, E., Frau, A., Corona, A., and Tramontano, E. (2018). Antiviral Agents against Ebola Virus Infection: Repositioning Old Drugs and Finding Novel Small Molecules. Annu. Rep. Med. Chem. 51, 135-173. doi:10.1016/bs.armc. 2018.08.004

Farias, K. J., Machado, P. R., de Almeida Junior, R. F., de Aquino, A. A., and da Fonseca, B. A. (2014). Chloroquine Interferes with Dengue-2 Virus Replication in U937 Cells. Microbiol. Immunol. 58 (6), 318-326. doi:10.1111/1348-0421. 12154

Farias, K. J., Machado, P. R., Muniz, J. A., Imbeloni, A. A., and da Fonseca, B. A. (2015). Antiviral Activity of Chloroquine Against Dengue Virus Type 2 Replication in Aotus Monkeys. Viral Immunol. 28 (3), 161-169. doi:10. 1089/vim.2014.0090

Faulds, D., Goa, K. L., and Benfield, P. (1993). Cyclosporin. A Review of its Pharmacodynamic and Pharmacokinetic Properties, and Therapeutic Use in Immunoregulatory Disorders. Drugs 45 (6), 953-1040. doi:10.2165/00003495199345060-00007

Feng, Z., Hensley, L., McKnight, K. L., Hu, F., Madden, V., Ping, L., et al. (2013). A Pathogenic Picornavirus Acquires an Envelope by Hijacking Cellular Membranes. Nature 496 (7445), 367-371. doi:10.1038/ nature 12029

Ferraris, O., Moroso, M., Pernet, O., Emonet, S., Ferrier Rembert, A., ParanhosBaccala, G., et al. (2015a). Evaluation of Crimean-Congo Hemorrhagic Fever Virus In Vitro Inhibition by Chloroquine and Chlorpromazine, Two FDA Approved Molecules. Antivir. Res 118, 75-81. doi:10.1016/j.antiviral.2015. 03.005

Ferraris, O., Moroso, M., Pernet, O., Emonet, S., Ferrier Rembert, A., ParanhosBaccalà, G., et al. (2015b). Evaluation of Crimean-Congo Hemorrhagic Fever Virus In Vitro Inhibition by Chloroquine and Chlorpromazine, Two FDA Approved Molecules. Antivir. Res. 118, 75-81. doi:10.1016/j.antiviral.2015. 03.005

Ferreira, A. C., Reis, P. A., de Freitas, C. S., Sacramento, C. Q., Villas Boas Hoelz, L., Bastos, M. M., et al. (2019). Beyond Members of the Flaviviridae Family, Sofosbuvir Also Inhibits Chikungunya Virus Replication. Antimicrob. Agents Chemother. 63 (2). doi:10.1128/AAC.01389-18
Firpi, R. J., Nelson, D. R., and Davis, G. L. (2003). Lack of Antiviral Effect of a Short Course of Mycophenolate Mofetil in Patients with Chronic Hepatitis C Virus Infection. Liver Transpl. 9 (1), 57-61. doi:10.1053/jlts.2003.50003

Fisher-Hoch, S. P., Khan, J. A., Rehman, S., Mirza, S., Khurshid, M., and McCormick, J. B. (1995). Crimean Congo-haemorrhagic Fever Treated with Oral Ribavirin. Lancet 346 (8973), 472-475. doi:10.1016/s0140-6736(95) 91323-8

Franke, E. K., Yuan, H. E., and Luban, J. (1994). Specific Incorporation of Cyclophilin A into HIV-1 Virions. Nature 372 (6504), 359-362. doi:10. 1038/372359a0

Fumian, T. M., Tuipulotu, D. E., Netzler, N. E., Lun, J. H., Russo, A. G., Yan, G. J. H., et al. (2018). Potential Therapeutic Agents for Feline Calicivirus Infection. Viruses 10 (8), 433. doi:10.3390/v10080433

Furuta, Y., Gowen, B. B., Takahashi, K., Shiraki, K., Smee, D. F., and Barnard, D. L. (2013). Favipiravir (T-705), a Novel Viral RNA Polymerase Inhibitor. Antivir. Res 100 (2), 446-454. doi:10.1016/j.antiviral.2013.09.015

Furuta, Y., Komeno, T., and Nakamura, T. (2017). Favipiravir (T-705), a Broad Spectrum Inhibitor of Viral RNA Polymerase. Proc. Jpn. Acad. Ser. B Phys. Biol. Sci. 93 (7), 449-463. doi:10.2183/pjab.93.027

Galban-Garcia, E., Vega-Sanchez, H., Gra-Oramas, B., Jorge-Riano, J. L., SoneirasPerez, M., Haedo-Castro, D., et al. (2000). Efficacy of Ribavirin in Patients with Chronic Hepatitis B. J. Gastroenterol. 35 (5), 347-352. doi:10.1007/ s005350050359

Gan, C. J., Li, W. F., Li, C. N., Li, L. L., Zhou, W. Y., and Peng, X. M. (2020). EGF Receptor Inhibitors Comprehensively Suppress Hepatitis B Virus by Downregulation of STAT3 Phosphorylation. Biochem. Biophys. Rep. 22, 100763. doi:10.1016/j.bbrep.2020.100763

Garcia, M., Cooper, A., Shi, W., Bornmann, W., Carrion, R., Kalman, D., et al. (2012). Productive Replication of Ebola Virus Is Regulated by the C-Abl1 Tyrosine Kinase. Sci. Transl. Med. 4 (123), 123ra124. doi:10.1126/scitranslmed. 3003500

Gheorghiade, M., van Veldhuisen, D. J., and Colucci, W. S. (2006). Contemporary Use of Digoxin in the Management of Cardiovascular Disorders. Circulation 113 (21), 2556-2564. doi:10.1161/CIRCULATIONAHA.105.560110

Giguère, J. F., and Tremblay, M. J. (2004). Statin Compounds Reduce Human Immunodeficiency Virus Type 1 Replication by Preventing the Interaction between Virion-Associated Host Intercellular Adhesion Molecule 1 and its Natural Cell Surface Ligand LFA-1. J. Virol. 78 (21), 12062-12065. doi:10.1128/ jvi.78.21.12062-12065.2004

Glück, B., Schmidtke, M., Walther, M., Meerbach, A., and Wutzler, P. (2013). Simvastatin Treatment Showed No Prophylactic Effect in Influenza VirusInfected Mice. J. Med. Virol. 85 (11), 1978-1982. doi:10.1002/jmv.23682

Gong, Z. J., De Meyer, S., Clarysse, C., Verslype, C., Neyts, J., De Clercq, E., et al. (1999). Mycophenolic Acid, an Immunosuppressive Agent, Inhibits HBV Replication In Vitro. J. Viral Hepat. 6 (3), 229-236. doi:10.1046/j.1365-2893. 1999.00163.x

Gordon, C. J., Tchesnokov, E. P., Feng, J. Y., Porter, D. P., and Gotte, M. (2020). The Antiviral Compound Remdesivir Potently Inhibits RNA-dependent RNA Polymerase from Middle East Respiratory Syndrome Coronavirus. J. Biol. Chem. 295 (15), 4773-4779. doi:10.1074/jbc.AC120.013056

Gower, T. L., and Graham, B. S. (2001). Antiviral Activity of Lovastatin against Respiratory Syncytial Virus In Vivo and In Vitro. Antimicrob. Agents Chemother. 45 (4), 1231-1237. doi:10.1128/aac.45.4.1231-1237.2001

Griffiths, C. E., and Voorhees, J. J. (1990). Cyclosporine A in the Treatment of Psoriasis: a Clinical and Mechanistic Perspective. J. Invest. Dermatol. 95 (5 Suppl. 1), 53S-55S. doi:10.1111/1523-1747.ep12505786

Grosso, F., Stoilov, P., Lingwood, C., Brown, M., and Cochrane, A. (2017). Suppression of Adenovirus Replication by Cardiotonic Steroids. J. Virol. 91 (3), e01623-16. doi:10.1128/jvi.01623-16

Guedj, J., Piorkowski, G., Jacquot, F., Madelain, V., Nguyen, T. H. T., Rodallec, A., et al. (2018). Antiviral Efficacy of Favipiravir against Ebola Virus: A Translational Study in Cynomolgus Macaques. Plos Med. 15 (3), e1002535. doi:10.1371/journal.pmed.1002535

Guisado-Vasco, P., Valderas-Ortega, S., Carralon-Gonzalez, M. M., RodaSantacruz, A., Gonzalez-Cortijo, L., Sotres-Fernandez, G., et al. (2020). Clinical Characteristics and Outcomes Among Hospitalized Adults with Severe COVID-19 Admitted to a Tertiary Medical Center and Receiving Antiviral, Antimalarials, Glucocorticoids, or Immunomodulation with 
Tocilizumab or Cyclosporine: A Retrospective Observational Study (COQUIMA Cohort). EClinicalMedicine 28, 100591. doi:10.1016/j.eclinm. 2020.100591

Guo, J., Jia, X., Liu, Y., Wang, S., Cao, J., Zhang, B., et al. (2020). Screening of Natural Extracts for Inhibitors against Japanese Encephalitis Virus Infection. Antimicrob. Agents Chemother. 64 (3), e02373-19. doi:10.1128/aac.02373-19

Haagmans, B. L., Kuiken, T., Martina, B. E., Fouchier, R. A., Rimmelzwaan, G. F., van Amerongen, G., et al. (2004). Pegylated Interferon-Alpha Protects Type 1 Pneumocytes against SARS Coronavirus Infection in Macaques. Nat. Med. 10 (3), 290-293. doi:10.1038/nm1001

Hacke, M., Björkholm, P., Hellwig, A., Himmels, P., Ruiz de Almodóvar, C., Brügger, B., et al. (2015). Inhibition of Ebola Virus Glycoprotein-Mediated Cytotoxicity by Targeting its Transmembrane Domain and Cholesterol. Nat. Commun. 6, 7688. doi:10.1038/ncomms8688

Haffizulla, J., Hartman, A., Hoppers, M., Resnick, H., Samudrala, S., Ginocchio, C., et al. (2014). Effect of Nitazoxanide in Adults and Adolescents with Acute Uncomplicated Influenza: a Double-Blind, Randomised, Placebo-Controlled, Phase 2b/3 Trial. Lancet Infect. Dis. 14 (7), 609-618. doi:10.1016/S14733099(14)70717-0

Haji Abdolvahab, M., Moradi-Kalbolandi, S., Zarei, M., Bose, D., Majidzadeh, A. K., and Farahmand, L. (2021). Potential Role of Interferons in Treating COVID-19 Patients. Int. Immunopharmacol 90, 107171. doi:10.1016/j. intimp.2020.107171

Hamamoto, I., Harazaki, K., Inase, N., Takaku, H., Tashiro, M., and Yamamoto, N. (2013). Cyclosporin A Inhibits the Propagation of Influenza Virus by Interfering with a Late Event in the Virus Life Cycle. Jpn. J. Infect. Dis. 66 (4), 276-283. doi:10.7883/yoken.66.276

Han, B., Martin, R., Xu, S., Parvangada, A., Svarovskaia, E. S., Mo, H., et al. (2019). Sofosbuvir Susceptibility of Genotype 1 to 6 HCV from DAA-Naive Subjects. Antivir. Res. 170, 104574. doi:10.1016/j.antiviral.2019.104574

Han, Y., Duan, X., Yang, L., Nilsson-Payant, B. E., Wang, P., Duan, F., et al. (2021). Identification of SARS-CoV-2 Inhibitors Using Lung and Colonic Organoids. Nature 589 (7841), 270-275. doi:10.1038/s41586-020-2901-9

Hartmann, J. T., and Kanz, L. (2008). Sunitinib and Periodic Hair Depigmentation Due to Temporary C-KIT Inhibition. Arch. Dermatol. 144 (11), 1525-1526. doi:10.1001/archderm.144.11.1525

Hatziioannou, T., Perez-Caballero, D., Cowan, S., and Bieniasz, P. D. (2005). Cyclophilin Interactions with Incoming Human Immunodeficiency Virus Type 1 Capsids with Opposing Effects on Infectivity in Human Cells. J. Virol. 79 (1), 176-183. doi:10.1128/JVI.79.1.176-183.2005

Hayden, F. G., Turner, R. B., Gwaltney, J. M., Chi-Burris, K., Gersten, M., Hsyu, P., et al. (2003). Phase II, Randomized, Double-Blind, Placebo-Controlled Studies of Ruprintrivir Nasal Spray 2-percent Suspension for Prevention and Treatment of Experimentally Induced Rhinovirus Colds in Healthy Volunteers. Antimicrob. Agents Chemother. 47 (12), 3907-3916. doi:10.1128/ aac.47.12.3907-3916.2003

Heim, M. H. (2013). 25 Years of Interferon-Based Treatment of Chronic Hepatitis C: an Epoch Coming to an End. Nat. Rev. Immunol. 13 (7), 535-542. doi:10. 1038/nri3463

Henry, S. D., Metselaar, H. J., Lonsdale, R. C., Kok, A., Haagmans, B. L., Tilanus, H. W., et al. (2006). Mycophenolic Acid Inhibits Hepatitis C Virus Replication and Acts in Synergy with Cyclosporin A and Interferon-Alpha. Gastroenterology 131 (5), 1452-1462. doi:10.1053/j.gastro.2006.08.027

Hoertel, N., Sanchez-Rico, M., Vernet, R., Jannot, A. S., Neuraz, A., Blanco, C., et al. (2021). Observational Study of Chlorpromazine in Hospitalized Patients with COVID-19. Clin. Drug Investig. 41 (3), 221-233. doi:10.1007/s40261-02101001-0

Hoffmann, M., Kleine-Weber, H., Schroeder, S., Kruger, N., Herrler, T., Erichsen, S., et al. (2020a). SARS-CoV-2 Cell Entry Depends on ACE2 and TMPRSS2 and Is Blocked by a Clinically Proven Protease Inhibitor. Cell 181 (2), 271-280. doi:10.1016/j.cell.2020.02.052

Hoffmann, M., Kleine-Weber, H., Schroeder, S., Krüger, N., Herrler, T., Erichsen, S., et al. (2020b). SARS-CoV-2 Cell Entry Depends on ACE2 and TMPRSS2 and Is Blocked by a Clinically Proven Protease Inhibitor. Cell 181 (2), 271-280. doi:10.1016/j.cell.2020.02.052

Holshue, M. L., DeBolt, C., Lindquist, S., Lofy, K. H., Wiesman, J., Bruce, H., et al. (2020). First Case of 2019 Novel Coronavirus in the United States. N. Engl. J. Med. 382 (10), 929-936. doi:10.1056/NEJMoa2001191
Hosoya, M., Matsuyama, S., Baba, M., Suzuki, H., and Shigeta, S. (1992). Effects of Protease Inhibitors on Replication of Various Myxoviruses. Antimicrob. Agents Chemother. 36 (7), 1432-1436. doi:10.1128/aac.36.7.1432

Hosoya, M., Shigeta, S., Ishii, T., Suzuki, H., and De Clercq, E. (1993). Comparative Inhibitory Effects of Various Nucleoside and Nonnucleoside Analogues on Replication of Influenza Virus Types A and B In Vitro and In Vivo. J. Infect. Dis. 168 (3), 641-646. doi:10.1093/infdis/168.3.641

Hu, Z., Lan, K. H., He, S., Swaroop, M., Hu, X., Southall, N., et al. (2014). Novel Cell-Based Hepatitis C Virus Infection Assay for Quantitative HighThroughput Screening of Anti-hepatitis C Virus Compounds. Antimicrob. Agents Chemother. 58 (2), 995-1004. doi:10.1128/AAC.02094-13

Huang, R., Southall, N., Wang, Y., Yasgar, A., Shinn, P., Jadhav, A., et al. (2011). The NCGC Pharmaceutical Collection: a Comprehensive Resource of Clinically Approved Drugs Enabling Repurposing and Chemical Genomics. Sci. Transl Med. 3 (80), 80ps16. doi:10.1126/scitranslmed.3001862

Hui, D. S., Lee, N., Chan, P. K., and Beigel, J. H. (2018). The Role of Adjuvant Immunomodulatory Agents for Treatment of Severe Influenza. Antivir. Res 150, 202-216. doi:10.1016/j.antiviral.2018.01.002

Hung, H. C., Wang, H. C., Shih, S. R., Teng, I. F., Tseng, C. P., and Hsu, J. T. (2011). Synergistic Inhibition of Enterovirus 71 Replication by Interferon and Rupintrivir. J. Infect. Dis. 203 (12), 1784-1790. doi:10.1093/infdis/jir174

Hussain, K. M., Leong, K. L., Ng, M. M., and Chu, J. J. (2011). The Essential Role of Clathrin-Mediated Endocytosis in the Infectious Entry of Human Enterovirus 71. J. Biol. Chem. 286 (1), 309-321. doi:10.1074/jbc.M110.168468

Ianevski, A., Zusinaite, E., Kuivanen, S., Strand, M., Lysvand, H., Teppor, M., et al. (2018). Novel Activities of Safe-In-Human Broad-Spectrum Antiviral Agents. Antivir. Res 154, 174-182. doi:10.1016/j.antiviral.2018.04.016

Ibarra, K. D., and Pfeiffer, J. K. (2009). Reduced Ribavirin Antiviral Efficacy via Nucleoside Transporter-Mediated Drug Resistance. J. Virol. 83 (9), 4538-4547. doi:10.1128/JVI.02280-08

Inoue, Y., Tanaka, N., Tanaka, Y., Inoue, S., Morita, K., Zhuang, M., et al. (2007). Clathrin-dependent Entry of Severe Acute Respiratory Syndrome Coronavirus into Target Cells Expressing ACE2 with the Cytoplasmic Tail Deleted. J. Virol. 81 (16), 8722-8729. doi:10.1128/JVI.00253-07

Isorce, N., Testoni, B., Locatelli, M., Fresquet, J., Rivoire, M., Luangsay, S., et al. (2016). Antiviral Activity of Various Interferons and Pro-inflammatory Cytokines in Non-transformed Cultured Hepatocytes Infected with Hepatitis B Virus. Antivir. Res 130, 36-45. doi:10.1016/j.antiviral.2016.03.008

Ivashchenko, A. A., Dmitriev, K. A., Vostokova, N. V., Azarova, V. N., Blinow, A. A., Egorova, A. N., et al. (2020). AVIFAVIR for treatment of patients with moderate coronavirus disease 2019 (COVID-19): interim results of a phase II/III multicenter randomized clinical trial. Clin. Infect. Dis. ciaa1176. doi:10.1093/cid/ciaa1176

Iwamoto, M., Saso, W., Sugiyama, R., Ishii, K., Ohki, M., Nagamori, S., et al. (2019). Epidermal Growth Factor Receptor Is a Host-Entry Cofactor Triggering Hepatitis B Virus Internalization. Proc. Natl. Acad. Sci. U. S. A. 116 (17), 8487-8492. doi:10.1073/pnas.1811064116

Iwasaki, M., Minder, P., Caì, Y., Kuhn, J. H., Yates, J. R., 3rd, Torbett, B. E., et al. (2018). Interactome Analysis of the Lymphocytic Choriomeningitis Virus Nucleoprotein in Infected Cells Reveals ATPase $\mathrm{Na}+\mathrm{K}+$ Transporting Subunit Alpha 1 and Prohibitin as Host-Cell Factors Involved in the Life Cycle of Mammarenaviruses. Plos Pathog. 14 (2), e1006892. doi:10.1371/ journal.ppat.1006892

Iyer, S. S., Bibollet-Ruche, F., Sherrill-Mix, S., Learn, G. H., Plenderleith, L., Smith, A. G., et al. (2017). Resistance to Type 1 Interferons Is a Major Determinant of HIV-1 Transmission Fitness. Proc. Natl. Acad. Sci. U. S. A. 114 (4), E590-E599. doi:10.1073/pnas.1620144114

Jacome, R., Campillo-Balderas, J. A., Ponce de Leon, S., Becerra, A., and Lazcano, A. (2020). Sofosbuvir as a Potential Alternative to Treat the SARS-CoV-2 Epidemic. Sci. Rep. 10 (1), 9294. doi:10.1038/s41598-020-66440-9

Jae, L. T., Raaben, M., Herbert, A. S., Kuehne, A. I., Wirchnianski, A. S., Soh, T. K., et al. (2014). Virus Entry. Lassa Virus Entry Requires a Trigger-Induced Receptor Switch. Science 344 (6191), 1506-1510. doi:10.1126/science. 1252480

Janes, J., Young, M. E., Chen, E., Rogers, N. H., Burgstaller-Muehlbacher, S., Hughes, L. D., et al. (2018). The ReFRAME Library as a Comprehensive Drug Repurposing Library and its Application to the Treatment of Cryptosporidiosis. Proc. Natl. Acad. Sci. U S A. 115 (42), 10750-10755. doi:10.1073/pnas. 1810137115 
Jasenosky, L. D., Cadena, C., Mire, C. E., Borisevich, V., Haridas, V., Ranjbar, S., et al. (2019). The FDA-Approved Oral Drug Nitazoxanide Amplifies Host Antiviral Responses and Inhibits Ebola Virus. iScience 19, 1279-1290. doi:10. 1016/j.isci.2019.07.003

Jia, D., Taguchi, M., and Otsuki, M. (2005). Synthetic Protease Inhibitor Camostat Prevents and Reverses Dyslipidemia, Insulin Secretory Defects, and Histological Abnormalities of the Pancreas in Genetically Obese and Diabetic Rats. Metabolism 54 (5), 619-627. doi:10.1016/j.metabol.2004.12.005

Jochmans, D., van Nieuwkoop, S., Smits, S. L., Neyts, J., Fouchier, R. A., and van den Hoogen, B. G. (2016). Antiviral Activity of Favipiravir (T-705) against a Broad Range of Paramyxoviruses In Vitro and against Human Metapneumovirus in Hamsters. Antimicrob. Agents Chemother. 60 (8), 4620-4629. doi:10.1128/AAC.00709-16

Johnson, S., Henschke, N., Maayan, N., Mills, I., Buckley, B. S., Kakourou, A., et al. (2018). Ribavirin for Treating Crimean Congo Haemorrhagic Fever. Cochrane Database Syst. Rev. 6 (6), CD012713. doi:10.1002/14651858.CD012713.pub2

Julander, J. G., Shafer, K., Smee, D. F., Morrey, J. D., and Furuta, Y. (2009). Activity of T-705 in a Hamster Model of Yellow Fever Virus Infection in Comparison with that of a Chemically Related Compound, T-1106. Antimicrob. Agents Chemother. 53 (1), 202-209. doi:10.1128/AAC.01074-08

Julander, J. G., Siddharthan, V., Evans, J., Taylor, R., Tolbert, K., Apuli, C., et al. (2017). Efficacy of the Broad-Spectrum Antiviral Compound BCX4430 against Zika Virus in Cell Culture and in a Mouse Model. Antivir. Res 137, 14-22. doi:10.1016/j.antiviral.2016.11.003

Kamar, N., Abravanel, F., Behrendt, P., Hofmann, J., Pageaux, G. P., Barbet, C., et al. (2019). Ribavirin for Hepatitis E Virus Infection after Organ Transplantation: A Large European Retrospective Multicenter Study. Clin. Infect. Dis. 71 (5), 1204-1211. doi:10.1093/cid/ciz953

Kamar, N., Izopet, J., Tripon, S., Bismuth, M., Hillaire, S., Dumortier, J., et al. (2014). Ribavirin for Chronic Hepatitis E Virus Infection in Transplant Recipients. N. Engl. J. Med. 370 (12), 1111-1120. doi:10.1056/NEJMoa1215246

Kamiyama, N., Soma, R., Hidano, S., Watanabe, K., Umekita, H., Fukuda, C., et al. (2017). Ribavirin Inhibits Zika Virus (ZIKV) Replication In Vitro and Suppresses Viremia in ZIKV-Infected STAT1-Deficient Mice. Antivir. Res 146, 1-11. doi:10.1016/j.antiviral.2017.08.007

Kapoor, A., Cai, H., Forman, M., He, R., Shamay, M., and Arav-Boger, R. (2012). Human Cytomegalovirus Inhibition by Cardiac Glycosides: Evidence for Involvement of the HERG Gene. Antimicrob. Agents Chemother. 56 (9), 4891-4899. doi:10.1128/aac.00898-12

Katano, H., Pesnicak, L., and Cohen, J. I. (2004). Simvastatin Induces Apoptosis of Epstein-Barr Virus (EBV)-transformed Lymphoblastoid Cell Lines and Delays Development of EBV Lymphomas. Proc. Natl. Acad. Sci. U. S. A. 101 (14), 4960-4965. doi:10.1073/pnas.0305149101

Kato, F., Matsuyama, S., Kawase, M., Hishiki, T., Katoh, H., and Takeda, M. (2020). Antiviral Activities of Mycophenolic Acid and IMD-0354 against SARS-CoV-2. Microbiol. Immunol. 64 (9), 635-639. doi:10.1111/1348-0421.12828

Kawase, M., Shirato, K., van der Hoek, L., Taguchi, F., and Matsuyama, S. (2012). Simultaneous Treatment of Human Bronchial Epithelial Cells with Serine and Cysteine Protease Inhibitors Prevents Severe Acute Respiratory Syndrome Coronavirus Entry. J. Virol. 86 (12), 6537-6545. doi:10.1128/JVI.00094-12

Keckesova, Z., Ylinen, L. M., and Towers, G. J. (2006). Cyclophilin A Renders Human Immunodeficiency Virus Type 1 Sensitive to Old World Monkey but Not Human TRIM5 Alpha Antiviral Activity. J. Virol. 80 (10), 4683-4690. doi:10.1128/jvi.80.10.4683-4690.2006

Kee, S. H., Cho, E. J., Song, J. W., Park, K. S., Baek, L. J., and Song, K. J. (2004). Effects of Endocytosis Inhibitory Drugs on Rubella Virus Entry into VeroE6 Cells. Microbiol. Immunol. 48 (11), 823-829. doi:10.1111/j.1348-0421.2004. tb03614.x

Keyaerts, E., Vijgen, L., Maes, P., Neyts, J., and Van Ranst, M. (2004). In vitro inhibition of Severe Acute Respiratory Syndrome Coronavirus by Chloroquine. Biochem. Biophys. Res. Commun. 323 (1), 264-268. doi:10.1016/j.bbrc.2004. 08.085

Khan, M., Santhosh, S. R., Tiwari, M., Lakshmana Rao, P. V., and Parida, M. (2010). Assessment of In Vitro Prophylactic and Therapeutic Efficacy of Chloroquine against Chikungunya Virus in Vero Cells. J. Med. Virol. 82 (5), 817-824. doi:10. 1002/jmv. 21663

Khandia, R., Munjal, A., Dhama, K., Karthik, K., Tiwari, R., Malik, Y. S., et al. (2018). Modulation of Dengue/Zika Virus Pathogenicity by Antibody- dependent Enhancement and Strategies to Protect against Enhancement in Zika Virus Infection. Front. Immunol. 9, 597. doi:10.3389/fimmu.2018.00597

Kim, Y. I., Pareek, R., Murphy, R., Harrison, L., Farrell, E., Cook, R., et al. (2017). The Antiviral Effects of RSV Fusion Inhibitor, MDT-637, on Clinical Isolates, vs. its Achievable Concentrations in the Human Respiratory Tract and Comparison to Ribavirin. Influenza Other Respir. Viruses 11 (6), 525-530. doi:10.1111/irv.12503

Kim, Y., Lovell, S., Tiew, K. C., Mandadapu, S. R., Alliston, K. R., Battaile, K. P., et al. (2012). Broad-spectrum Antivirals against 3C or 3C-like Proteases of Picornaviruses, Noroviruses, and Coronaviruses. J. Virol. 86 (21), 11754-11762. doi:10.1128/JVI.01348-12

Kindler, E., Thiel, V., and Weber, F. (2016). Interaction of SARS and MERS Coronaviruses with the Antiviral Interferon Response. Adv. Virus. Res. 96, 219-243. doi:10.1016/bs.aivir.2016.08.006

Koizumi, Y., Ohashi, H., Nakajima, S., Tanaka, Y., Wakita, T., Perelson, A. S., et al. (2017). Quantifying Antiviral Activity Optimizes Drug Combinations against Hepatitis C Virus Infection. Proc. Natl. Acad. Sci. U S A. 114 (8), 1922-1927. doi:10.1073/pnas.1610197114

Konde, M. K., Baker, D. P., Traore, F. A., Sow, M. S., Camara, A., Barry, A. A., et al. (2017). Interferon Beta-1a for the Treatment of Ebola Virus Disease: A Historically Controlled, Single-Arm Proof-Of-Concept Trial. PLoS One 12 (2), e0169255. doi:10.1371/journal.pone.0169255

Korba, B. E., Montero, A. B., Farrar, K., Gaye, K., Mukerjee, S., Ayers, M. S., et al. (2008). Nitazoxanide, Tizoxanide and Other Thiazolides Are Potent Inhibitors of Hepatitis B Virus and Hepatitis C Virus Replication. Antivir. Res 77 (1), 56-63. doi:10.1016/j.antiviral.2007.08.005

Kouznetsova, J., Sun, W., Martinez-Romero, C., Tawa, G., Shinn, P., Chen, C. Z., et al. (2014). Identification of 53 Compounds that Block Ebola Virus-like Particle Entry via a Repurposing Screen of Approved Drugs. Emerg. Microbes Infect. 3 (12), e84. doi:10.1038/emi.2014.88

Kumaki, Y., Morrey, J. D., and Barnard, D. L. (2012). Effect of Statin Treatments on Highly Pathogenic Avian Influenza H5N1, Seasonal and H1N1pdm09 Virus Infections in BALB/c Mice. Future Virol. 7 (8), 801-818. doi:10.2217/fvl.12.71

La Frazia, S., Ciucci, A., Arnoldi, F., Coira, M., Gianferretti, P., Angelini, M., et al. (2013). Thiazolides, a New Class of Antiviral Agents Effective against Rotavirus Infection, Target Viral Morphogenesis, Inhibiting Viroplasm Formation. J. Virol. 87 (20), 11096-11106. doi:10.1128/jvi.01213-13

Lan, J., Ge, J., Yu, J., Shan, S., Zhou, H., Fan, S., et al. (2020). Structure of the SARSCoV-2 Spike Receptor-Binding Domain Bound to the ACE2 Receptor. Nature 581 (7807), 215-220. doi:10.1038/s41586-020-2180-5

Lazear, H. M., Govero, J., Smith, A. M., Platt, D. J., Fernandez, E., Miner, J. J., et al. (2016). A Mouse Model of Zika Virus Pathogenesis. Cell Host Microbe 19 (5), 720-730. doi:10.1016/j.chom.2016.03.010

Lee, J. S., Adhikari, N. K. J., Kwon, H. Y., Teo, K., Siemieniuk, R., Lamontagne, F., et al. (2019). Anti-Ebola Therapy for Patients with Ebola Virus Disease: a Systematic Review. BMC Infect. Dis. 19 (1), 376. doi:10.1186/s12879-0193980-9

Lee, M. G., Kim, K. H., Park, K. Y., and Kim, J. S. (1996). Evaluation of Antiinfluenza Effects of Camostat in Mice Infected with Non-adapted Human Influenza Viruses. Arch. Virol. 141 (10), 1979-1989. doi:10.1007/bf01718208

Li, C., Deng, Y. Q., Wang, S., Ma, F., Aliyari, R., Huang, X. Y., et al. (2017a). 25Hydroxycholesterol Protects Host against Zika Virus Infection and its Associated Microcephaly in a Mouse Model. Immunity 46 (3), 446-456. doi:10.1016/j.immuni.2017.02.012

Li, C., Zhu, X., Ji, X., Quanquin, N., Deng, Y. Q., Tian, M., et al. (2017b). Chloroquine, a FDA-Approved Drug, Prevents Zika Virus Infection and its Associated Congenital Microcephaly in Mice. EBioMedicine 24, 189-194. doi:10.1016/j.ebiom.2017.09.034

Li, H. S., Kuok, D. I. T., Cheung, M. C., Ng, M. M. T., Ng, K. C., Hui, K. P. Y., et al. (2018). Effect of Interferon Alpha and Cyclosporine Treatment Separately and in Combination on Middle East Respiratory Syndrome Coronavirus (MERSCoV) Replication in a Human In-Vitro and Ex-Vivo Culture Model. Antivir. Res 155, 89-96. doi:10.1016/j.antiviral.2018.05.007

Li, M., Zhang, D., Li, C., Zheng, Z., Fu, M., Ni, F., et al. (2020a). Characterization of Zika Virus Endocytic Pathways in Human Glioblastoma Cells. Front. Microbiol. 11, 242. doi:10.3389/fmicb.2020.00242

Li, Q., Guan, X., Wu, P., Wang, X., Zhou, L., Tong, Y., et al. (2020b). Early Transmission Dynamics in Wuhan, China, of Novel Coronavirus-Infected 
Pneumonia. N. Engl. J. Med. 382 (13), 1199-1207. doi:10.1056/ NEJMoa2001316

Li, W., Moore, M. J., Vasilieva, N., Sui, J., Wong, S. K., Berne, M. A., et al. (2003). Angiotensin-converting Enzyme 2 Is a Functional Receptor for the SARS Coronavirus. Nature 426 (6965), 450-454. doi:10.1038/nature02145

Li, Z., Brecher, M., Deng, Y. Q., Zhang, J., Sakamuru, S., Liu, B., et al. (2017c). Existing Drugs as Broad-Spectrum and Potent Inhibitors for Zika Virus by Targeting NS2B-NS3 Interaction. Cell Res 27 (8), 1046-1064. doi:10.1038/cr. 2017.88

Lingemann, M., McCarty, T., Liu, X., Buchholz, U. J., Surman, S., Martin, S. E., et al. (2019). The Alpha-1 Subunit of the Na+,K+-ATPase (ATP1A1) Is Required for Macropinocytic Entry of Respiratory Syncytial Virus (RSV) in Human Respiratory Epithelial Cells. Plos Pathog. 15 (8), e1007963. doi:10.1371/ journal.ppat.1007963

Liu, S. Y., Aliyari, R., Chikere, K., Li, G., Marsden, M. D., Smith, J. K., et al. (2013). Interferon-inducible Cholesterol-25-Hydroxylase Broadly Inhibits Viral Entry by Production of 25-hydroxycholesterol. Immunity 38 (1), 92-105. doi:10.1016/ j.immuni.2012.11.005

Liu, X., Sun, L., Yu, M., Wang, Z., Xu, C., Xue, Q., et al. (2009). Cyclophilin A Interacts with Influenza A Virus M1 Protein and Impairs the Early Stage of the Viral Replication. Cell Microbiol 11 (5), 730-741. doi:10.1111/j.1462-5822.2009. 01286.x

Liu, X., Zhao, Z., Li, Z., Xu, C., Sun, L., Chen, J., et al. (2012). Cyclosporin A Inhibits the Influenza Virus Replication through Cyclophilin A-dependent and -independent Pathways. PLoS One 7 (5), e37277. doi:10.1371/journal.pone. 0037277

Livonesi, M. C., Moro de Sousa, R. L., and Moraes Figueiredo, L. T. (2007). In vitro study of Antiviral Activity of Mycophenolic Acid on Brazilian Orthobunyaviruses. Intervirology 50 (3), 204-208. doi:10.1159/000099219

Lo, M. K., Jordan, R., Arvey, A., Sudhamsu, J., Shrivastava-Ranjan, P., Hotard, A. L., et al. (2017). GS-5734 and its Parent Nucleoside Analog Inhibit Filo-, Pneumo-, and Paramyxoviruses. Sci. Rep. 7, 43395. doi:10.1038/srep43395

Lopez-Munoz, F., Alamo, C., Cuenca, E., Shen, W. W., Clervoy, P., and Rubio, G. (2005). History of the Discovery and Clinical Introduction of Chlorpromazine. Ann. Clin. Psychiatry 17 (3), 113-135. doi:10.1080/10401230591002002

Loutfy, M. R., Blatt, L. M., Siminovitch, K. A., Ward, S., Wolff, B., Lho, H., et al. (2003). Interferon Alfacon-1 Plus Corticosteroids in Severe Acute Respiratory Syndrome: a Preliminary Study. JAMA 290 (24), 3222-3228. doi:10.1001/jama. 290.24.3222

Lupberger, J., Zeisel, M. B., Xiao, F., Thumann, C., Fofana, I., Zona, L., et al. (2011). EGFR and EphA2 Are Host Factors for Hepatitis C Virus Entry and Possible Targets for Antiviral Therapy. Nat. Med. 17 (5), 589-595. doi:10.1038/nm.2341

Ma, C., Li, F., Musharrafieh, R. G., and Wang, J. (2016). Discovery of Cyclosporine A and its Analogs as Broad-Spectrum Anti-influenza Drugs with a High In Vitro Genetic Barrier of Drug Resistance. Antivir. Res 133, 62-72. doi:10.1016/j. antiviral.2016.07.019

Mallhi, T. H., Khan, Y. H., Alotaibi, N. H., Alzarea, A. I., Alanazi, A. S., Qasim, S., et al. (2020a). Drug repurposing for COVID-19: a potential threat of selfmedication and controlling measures. Postgrad. Med. J. 0, 1-2. doi:10.1136/ postgradmedj-2020-138447

Mallhi, T. H., Liaqat, A., Abid, A., Khan, Y. H., Alotaibi, N. H., Alzarea, A. I., et al. (2020b). Multilevel Engagements of Pharmacists during the COVID-19 Pandemic: The Way Forward. Front. Public Health 8 (8), 561924. doi:10. 3389/fpubh.2020.561924

Manchala, N. R., Dungdung, R., Trivedi, P., Unniyampurath, U., and Pilankatta, R. (2019). Mycophenolic Acid (MPA) Modulates Host Cellular Autophagy Progression in Sub Genomic Dengue Virus-2 Replicon Cells. Microb. Pathog. 137, 103762. doi:10.1016/j.micpath.2019.103762

Mandal, A., Gote, V., Pal, D., Ogundele, A., and Mitra, A. K. (2019). Ocular Pharmacokinetics of a Topical Ophthalmic Nanomicellar Solution of Cyclosporine [Cequa(R)] for Dry Eye Disease. Pharm. Res. 36 (2), 36. doi:10.1007/s11095-018-2556-5

Mantlo, E., Bukreyeva, N., Maruyama, J., Paessler, S., and Huang, C. (2020). Antiviral Activities of Type I Interferons to SARS-CoV-2 Infection. Antivir. Res 179, 104811. doi:10.1016/j.antiviral.2020.104811

Margolis, D., Heredia, A., Gaywee, J., Oldach, D., Drusano, G., and Redfield, R. (1999). Abacavir and Mycophenolic Acid, an Inhibitor of Inosine
Monophosphate Dehydrogenase, Have Profound and Synergistic Anti-HIV Activity. J. Acquir Immune Defic Syndr. 21 (5), 362-370.

Martinez-Gutierrez, M., Castellanos, J. E., and Gallego-Gomez, J. C. (2011). Statins Reduce Dengue Virus Production via Decreased Virion Assembly. Intervirology 54 (4), 202-216. doi:10.1159/000321892

Martinez-Gutierrez, M., Correa-Londoño, L. A., Castellanos, J. E., Gallego-Gómez, J. C., and Osorio, J. E. (2014). Lovastatin Delays Infection and Increases Survival Rates in AG129 Mice Infected with Dengue Virus Serotype 2. PLoS One 9 (2), e87412. doi:10.1371/journal.pone.0087412

Maruyama, Y., Yoshida, H., Uchino, S., Yokoyama, K., Yamamoto, H., Takinami, M., et al. (2011). Nafamostat Mesilate as an Anticoagulant during Continuous Veno-Venous Hemodialysis: a Three-Year Retrospective Cohort Study. Int. J. Artif. Organs 34 (7), 571-576. doi:10.5301/IJAO.2011.8535

Masse, S., Lu, X., Dekhtyar, T., Lu, L., Koev, G., Gao, F., et al. (2007). In vitro selection and Characterization of Human Immunodeficiency Virus Type 2 with Decreased Susceptibility to Lopinavir. Antimicrob. Agents Chemother. 51 (9), 3075-3080. doi:10.1128/AAC.00146-07

Matsuda, S., and Koyasu, S. (2000). Mechanisms of Action of Cyclosporine. Immunopharmacology 47 (2-3), 119-125. doi:10.1016/s0162-3109(00)00192-2

Mazière, J. C., Landureau, J. C., Giral, P., Auclair, M., Fall, L., Lachgar, A., et al. (1994). Lovastatin Inhibits HIV-1 Expression in H9 Human T Lymphocytes Cultured in Cholesterol-Poor Medium. Biomed. Pharmacother. 48 (2), 63-67. doi:10.1016/0753-3322(94)90077-9

McCarthy, S. D., Majchrzak-Kita, B., Racine, T., Kozlowski, H. N., Baker, D. P., Hoenen, T., et al. (2016). A Rapid Screening Assay Identifies Monotherapy with Interferon-Ss and Combination Therapies with Nucleoside Analogs as Effective Inhibitors of Ebola Virus. Plos Negl. Trop. Dis. 10 (1), e0004364. doi:10.1371/ journal.pntd.0004364

McCormick, J. B., King, I. J., Webb, P. A., Scribner, C. L., Craven, R. B., Johnson, K. M., et al. (1986). Lassa Fever. Effective Therapy with Ribavirin. N. Engl. J. Med. 314 (1), 20-26. doi:10.1056/NEJM198601023140104

Mikuličić, S., Finke, J., Boukhallouk, F., Wüstenhagen, E., Sons, D., Homsi, Y., et al. (2019). ADAM17-dependent signaling is required for oncogenic human papillomavirus entry platform assembly. Elife 8, e44345. doi:10.7554/eLife.44345

Milligan, G. N., Sarathy, V. V., White, M. M., Greenberg, M. B., Campbell, G. A., Pyles, R. B., et al. (2017). A Lethal Model of Disseminated Dengue Virus Type 1 Infection in AG129 Mice. J. Gen. Virol. 98 (10), 2507-2519. doi:10.1099/jgv.0. 000923

Min, J. S., Kim, G. W., Kwon, S., and Jin, Y. H. (2020). A Cell-Based Reporter Assay for Screening Inhibitors of MERS Coronavirus RNA-dependent RNA Polymerase Activity. J. Clin. Med. 9 (8). doi:10.3390/jcm9082399

Morrey, J. D., Smee, D. F., Sidwell, R. W., and Tseng, C. (2002). Identification of Active Antiviral Compounds against a New York Isolate of West Nile Virus. Antivir. Res 55 (1), 107-116. doi:10.1016/s0166-3542(02)00013-x

Morrey, J. D., Taro, B. S., Siddharthan, V., Wang, H., Smee, D. F., Christensen, A. J., et al. (2008). Efficacy of Orally Administered T-705 Pyrazine Analog on Lethal West Nile Virus Infection in Rodents. Antivir. Res 80 (3), 377-379. doi:10.1016/ j.antiviral.2008.07.009

Mukhopadhyay, S., Kuhn, R. J., and Rossmann, M. G. (2005). A Structural Perspective of the Flavivirus Life Cycle. Nat. Rev. Microbiol. 3 (1), 13-22. doi:10.1038/nrmicro1067

Mulangu, S., Dodd, L. E., Davey, R. T., Jr., Tshiani Mbaya, O., Proschan, M., Mukadi, D., et al. (2019). A Randomized, Controlled Trial of Ebola Virus Disease Therapeutics. N. Engl. J. Med. 381 (24), 2293-2303. doi:10.1056/ NEJMoa1910993

Mumtaz, N., Jimmerson, L. C., Bushman, L. R., Kiser, J. J., Aron, G., Reusken, C., et al. (2017). Cell-line Dependent Antiviral Activity of Sofosbuvir against Zika Virus. Antivir. Res 146, 161-163. doi:10.1016/j.antiviral.2017.09.004

Musarrat, F., Chouljenko, V., Dahal, A., Nabi, R., Chouljenko, T., Jois, S. D., et al. (2020). The Anti-HIV Drug Nelfinavir Mesylate (Viracept) Is a Potent Inhibitor of Cell Fusion Caused by the SARS-CoV-2 Spike (S) Glycoprotein Warranting Further Evaluation as an Antiviral against COVID-19 Infections. J. Med. Virol. 92 (10), 2087-2095. doi:10.1002/jmv.25985

Nakkazi, E. (2018). Randomised Controlled Trial Begins for Ebola Therapeutics. Lancet 392 (10162), 2338. doi:10.1016/S0140-6736(18)33011-3

Netzler, N. E., Enosi Tuipulotu, D., Vasudevan, S. G., Mackenzie, J. M., and White, P. A. (2019). Antiviral Candidates for Treating Hepatitis E Virus Infection. 
Antimicrob. Agents Chemother. 63 (6), e00003-00019. doi:10.1128/AAC. 00003-19

Neveu, G., Ziv-Av, A., Barouch-Bentov, R., Berkerman, E., Mulholland, J., and Einav, S. (2015). AP-2-associated Protein Kinase 1 and Cyclin G-Associated Kinase Regulate Hepatitis C Virus Entry and Are Potential Drug Targets. J. Virol. 89 (8), 4387-4404. doi:10.1128/JVI.02705-14

Ngono, A. E., and Shresta, S. (2018). Immune Response to Dengue and Zika. Annu. Rev. Immunol. 36, 279-308. doi:10.1146/annurev-immunol-042617-053142

Nguyen, T. H., Guedj, J., Anglaret, X., Laouenan, C., Madelain, V., Taburet, A. M., et al. (2017). Favipiravir Pharmacokinetics in Ebola-Infected Patients of the JIKI Trial Reveals Concentrations Lower Than Targeted. Plos Negl. Trop. Dis. 11 (2), e0005389. doi:10.1371/journal.pntd.0005389

Nicolás, D., Ambrosioni, J., Sued, O., Brunet, M., López-Diéguez, M., Manzardo, C., et al. (2017). Cyclosporine A in Addition to Standard ART during Primary HIV-1 Infection: Pilot Randomized Clinical Trial. J. Antimicrob. Chemother. 72 (3), 829-836. doi:10.1093/jac/dkw462

Noel, F., Azalim, P., do Monte, F. M., Quintas, L. E. M., Katz, A., and Karlish, S. J. D. (2018). Revisiting the Binding Kinetics and Inhibitory Potency of Cardiac Glycosides on $\mathrm{Na}(+), \mathrm{K}(+)$-ATPase (Alphalbeta1): Methodological Considerations. J. Pharmacol. Toxicol. Methods 94 (Pt 2), 64-72. doi:10. 1016/j.vascn.2018.09.001

Norris, M. J., Malhi, M., Duan, W., Ouyang, H., Granados, A., Cen, Y., et al. (2018). Targeting Intracellular Ion Homeostasis for the Control of Respiratory Syncytial Virus. Am. J. Respir. Cel Mol Biol 59 (6), 733-744. doi:10.1165/ rcmb.2017-0345OC

Oestereich, L., Ludtke, A., Wurr, S., Rieger, T., Munoz-Fontela, C., and Gunther, S. (2014a). Successful Treatment of Advanced Ebola Virus Infection with T-705 (Favipiravir) in a Small Animal Model. Antivir. Res 105, 17-21. doi:10.1016/j. antiviral.2014.02.014

Oestereich, L., Rieger, T., Ludtke, A., Ruibal, P., Wurr, S., Pallasch, E., et al. (2016). Efficacy of Favipiravir Alone and in Combination with Ribavirin in a Lethal, Immunocompetent Mouse Model of Lassa Fever. J. Infect. Dis. 213 (6), 934-938. doi:10.1093/infdis/jiv522

Oestereich, L., Rieger, T., Neumann, M., Bernreuther, C., Lehmann, M., Krasemann, S., et al. (2014b). Evaluation of Antiviral Efficacy of Ribavirin, Arbidol, and T-705 (Favipiravir) in a Mouse Model for Crimean-Congo Hemorrhagic Fever. Plos Negl. Trop. Dis. 8 (5), e2804. doi:10.1371/journal. pntd.0002804

Ogg, M., Jonsson, C. B., Camp, J. V., and Hooper, J. W. (2013). Ribavirin Protects Syrian Hamsters against Lethal Hantavirus Pulmonary Syndrome-Aafter Intranasal Exposure to Andes Virus. Viruses 5 (11), 2704-2720. doi:10.3390/ v5112704

Okuse, C., Rinaudo, J. A., Farrar, K., Wells, F., and Korba, B. E. (2005). Enhancement of Antiviral Activity against Hepatitis C Virus In Vitro by Interferon Combination Therapy. Antivir. Res 65 (1), 23-34. doi:10.1016/j. antiviral.2004.09.002

Okuyama-Dobashi, K., Kasai, H., Tanaka, T., Yamashita, A., Yasumoto, J., Chen, W., et al. (2015). Hepatitis B Virus Efficiently Infects Non-adherent Hepatoma Cells via Human Sodium Taurocholate Cotransporting Polypeptide. Sci. Rep. 5, 17047. doi:10.1038/srep 17047

Omrani, A. S., Saad, M. M., Baig, K., Bahloul, A., Abdul-Matin, M., Alaidaroos, A. Y., et al. (2014). Ribavirin and Interferon Alfa-2a for Severe Middle East Respiratory Syndrome Coronavirus Infection: a Retrospective Cohort Study. Lancet Infect. Dis. 14 (11), 1090-1095. doi:10.1016/S1473-3099(14)70920-X

Ortega-Prieto, A. M., Sheldon, J., Grande-Perez, A., Tejero, H., Gregori, J., Quer, J., et al. (2013). Extinction of Hepatitis C Virus by Ribavirin in Hepatoma Cells Involves Lethal Mutagenesis. PLoS One 8 (8), e71039. doi:10.1371/journal.pone. 0071039

Ortiz, J. J., Ayoub, A., Gargala, G., Chegne, N. L., and Favennec, L. (2001). Randomized Clinical Study of Nitazoxanide Compared to Metronidazole in the Treatment of Symptomatic Giardiasis in Children from Northern Peru. Aliment. Pharmacol. Ther. 15 (9), 1409-1415. doi:10.1046/j.1365-2036.2001. 01066.x

Pan, Q., de Ruiter, P. E., Metselaar, H. J., Kwekkeboom, J., de Jonge, J., Tilanus, H. W., et al. (2012). Mycophenolic Acid Augments Interferon-Stimulated Gene Expression and Inhibits Hepatitis C Virus Infection In Vitro and In Vivo. Hepatology 55 (6), 1673-1683. doi:10.1002/hep.25562
Panel, A.-I. H. G. (2018). Hepatitis C Guidance 2018 Update: AASLD-IDSA Recommendations for Testing, Managing, and Treating Hepatitis C Virus Infection. Clin. Infect. Dis. 67 (10), 1477-1492. doi:10.1093/cid/ciy585

Patel, H., and Kukol, A. (2017). Evolutionary Conservation of Influenza A PB2 Sequences Reveals Potential Target Sites for Small Molecule Inhibitors. Virology 509, 112-120. doi:10.1016/j.virol.2017.06.009

Pedersen, N. C., Perron, M., Bannasch, M., Montgomery, E., Murakami, E., Liepnieks, M., et al. (2019). Efficacy and Safety of the Nucleoside Analog GS-441524 for Treatment of Cats with Naturally Occurring Feline Infectious Peritonitis. J. Feline Med. Surg. 21 (4), 271-281. doi:10.1177/ 1098612X19825701

Peiris, J. S., Chu, C. M., Cheng, V. C., Chan, K. S., Hung, I. F., Poon, L. L., et al. (2003). Clinical Progression and Viral Load in a Community Outbreak of Coronavirus-Associated SARS Pneumonia: a Prospective Study. Lancet 361 (9371), 1767-1772. doi:10.1016/s0140-6736(03)13412-5

Perelygina, L., Hautala, T., Seppänen, M., Adebayo, A., Sullivan, K. E., and Icenogle, J. (2017). Inhibition of Rubella Virus Replication by the Broad-Spectrum Drug Nitazoxanide in Cell Culture and in a Patient with a Primary Immune Deficiency. Antivir. Res 147, 58-66. doi:10.1016/j.antiviral.2017.09.019

Persaud, M., Martinez-Lopez, A., Buffone, C., Porcelli, S. A., and Diaz-Griffero, F. (2018). Infection by Zika Viruses Requires the Transmembrane Protein AXL, Endocytosis and Low pH. Virology 518, 301-312. doi:10.1016/j.virol.2018. 03.009

Pfefferle, S., Schöpf, J., Kögl, M., Friedel, C. C., Müller, M. A., Carbajo-Lozoya, J., et al. (2011). The SARS-Coronavirus-Host Interactome: Identification of Cyclophilins as Target for Pan-Coronavirus Inhibitors. Plos Pathog. 7 (10), e1002331. doi:10.1371/journal.ppat.1002331

Phillips, S., Chokshi, S., Chatterji, U., Riva, A., Bobardt, M., Williams, R., et al. (2015). Alisporivir Inhibition of Hepatocyte Cyclophilins Reduces HBV Replication and Hepatitis B Surface Antigen Production. Gastroenterology 148 (2), 403-414. doi:10.1053/j.gastro.2014.10.004

Piacentini, S., La Frazia, S., Riccio, A., Pedersen, J. Z., Topai, A., Nicolotti, O., et al. (2018). Nitazoxanide Inhibits Paramyxovirus Replication by Targeting the Fusion Protein Folding: Role of Glycoprotein-specific Thiol Oxidoreductase ERp57. Sci. Rep. 8 (1), 10425. doi:10.1038/s41598-018-28172-9

Pires de Mello, C. P., Drusano, G. L., Rodriquez, J. L., Kaushik, A., and Brown, A. N. (2018a). Antiviral Effects of Clinically-Relevant Interferon-Alpha and Ribavirin Regimens against Dengue Virus in the Hollow Fiber Infection Model (HFIM). Viruses 10 (6). doi:10.3390/v10060317

Pires de Mello, C. P., Tao, X., Kim, T. H., Bulitta, J. B., Rodriquez, J. L., Pomeroy, J. J., et al. (2018b). Zika Virus Replication Is Substantially Inhibited by Novel Favipiravir and Interferon Alpha Combination Regimens. Antimicrob. Agents Chemother. 62 (1). doi:10.1128/AAC.01983-17

Pohjala, L., Utt, A., Varjak, M., Lulla, A., Merits, A., Ahola, T., et al. (2011). Inhibitors of Alphavirus Entry and Replication Identified with a Stable Chikungunya Replicon Cell Line and Virus-Based Assays. PLoS One 6 (12), e28923. doi:10.1371/journal.pone.0028923

Pontremoli, C., Forni, D., and Sironi, M. (2019). Arenavirus Genomics: Novel Insights into Viral Diversity, Origin, and Evolution. Curr. Opin. Virol. 34, 18-28. doi:10.1016/j.coviro.2018.11.001

Qian, Z., Dominguez, S. R., and Holmes, K. V. (2013). Role of the Spike Glycoprotein of Human Middle East Respiratory Syndrome Coronavirus (MERS-CoV) in Virus Entry and Syncytia Formation. PLoS One 8 (10), e76469. doi:10.1371/journal.pone.0076469

Qing, M., Yang, F., Zhang, B., Zou, G., Robida, J. M., Yuan, Z., et al. (2009). Cyclosporine Inhibits Flavivirus Replication through Blocking the Interaction between Host Cyclophilins and Viral NS5 Protein. Antimicrob. Agents Chemother. 53 (8), 3226-3235. doi:10.1128/AAC.00189-09

Rainsford, K. D., Parke, A. L., Clifford-Rashotte, M., and Kean, W. F. (2015). Therapy and Pharmacological Properties of Hydroxychloroquine and Chloroquine in Treatment of Systemic Lupus Erythematosus, Rheumatoid Arthritis and Related Diseases. Inflammopharmacology 23 (5), 231-269. doi:10. 1007/s10787-015-0239-y

Raj, V. S., Mou, H., Smits, S. L., Dekkers, D. H., Müller, M. A., Dijkman, R., et al. (2013). Dipeptidyl Peptidase 4 Is a Functional Receptor for the Emerging Human Coronavirus-EMC. Nature 495 (7440), 251-254. doi:10.1038/ nature 12005 
Ramos, I., and Fernandez-Sesma, A. (2012). Cell Receptors for Influenza a Viruses and the Innate Immune Response. Front. Microbiol. 3, 117. doi:10.3389/fmicb. 2012.00117

Rathore, A. P., Mantri, C. K., Aman, S. A., Syenina, A., Ooi, J., Jagaraj, C. J., et al. (2019). Dengue Virus-Elicited Tryptase Induces Endothelial Permeability and Shock. J. Clin. Invest. 130 (10), 4180-4193. doi:10.1172/jci128426

Ravi, L. I., Li, L., Wong, P. S., Sutejo, R., Tan, B. H., and Sugrue, R. J. (2013a). Lovastatin Treatment Mitigates the Pro-inflammatory Cytokine Response in Respiratory Syncytial Virus Infected Macrophage Cells. Antivir. Res 98 (2), 332-343. doi:10.1016/j.antiviral.2013.03.015

Ravi, L. I., Liang, L., Wong, P. S., Brown, G., Tan, B. H., and Sugrue, R. J. (2013b). Increased Hydroxymethylglutaryl Coenzyme A Reductase Activity during Respiratory Syncytial Virus Infection Mediates Actin Dependent Intercellular Virus Transmission. Antivir. Res 100 (1), 259-268. doi:10.1016/j. antiviral.2013.08.012

Reeves, P. M., Smith, S. K., Olson, V. A., Thorne, S. H., Bornmann, W., Damon, I. K., et al. (2011). Variola and Monkeypox Viruses Utilize Conserved Mechanisms of Virion Motility and Release that Depend on Abl and SRC Family Tyrosine Kinases. J. Virol. 85 (1), 21-31. doi:10.1128/JVI.01814-10

Rhein, B. A., Powers, L. S., Rogers, K., Anantpadma, M., Singh, B. K., Sakurai, Y., et al. (2015). Interferon- $\gamma$ Inhibits Ebola Virus Infection. Plos Pathog. 11 (11), e1005263. doi:10.1371/journal.ppat.1005263

Rice, G. P., Incorvaia, B., Munari, L., Ebers, G., Polman, C., D'Amico, R., et al. (2001). Interferon in Relapsing-Remitting Multiple Sclerosis. Cochrane Database Syst. Rev. 4, CD002002. doi:10.1002/14651858.CD002002

Ricotta, D., Conner, S. D., Schmid, S. L., von Figura, K., and Honing, S. (2002). Phosphorylation of the AP2 Mu Subunit by AAK1 Mediates High Affinity Binding to Membrane Protein Sorting Signals. J. Cel Biol. 156 (5), 791-795. doi: $10.1083 /$ jcb. 200111068

Riva, L., Yuan, S., Yin, X., Martin-Sancho, L., Matsunaga, N., Pache, L., et al. (2020). Discovery of SARS-CoV-2 Antiviral Drugs through Large-Scale Compound Repurposing. Nature 586 (7827), 113-119. doi:10.1038/s41586-020-2577-1

Rivera-Serrano, E. E., Gonzalez-Lopez, O., Das, A., and Lemon, S. M. (2019). Cellular Entry and Uncoating of Naked and Quasi-Enveloped Human Hepatoviruses. Elife 8, e43983. doi:10.7554/eLife.43983

Robinzon, S., Dafa-Berger, A., Dyer, M. D., Paeper, B., Proll, S. C., Teal, T. H., et al. (2009). Impaired Cholesterol Biosynthesis in a Neuronal Cell Line Persistently Infected with Measles Virus. J. Virol. 83 (11), 5495-5504. doi:10.1128/jvi. 01880-08

Rocco, P. R. M., Silva, P. L., Cruz, F. F., Junior, M., Tierno, P., Moura, M. A., et al. (2021). Early Use of Nitazoxanide in Mild Covid-19 Disease: Randomised, Placebo-Controlled Trial. Eur. Respir. J. doi:10.1183/ 13993003.03725-2020

Rocha-Pereira, J., Nascimento, M. S., Ma, Q., Hilgenfeld, R., Neyts, J., and Jochmans, D. (2014). The Enterovirus Protease Inhibitor Rupintrivir Exerts Cross-Genotypic Anti-norovirus Activity and Clears Cells from the Norovirus Replicon. Antimicrob. Agents Chemother. 58 (8), 4675-4681. doi:10.1128/AAC. 02546-13

Rossignol, J. F., and El-Gohary, Y. M. (2006). Nitazoxanide in the Treatment of Viral Gastroenteritis: a Randomized Double-Blind Placebo-Controlled Clinical Trial. Aliment. Pharmacol. Ther. 24 (10), 1423-1430. doi:10.1111/j.1365-2036. 2006.03128.x

Rossignol, J. F., Elfert, A., and Keeffe, E. B. (2010). Treatment of Chronic Hepatitis C Using a 4-week Lead-In with Nitazoxanide before Peginterferon Plus Nitazoxanide. J. Clin. Gastroenterol. 44 (7), 504-509. doi:10.1097/MCG. 0b013e3181bf9b15

Rossignol, J. F., Kabil, S. M., El-Gohary, Y., Elfert, A., and Keeffe, E. B. (2008). Clinical Trial: Randomized, Double-Blind, Placebo-Controlled Study of Nitazoxanide Monotherapy for the Treatment of Patients with Chronic Hepatitis C Genotype 4. Aliment. Pharmacol. Ther. 28 (5), 574-580. doi:10. 1111/j.1365-2036.2008.03781.x

Rossignol, J. F., and Keeffe, E. B. (2008). Thiazolides: a New Class of Drugs for the Treatment of Chronic Hepatitis B and C. Future Microbiol. 3 (5), 539-545. doi:10.2217/17460913.3.5.539

Rossignol, J. F., La Frazia, S., Chiappa, L., Ciucci, A., and Santoro, M. G. (2009). Thiazolides, a New Class of Anti-influenza Molecules Targeting Viral Hemagglutinin at the Post-translational Level. J. Biol. Chem. 284 (43), 29798-29808. doi:10.1074/jbc.M109.029470
Rossignol, J. F. (2016). Nitazoxanide, a New Drug Candidate for the Treatment of Middle East Respiratory Syndrome Coronavirus. J. Infect. Public Health 9 (3), 227-230. doi:10.1016/j.jiph.2016.04.001

Rossignol, J. F. (2014). Nitazoxanide: a First-In-Class Broad-Spectrum Antiviral Agent. Antivir. Res 110, 94-103. doi:10.1016/j.antiviral.2014.07.014

Rothberg, M. B., Bigelow, C., Pekow, P. S., and Lindenauer, P. K. (2012). Association between Statins Given in Hospital and Mortality in Pneumonia Patients. J. Gen. Intern. Med. 27 (3), 280-286. doi:10.1007/s11606-011-1826-2

Sacramento, C. Q., de Melo, G. R., de Freitas, C. S., Rocha, N., Hoelz, L. V., Miranda, M., et al. (2017). The Clinically Approved Antiviral Drug Sofosbuvir Inhibits Zika Virus Replication. Sci. Rep. 7, 40920. doi:10.1038/srep40920

Saijo, M., Morikawa, S., Fukushi, S., Mizutani, T., Hasegawa, H., Nagata, N., et al. (2005). Inhibitory Effect of Mizoribine and Ribavirin on the Replication of Severe Acute Respiratory Syndrome (SARS)-associated Coronavirus. Antivir. Res 66 (2-3), 159-163. doi:10.1016/j.antiviral.2005.01.003

Saini, M., and Potash, M. J. (2006). Novel Activities of Cyclophilin A and Cyclosporin A during HIV-1 Infection of Primary Lymphocytes and Macrophages. J. Immunol. 177 (1), 443-449. doi:10.4049/jimmunol.177.1.443

Sarathy, V. V., White, M., Li, L., Gorder, S. R., Pyles, R. B., Campbell, G. A., et al. (2015). A Lethal Murine Infection Model for Dengue Virus 3 in AG129 Mice Deficient in Type I and II Interferon Receptors Leads to Systemic Disease. J. Virol. 89 (2), 1254-1266. doi:10.1128/JVI.01320-14

Savarino, A., Gennero, L., Sperber, K., and Boelaert, J. R. (2001). The Anti-HIV-1 Activity of Chloroquine. J. Clin. Virol. 20 (3), 131-135. doi:10.1016/s13866532(00)00139-6

Scheidel, L. M., and Stollar, V. (1991). Mutations that Confer Resistance to Mycophenolic Acid and Ribavirin on Sindbis Virus Map to the Nonstructural Protein nsP1. Virology 181 (2), 490-499. doi:10.1016/00426822(91)90881-b

Sebastian, L., Madhusudana, S. N., Ravi, V., and Desai, A. (2011). Mycophenolic Acid Inhibits Replication of Japanese Encephalitis Virus. Chemotherapy 57 (1), 56-61. doi:10.1159/000321483

Shah, N. R., Sunderland, A., and Grdzelishvili, V. Z. (2010). Cell Type Mediated Resistance of Vesicular Stomatitis Virus and Sendai Virus to Ribavirin. PLoS One 5 (6), e11265. doi:10.1371/journal.pone.0011265

Sheahan, T. P., Sims, A. C., Graham, R. L., Menachery, V. D., Gralinski, L. E., Case, J. B., et al. (2017a). Broad-spectrum Antiviral GS-5734 Inhibits Both Epidemic and Zoonotic Coronaviruses. Sci. Transl Med. 9 (396), eaal3653. doi:10.1126/ scitranslmed.aal3653

Sheahan, T. P., Sims, A. C., Graham, R. L., Menachery, V. D., Gralinski, L. E., Case, J. B., et al. (2017b). Broad-spectrum Antiviral GS-5734 Inhibits Both Epidemic and Zoonotic Coronaviruses. Sci. Transl Med. 9 (396). doi:10.1126/ scitranslmed.aal3653

Sheahan, T. P., Sims, A. C., Leist, S. R., Schafer, A., Won, J., Brown, A. J., et al. (2020). Comparative Therapeutic Efficacy of Remdesivir and Combination Lopinavir, Ritonavir, and Interferon Beta against MERS-CoV. Nat. Commun. 11 (1), 222. doi:10.1038/s41467-019-13940-6

Shen, Z., Tian, Z., He, H., Zhang, J., Li, J., and Wu, Y. (2015). Antiviral Effects of Cyclosporine A in Neonatal Mice with Rotavirus-Induced Diarrhea. J. Pediatr. Gastroenterol. Nutr. 60 (1), 11-17. doi:10.1097/mpg.0000000000000493

Shi, B. J., Liu, C. C., Zhou, J., Wang, S. Q., Gao, Z. C., Zhang, X. M., et al. (2016). Entry of Classical Swine Fever Virus into PK-15 Cells via a pH-, Dynamin-, and Cholesterol-dependent, Clathrin-Mediated Endocytic Pathway that Requires Rab5 and Rab7. J. Virol. 90 (20), 9194-9208. doi:10.1128/jvi.00688-16

Shi, Z., Wei, J., Deng, X., Li, S., Qiu, Y., Shao, D., et al. (2014). Nitazoxanide Inhibits the Replication of Japanese Encephalitis Virus in Cultured Cells and in a Mouse Model. Virol. J. 11, 10. doi:10.1186/1743-422x-11-10

Shie, J. J., Fang, J. M., Kuo, T. H., Kuo, C. J., Liang, P. H., Huang, H. J., et al. (2005). Inhibition of the Severe Acute Respiratory Syndrome 3CL Protease by Peptidomimetic Alpha, beta-Unsaturated Esters. Bioorg. Med. Chem. 13 (17), 5240-5252. doi:10.1016/j.bmc.2005.05.065

Shimura, S., Watashi, K., Fukano, K., Peel, M., Sluder, A., Kawai, F., et al. (2017). Cyclosporin Derivatives Inhibit Hepatitis B Virus Entry without Interfering with NTCP Transporter Activity. J. Hepatol. 66 (4), 685-692. doi:10.1016/j. jhep.2016.11.009

Shirato, K., Kawase, M., and Matsuyama, S. (2013). Middle East Respiratory Syndrome Coronavirus Infection Mediated by the Transmembrane Serine Protease TMPRSS2. J. Virol. 87 (23), 12552-12561. doi:10.1128/jvi.01890-13 
Shiryaev, S. A., Mesci, P., Pinto, A., Fernandes, I., Sheets, N., Shresta, S., et al. (2017). Repurposing of the Anti-malaria Drug Chloroquine for Zika Virus Treatment and Prophylaxis. Sci. Rep. 7 (1), 15771. doi:10.1038/s41598-01715467-6

Shrivastava-Ranjan, P., Flint, M., Bergeron, É., McElroy, A. K., Chatterjee, P., Albariño, C. G., et al. (2018). Statins Suppress Ebola Virus Infectivity by Interfering with Glycoprotein Processing. mBio 9 (3). doi:10.1128/mBio. 00660-18

Simmons, G., Gosalia, D. N., Rennekamp, A. J., Reeves, J. D., Diamond, S. L., and Bates, P. (2005). Inhibitors of Cathepsin L Prevent Severe Acute Respiratory Syndrome Coronavirus Entry. Proc. Natl. Acad. Sci. U. S. A. 102 (33), 11876-11881. doi:10.1073/pnas.0505577102

Simon, M., Johansson, C., and Mirazimi, A. (2009). Crimean-Congo Hemorrhagic Fever Virus Entry and Replication Is Clathrin-, $\mathrm{pH}-$ and Cholesteroldependent. J. Gen. Virol. 90 (Pt 1), 210-215. doi:10.1099/vir.0.006387-0

Sissoko, D., Laouenan, C., Folkesson, E., M'Lebing, A. B., Beavogui, A. H., Baize, S., et al. (2016). Experimental Treatment with Favipiravir for Ebola Virus Disease (The JIKI Trial): A Historically Controlled, Single-Arm Proof-Of-Concept Trial in Guinea. Plos Med. 13 (3), e1001967. doi:10.1371/journal.pmed.1001967

Sleeman, K., Mishin, V. P., Deyde, V. M., Furuta, Y., Klimov, A. I., and Gubareva, L. V. (2010). In vitro antiviral Activity of Favipiravir (T-705) against DrugResistant Influenza and $2009 \mathrm{~A}(\mathrm{H} 1 \mathrm{~N} 1)$ Viruses. Antimicrob. Agents Chemother. 54 (6), 2517-2524. doi:10.1128/AAC.01739-09

Smee, D. F., Bray, M., and Huggins, J. W. (2001). Antiviral Activity and Mode of Action Studies of Ribavirin and Mycophenolic Acid against Orthopoxviruses In Vitro. Antivir. Chem. Chemother. 12 (6), 327-335. doi:10.1177/ 095632020101200602

Softic, L., Brillet, R., Berry, F., Ahnou, N., Nevers, Q., Morin-Dewaele, M., et al. (2020). Inhibition of SARS-CoV-2 Infection by the Cyclophilin Inhibitor Alisporivir (Debio 025). Antimicrob. Agents Chemother. 64 (7), e0087620. doi:10.1128/AAC.00876-20

Soto-Acosta, R., Bautista-Carbajal, P., Cervantes-Salazar, M., Angel-Ambrocio, A. H., and Del Angel, R. M. (2017). DENV Up-Regulates the HMG-CoA Reductase Activity through the Impairment of AMPK Phosphorylation: A Potential Antiviral Target. Plos Pathog. 13 (4), e1006257. doi:10.1371/journal. ppat.1006257

Sperber, K., Louie, M., Kraus, T., Proner, J., Sapira, E., Lin, S., et al. (1995). Hydroxychloroquine Treatment of Patients with Human Immunodeficiency Virus Type 1. Clin. Ther. 17 (4), 622-636. doi:10. 1016/0149-2918(95)80039-5

Spinner, C. D., Gottlieb, R. L., Criner, G. J., Arribas Lopez, J. R., Cattelan, A. M., Soriano Viladomiu, A., et al. (2020). Effect of Remdesivir vs Standard Care on Clinical Status at 11 Days in Patients with Moderate COVID-19: A Randomized Clinical Trial. JAMA 324 (11), 1048-1057. doi:10.1001/jama.2020.16349

Stanciu, C., Trifan, A., Muzica, C., and Sfarti, C. (2019). Efficacy and Safety of Alisporivir for the Treatment of Hepatitis C Infection. Expert Opin. Pharmacother. 20 (4), 379-384. doi:10.1080/14656566.2018.1560424

Stanifer, M. L., Pervolaraki, K., and Boulant, S. (2019). Differential Regulation of Type I and Type III Interferon Signaling. Int. J. Mol. Sci. 20 (6), 1445. doi:10. 3390/ijms20061445

Su, C. T., Hsu, J. T., Hsieh, H. P., Lin, P. H., Chen, T. C., Kao, C. L., et al. (2008). Anti-HSV Activity of Digitoxin and its Possible Mechanisms. Antivir. Res 79 (1), 62-70. doi:10.1016/j.antiviral.2008.01.156

Tam, R. C., Pai, B., Bard, J., Lim, C., Averett, D. R., Phan, U. T., et al. (1999). Ribavirin Polarizes Human T Cell Responses towards a Type 1 Cytokine Profile. J. Hepatol. 30 (3), 376-382. doi:10.1016/s0168-8278(99)80093-2

Tan, E. L., Ooi, E. E., Lin, C. Y., Tan, H. C., Ling, A. E., Lim, B., et al. (2004). Inhibition of SARS Coronavirus Infection In Vitro with Clinically Approved Antiviral Drugs. Emerg. Infect. Dis. 10 (4), 581-586. doi:10.3201/eid1004. 030458

Tan, X., Hu, L., Luquette, L. J., 3rd, Gao, G., Liu, Y., Qu, H., et al. (2012). Systematic Identification of Synergistic Drug Pairs Targeting HIV. Nat. Biotechnol. 30 (11), 1125-1130. doi:10.1038/nbt.2391

Tan, X., Sun, L., Chen, J., and Chen, Z. J. (2018). Detection of Microbial Infections through Innate Immune Sensing of Nucleic Acids. Annu. Rev. Microbiol. 72, 447-478. doi:10.1146/annurev-micro-102215-095605

Tanaka, Y., Sato, Y., and Sasaki, T. (2013). Suppression of Coronavirus Replication by Cyclophilin Inhibitors. Viruses 5 (5), 1250-1260. doi:10.3390/v5051250
Tchesnokov, E. P., Feng, J. Y., Porter, D. P., and Gotte, M. (2019). Mechanism of Inhibition of Ebola Virus RNA-dependent RNA Polymerase by Remdesivir. Viruses 11 (4). doi:10.3390/v11040326

Teran, C. G., Teran-Escalera, C. N., and Villarroel, P. (2009). Nitazoxanide vs. Probiotics for the Treatment of Acute Rotavirus Diarrhea in Children: a Randomized, Single-Blind, Controlled Trial in Bolivian Children. Int. J. Infect. Dis. 13 (4), 518-523. doi:10.1016/j.ijid.2008.09.014

Thome, R., Lopes, S. C., Costa, F. T., and Verinaud, L. (2013). Chloroquine: Modes of Action of an Undervalued Drug. Immunol. Lett. 153 (1-2), 50-57. doi:10. 1016/j.imlet.2013.07.004

To, K. K. W., Mok, K. Y., Chan, A. S. F., Cheung, N. N., Wang, P., Lui, Y. M., et al. (2016). Mycophenolic Acid, an Immunomodulator, Has Potent and BroadSpectrum In Vitro Antiviral Activity against Pandemic, Seasonal and Avian Influenza Viruses Affecting Humans. J. Gen. Virol. 97 (8), 1807-1817. doi:10. 1099/jgv.0.000512

Todt, D., Moeller, N., Praditya, D., Kinast, V., Friesland, M., Engelmann, M., et al. (2018). The Natural Compound Silvestrol Inhibits Hepatitis E Virus (HEV) Replication In Vitro and In Vivo. Antivir. Res 157, 151-158. doi:10.1016/j. antiviral.2018.07.010

Tricou, V., Minh, N. N., Van, T. P., Lee, S. J., Farrar, J., Wills, B., et al. (2010). A Randomized Controlled Trial of Chloroquine for the Treatment of Dengue in Vietnamese Adults. Plos Negl. Trop. Dis. 4 (8), e785. doi:10.1371/journal.pntd. 0000785

Tsai, W. P., Nara, P. L., Kung, H. F., and Oroszlan, S. (1990). Inhibition of Human Immunodeficiency Virus Infectivity by Chloroquine. AIDS Res. Hum. Retroviruses 6 (4), 481-489. doi:10.1089/aid.1990.6.481

Ulferts, R., de Boer, S. M., van der Linden, L., Bauer, L., Lyoo, H. R., Mate, M. J., et al. (2016). Screening of a Library of FDA-Approved Drugs Identifies Several Enterovirus Replication Inhibitors that Target Viral Protein 2C. Antimicrob. Agents Chemother. 60 (5), 2627-2638. doi:10.1128/AAC.02182-15

Urata, S., Uno, Y., Kurosaki, Y., and Yasuda, J. (2018). The Cholesterol, Fatty Acid and Triglyceride Synthesis Pathways Regulated by Site 1 Protease (S1P) Are Required for Efficient Replication of Severe Fever with Thrombocytopenia Syndrome Virus. Biochem. Biophys. Res. Commun. 503 (2), 631-636. doi:10. 1016/j.bbrc.2018.06.053

van Cleef, K. W., Overheul, G. J., Thomassen, M. C., Kaptein, S. J., Davidson, A. D., Jacobs, M., et al. (2013). Identification of a New Dengue Virus Inhibitor that Targets the Viral NS4B Protein and Restricts Genomic RNA Replication. Antivir. Res 99 (2), 165-171. doi:10.1016/j.antiviral.2013.05.011

van der Schaar, H. M., Dorobantu, C. M., Albulescu, L., Strating, J., and van Kuppeveld, F. J. M. (2016). Fat(al) Attraction: Picornaviruses Usurp Lipid Transfer at Membrane Contact Sites to Create Replication Organelles. Trends Microbiol. 24 (7), 535-546. doi:10.1016/j.tim.2016.02.017

van Gelder, T., and Hesselink, D. A. (2015). Mycophenolate Revisited. Transpl. Int. 28 (5), 508-515. doi:10.1111/tri.12554

Vatansever, E. C., Yang, K. S., Drelich, A. K., Kratch, K. C., Cho, C. C., Kempaiah, K. R., et al. (2021). Bepridil Is Potent against SARS-CoV-2 In Vitro. Proc. Natl. Acad. Sci. U S A. 118 (10), e2012201118. doi:10.1073/pnas.2012201118

Vincent, M. J., Bergeron, E., Benjannet, S., Erickson, B. R., Rollin, P. E., Ksiazek, T. G., et al. (2005). Chloroquine Is a Potent Inhibitor of SARS Coronavirus Infection and Spread. Virol. J. 2, 69. doi:10.1186/1743-422x-2-69

Wang, L. H., Rothberg, K. G., and Anderson, R. G. (1993). Mis-assembly of Clathrin Lattices on Endosomes Reveals a Regulatory Switch for Coated Pit Formation. J. Cel Biol 123 (5), 1107-1117. doi:10.1083/jcb.123.5.1107

Wang, M., Cao, R., Zhang, L., Yang, X., Liu, J., Xu, M., et al. (2020a). Remdesivir and Chloroquine Effectively Inhibit the Recently Emerged Novel Coronavirus (2019-nCoV) In Vitro. Cel Res 30 (3), 269-271. doi:10. 1038/s41422-020-0282-0

Wang, M., Cao, R., Zhang, L., Yang, X., Liu, J., Xu, M., et al. (2020b). Remdesivir and Chloroquine Effectively Inhibit the Recently Emerged Novel Coronavirus (2019-nCoV) In Vitro. Cel Res 30 (3), 269-271. doi:10.1038/s41422-020-0282-0

Wang, R., Wang, X., Ni, B., Huan, C. C., Wu, J. Q., Wen, L. B., et al. (2016a). Syndecan-4, a PRRSV Attachment Factor, Mediates PRRSV Entry through its Interaction with EGFR. Biochem. Biophys. Res. Commun. 475 (2), 230-237. doi:10.1016/j.bbrc.2016.05.084

Wang, Y., Li, G., Yuan, S., Gao, Q., Lan, K., Altmeyer, R., et al. (2016b). In Vitro Assessment of Combinations of Enterovirus Inhibitors against Enterovirus 71. Antimicrob. Agents Chemother. 60 (9), 5357-5367. doi:10.1128/AAC.01073-16 
Wang, Y. M., Lu, J. W., Lin, C. C., Chin, Y. F., Wu, T. Y., Lin, L. I., et al. (2016c). Antiviral Activities of Niclosamide and Nitazoxanide against Chikungunya Virus Entry and Transmission. Antivir. Res 135, 81-90. doi:10.1016/j.antiviral. 2016.10.003

Wang, Y., Zhang, D., Du, G., Du, R., Zhao, J., Jin, Y., et al. (2020c). Remdesivir in Adults with Severe COVID-19: a Randomised, Double-Blind, PlaceboControlled, Multicentre Trial. Lancet 395 (10236), 1569-1578. doi:10.1016/ s0140-6736(20)31022-9

Wang, Y., Zhou, X., Debing, Y., Chen, K., Van Der Laan, L. J., Neyts, J., et al. (2014). Calcineurin Inhibitors Stimulate and Mycophenolic Acid Inhibits Replication of Hepatitis E Virus. Gastroenterology 146 (7), 1775-1783. doi:10.1053/j.gastro. 2014.02.036

Warren, T. K., Jordan, R., Lo, M. K., Ray, A. S., Mackman, R. L., Soloveva, V., et al. (2016). Therapeutic Efficacy of the Small Molecule GS-5734 against Ebola Virus in Rhesus Monkeys. Nature 531 (7594), 381-385. doi:10.1038/nature17180

Warren, T. K., Wells, J., Panchal, R. G., Stuthman, K. S., Garza, N. L., Van Tongeren, S. A., et al. (2014). Protection against Filovirus Diseases by a Novel Broad-Spectrum Nucleoside Analogue BCX4430. Nature 508 (7496), 402-405. doi:10.1038/nature13027

Watashi, K., Hijikata, M., Hosaka, M., Yamaji, M., and Shimotohno, K. (2003). Cyclosporin A Suppresses Replication of Hepatitis C Virus Genome in Cultured Hepatocytes. Hepatology 38 (5), 1282-1288. doi:10.1053/jhep.2003.50449

Watashi, K., Sluder, A., Daito, T., Matsunaga, S., Ryo, A., Nagamori, S., et al. (2014). Cyclosporin A and its Analogs Inhibit Hepatitis B Virus Entry into Cultured Hepatocytes through Targeting a Membrane Transporter, Sodium Taurocholate Cotransporting Polypeptide (NTCP). Hepatology 59 (5), 1726-1737. doi:10.1002/hep.26982

Welch, S. R., Guerrero, L. W., Chakrabarti, A. K., McMullan, L. K., Flint, M., Bluemling, G. R., et al. (2016). Lassa and Ebola Virus Inhibitors Identified Using Minigenome and Recombinant Virus Reporter Systems. Antivir. Res 136, 9-18. doi:10.1016/j.antiviral.2016.10.007

Werner, B., Dittmann, S., Funke, C., Überla, K., Piper, C., Niehaus, K., et al. (2014). Effect of Lovastatin on Coxsackievirus B3 Infection in Human Endothelial Cells. Inflamm. Res. 63 (4), 267-276. doi:10.1007/s00011-013-0695-z

Westover, J. B., Mathis, A., Taylor, R., Wandersee, L., Bailey, K. W., Sefing, E. J., et al. (2018). Galidesivir Limits Rift Valley Fever Virus Infection and Disease in Syrian Golden Hamsters. Antivir. Res 156, 38-45. doi:10.1016/j.antiviral.2018. 05.013

Wilen, C. B., Tilton, J. C., and Doms, R. W. (2012). HIV: Cell Binding and Entry. Cold Spring Harb Perspect. Med. 2 (8), a006866. doi:10.1101/cshperspect. a006866

Wong, R. W., Balachandran, A., Ostrowski, M. A., and Cochrane, A. (2013). Digoxin Suppresses HIV-1 Replication by Altering Viral RNA Processing. Plos Pathog. 9 (3), e1003241. doi:10.1371/journal.ppat.1003241

Wong, R. W., Lingwood, C. A., Ostrowski, M. A., Cabral, T., and Cochrane, A. (2018). Cardiac Glycoside/aglycones Inhibit HIV-1 Gene Expression by a Mechanism Requiring MEK1/2-Erk1/2 Signaling. Sci. Rep. 8 (1), 850. doi:10. 1038/s41598-018-19298-x

Xu, H. T., Colby-Germinario, S. P., Hassounah, S. A., Fogarty, C., Osman, N., Palanisamy, N., et al. (2017). Evaluation of Sofosbuvir (Beta-D-2'-Deoxy-2'Alpha-Fluoro-2'-Beta-C-Methyluridine) as an Inhibitor of Dengue Virus Replication. Sci. Rep. 7 (1), 6345. doi:10.1038/s41598-017-06612-2

Xu, M., Lee, E. M., Wen, Z., Cheng, Y., Huang, W. K., Qian, X., et al. (2016). Identification of Small-Molecule Inhibitors of Zika Virus Infection and Induced Neural Cell Death via a Drug Repurposing Screen. Nat. Med. 22 (10), 1101-1107. doi:10.1038/nm.4184

Yamada, K., Noguchi, K., Komeno, T., Furuta, Y., and Nishizono, A. (2016). Efficacy of Favipiravir (T-705) in Rabies Postexposure Prophylaxis. J. Infect. Dis. 213 (8), 1253-1261. doi:10.1093/infdis/jiv586

Yamamoto, M., Matsuyama, S., Li, X., Takeda, M., Kawaguchi, Y., Inoue, J. I., et al. (2016). Identification of Nafamostat as a Potent Inhibitor of Middle East Respiratory Syndrome Coronavirus S Protein-Mediated Membrane Fusion Using the Split-Protein-Based Cell-Cell Fusion Assay. Antimicrob. Agents Chemother. 60 (11), 6532-6539. doi:10.1128/AAC.01043-16

Yamaya, M., Shimotai, Y., Hatachi, Y., Lusamba Kalonji, N., Tando, Y., Kitajima, Y., et al. (2015). The Serine Protease Inhibitor Camostat Inhibits Influenza Virus Replication and Cytokine Production in Primary Cultures of Human
Tracheal Epithelial Cells. Pulm. Pharmacol. Ther. 33, 66-74. doi:10.1016/j.pupt. 2015.07.001

Yao, Z. H., Liao, W. Y., Ho, C. C., Chen, K. Y., Shih, J. Y., Chen, J. S., et al. (2019). Incidence of Hepatitis B Reactivation during Epidermal Growth Factor Receptor Tyrosine Kinase Inhibitor Treatment in Non-small-cell Lung Cancer Patients. Eur. J. Cancer 117, 107-115. doi:10.1016/j.ejca.2019.05.032

Ye, J., Wang, C., Sumpter, R., Jr., Brown, M. S., Goldstein, J. L., and Gale, M., Jr. (2003). Disruption of Hepatitis C Virus RNA Replication through Inhibition of Host Protein Geranylgeranylation. Proc. Natl. Acad. Sci. U. S. A. 100 (26), 15865-15870. doi:10.1073/pnas.2237238100

Ye, L., Li, J., Zhang, T., Wang, X., Wang, Y., Zhou, Y., et al. (2012). Mycophenolate Mofetil Inhibits Hepatitis C Virus Replication in Human Hepatic Cells. Virus. Res. 168 (1-2), 33-40. doi:10.1016/j.virusres.2012.06.009

Yin, X., Ambardekar, C., Lu, Y., and Feng, Z. (2016a). Distinct Entry Mechanisms for Nonenveloped and Quasi-Enveloped Hepatitis E Viruses. J. Virol. 90 (8), 4232-4242. doi:10.1128/JVI.02804-15

Yin, Y., Wang, Y., Dang, W., Xu, L., Su, J., Zhou, X., et al. (2016b). Mycophenolic Acid Potently Inhibits Rotavirus Infection with a High Barrier to Resistance Development. Antivir. Res 133, 41-49. doi:10.1016/j.antiviral.2016.07.017

Ying, C., Colonno, R., De Clercq, E., and Neyts, J. (2007). Ribavirin and Mycophenolic Acid Markedly Potentiate the Anti-hepatitis B Virus Activity of Entecavir. Antivir. Res 73 (3), 192-196. doi:10.1016/j.antiviral.2006.10.003

Ying, C., De Clercq, E., and Neyts, J. (2000). Ribavirin and Mycophenolic Acid Potentiate the Activity of Guanine- and Diaminopurine-Based Nucleoside Analogues against Hepatitis B Virus. Antivir. Res 48 (2), 117-124. doi:10. 1016/s0166-3542(00)00121-2

Zhang, X. J., Qin, J. J., Cheng, X., Shen, L., Zhao, Y. C., Yuan, Y., et al. (2020). In-Hospital Use of Statins Is Associated with a Reduced Risk of Mortality Among Individuals with COVID-19. Cell Metab 32 (2), 176-187. doi:10.1016/j.cmet.2020.06.015

Zhang, X., Song, Z., Qin, B., Zhang, X., Chen, L., Hu, Y., et al. (2013). Rupintrivir Is a Promising Candidate for Treating Severe Cases of Enterovirus-71 Infection: Evaluation of Antiviral Efficacy in a Murine Infection Model. Antivir. Res 97 (3), 264-269. doi:10.1016/j.antiviral.2012.12.029

Zhou, Y., Vedantham, P., Lu, K., Agudelo, J., Carrion, R., Jr., Nunneley, J. W., et al. (2015). Protease Inhibitors Targeting Coronavirus and Filovirus Entry. Antivir. Res 116, 76-84. doi:10.1016/j.antiviral.2015.01.011

Zhu, N., Zhang, D., Wang, W., Li, X., Yang, B., Song, J., et al. China Novel Coronavirus Investigating and Research Team (2020). A Novel Coronavirus from Patients with Pneumonia in China, 2019. N. Engl. J. Med. 382, 727-733. doi:10.1056/NEJMoa2001017

Zhu, Y. Z., Xu, Q. Q., Wu, D. G., Ren, H., Zhao, P., Lao, W. G., et al. (2012). Japanese Encephalitis Virus Enters Rat Neuroblastoma Cells via a $\mathrm{pH}_{-}$ dependent, Dynamin and Caveola-Mediated Endocytosis Pathway. J. Virol. 86 (24), 13407-13422. doi:10.1128/JVI.00903-12

Zhyvoloup, A., Melamed, A., Anderson, I., Planas, D., Lee, C. H., Kriston-Vizi, J., et al. (2017). Digoxin Reveals a Functional Connection between HIV-1 Integration Preference and T-Cell Activation. Plos Pathog. 13 (7), e1006460. doi:10.1371/journal.ppat.1006460

Zivcec, M., Scholte, F. E., Spiropoulou, C. F., Spengler, J. R., and Bergeron, E. (2016). Molecular Insights into Crimean-Congo Hemorrhagic Fever Virus. Viruses 8 (4), 106. doi:10.3390/v8040106

Zmurko, J., Marques, R. E., Schols, D., Verbeken, E., Kaptein, S. J., and Neyts, J. (2016). The Viral Polymerase Inhibitor 7-Deaza-2'-C-Methyladenosine Is a Potent Inhibitor of In Vitro Zika Virus Replication and Delays Disease Progression in a Robust Mouse Infection Model. Plos Negl. Trop. Dis. 10 (5), e0004695. doi:10.1371/journal.pntd.0004695

Conflict of Interest: The authors declare that the research was conducted in the absence of any commercial or financial relationships that could be construed as a potential conflict of interest.

Copyright $\odot 2021$ Li and Peng. This is an open-access article distributed under the terms of the Creative Commons Attribution License (CC BY). The use, distribution or reproduction in other forums is permitted, provided the original author(s) and the copyright owner(s) are credited and that the original publication in this journal is cited, in accordance with accepted academic practice. No use, distribution or reproduction is permitted which does not comply with these terms. 


\section{GLOSSARY}

BOC bovine coronavirus

CCHFV Crimean-Congo hemorrhagic fever virus

CHIKV chikungunya virus

CVA16 Coxsackievirus A16

CVB1 Coxsackievirus B1

DENV dengue virus

EBOV Ebola virus

EBV Epstein-Barr virus

EV71 enterovirus 71

FIPV feline infectious peritonitis virus

HBV hepatitis B virus

HCoV-229E human coronavirus 229E

HCV hepatitis $\mathrm{C}$ virus

HEV hepatitis E virus

HIV human immunodeficiency virus

hPIV human parainfluenza virus

HRV human rhinovirus

HSV herpes simplex virus

HuNoV human Norovirus

IAV influenza A virus

JEV Japanese encephalitis virus

JUNV Junin virus

KFDV Kyasanur Forest disease virus
LASV Lassa virus

LCMV lymphocytic choriomeningitis virus

MARV Marburg virus

MERS-CoV Middle East respiratory syndrome

MHV murine hepatitis virus

MuV Mumps virus

MV Measles virus

OHFV Omsk Hemorrhagic Fever virus

PRV pseudorabies virus

RRV Ross River virus

RSV respiratory syncytial virus

RVFV Rift Valley fever virus

SARS-CoV severe acute respiratory syndrome coronavirus

SARS-CoV-2 severe acute respiratory syndrome coronavirus-2

SFTSV Severe fever with thrombocytopenia syndrome virus

SFV Semliki Forest virus

SINV sindbis virus

SUDV Sudan virus

TBEV Tick-borne encephalitis (TBEV)

TGEV transmissible gastroenteritis virus

VZV varicella zoster virus

WNV West Nile virus

YFV yellow fever virus

ZIKV Zika virus 